\title{
Clinical and genetic aspects of the X-linked hydrocephalus/masa spectrum
}

Citation for published version (APA):

Schrander-Stumpel, C. T. R. M. (1995). Clinical and genetic aspects of the $X$-linked hydrocephalus/masa spectrum. [Doctoral Thesis, Maastricht University]. Rijksuniversiteit Limburg. https://doi.org/10.26481/dis.19950519cs

Document status and date:

Published: 01/01/1995

DOI:

10.26481/dis.19950519cs

Document Version:

Publisher's PDF, also known as Version of record

\section{Please check the document version of this publication:}

- A submitted manuscript is the version of the article upon submission and before peer-review. There can be important differences between the submitted version and the official published version of record.

People interested in the research are advised to contact the author for the final version of the publication, or visit the DOI to the publisher's website.

- The final author version and the galley proof are versions of the publication after peer review.

- The final published version features the final layout of the paper including the volume, issue and page numbers.

Link to publication

\footnotetext{
General rights rights.

- You may freely distribute the URL identifying the publication in the public portal. please follow below link for the End User Agreement:

www.umlib.nl/taverne-license

Take down policy

If you believe that this document breaches copyright please contact us at:

repository@maastrichtuniversity.nl

providing details and we will investigate your claim.
}

Copyright and moral rights for the publications made accessible in the public portal are retained by the authors and/or other copyright owners and it is a condition of accessing publications that users recognise and abide by the legal requirements associated with these

- Users may download and print one copy of any publication from the public portal for the purpose of private study or research.

- You may not further distribute the material or use it for any profit-making activity or commercial gain

If the publication is distributed under the terms of Article $25 \mathrm{fa}$ of the Dutch Copyright Act, indicated by the "Taverne" license above, 
CLINICAL AND GENETIC ASPECTS OF

THE X-LINKED HYDROCEPHALUS/MASA SPECTRUM 
CIP GEGEVENS KONINKLIJKE BIBLIOTHEEK DEN HAAG

Schrander-Stumpel, Constance Theresia Rimbertha Maria

Clinical and genetic aspects of the $x$-linked

hydrocephalus/MASA spectrum / Constance Theresia

Rimbertha Maria Schrander-Stumpel. - [S.I. : s.n.] - Ill.

Proefschrift Rijksuniversiteit Limburg Maastricht. - Met

lit. opg. - Met samenvatting in het Nederlands.

ISBN 90-9008231-X

Trefw.: mentale retardatie

Printing: Datawyse / Universitaire Pers Maastricht

Omslagfoto: naar een idee van Rini Stumpel-Jorna, met dank aan Francis van der Lubbe en Guus Hamers 


\section{CLINICAL AND GENETIC ASPECTS OF}

\section{THE X-LINKED HYDROCEPHALUS/MASA SPECTRUM}

\section{Proefschrift}

ter verkrijging van de graad van doctor aan de

Rijksuniversiteit Limburg te Maastricht

op gezag van de Rector Magnificus, Prof.mr. M.J. Cohen, volgens het besluit van het College van Dekanen, in het openbaar te verdedigen

op vrijdag 19 mei 1995 om 14.00 uur

door

Constance Theresia Rimbertha Maria Schrander-Stumpel

geboren te Amsterdam op 12 augustus 1954 
Promotores: $\quad$ Prof.dr. J.P. Fryns

Prof.dr. J.P.M. Geraedts

Co-Promotor: Dr. C.J. Höweller

Beoordelingscommissie:

Prof.dr. J. Troost, voorzitter

Prof.dr. J.L. Frias (University of South Florida, Tampa, USA)

Prof dr. J. de Haan

Prof.dr. R.H. Kuijten

Prof.dr. H.A. Lubs (University of Miami, Miami, USA)

De uitgave van dit proefschrift werd mede mogelijk gemaakt door de Stichting Klinische Genetica Limburg. 
Voor Dirk en Anna 


\section{CONTENTS}

\section{Chapter 1}

General introduction and aims of the study

\section{Chapter 2}

- A. MASA syndrome: new clinical features and linkage analysis using DNA probes.

(J Med Genet 1990;27:688-692)

- B. MASA syndrome: delineation of the clinical spectrum at prepubertal age.

(Am J Med Genet 1992;43:402-407)

\section{Chapter 3}

The spectrum of X-linked hydrocephalus (HSAS), MASA syndrome and complicated spastic paraplegia (SPGII): clinical review with 6 additional families.

(Am J Med Genet 1995;56:1-8)

\section{Chapter 4}

The spectrum of X-linked hydrocephalus (HSAS), MASA syndrome and complicated spastic paraplegia (SPG1): contribution of DNA linkage analysis in genetic counseling of individual families.

(Genetic Counseling 1994;5:1-10)

\section{Chapter 5}

- A. A duplication in the LICAM gene associated with X-linked hydrocephallus.

(Nature Genet 1993;4:421-425)

- B. MASA syndrome is due to mutations in the neural cell adhesion gene L1CAM.

(Nature Genet 1994;7:408-414)

- C. X-linked hydrocephalus and MASA syndrome present in one family are due to a single missense mutation in exon 28 of the LICAM gene.

(Hum Mol Genet 1994;3:2255-2256) 


\section{Chapter 6}

X-linked mental retardation and neurological symptoms:

a nosological approach.

(Genetic Counseling 1995;6:21-32)

\section{Chapter 7}

General discussion

Chapter 8

Summary

Chapter 9

Samenvatting

List of abbrevations

Nawoord

Curriculum vitae

130

Publicatielijst van de auteur 


\section{Chapter 1}

\section{General introduction and aims of the study}

Contents chapter 1

1.1 Mental retardation

1.2 X-linked mental retardation (XLMR)

1.3 XLMR with complicated spastic paraplegia

1.4 Aims of the study 


\subsection{MENTAL RETARDATION}

\subsubsection{Definition}

Defining mental retardation has been a matter of controversy over the years and many attempts have been made. A widely accepted definition is the one given by the AAMR (American Association on Mental Retardation): "mental retardation refers to significantly subaverage general intellectual functioning, existing concurrently with deficits in adaptive behaviour and manifested during the developmental period" (24).

General intellectual functioning is defined as the assessment results obtained with one or more of the individually administered general intelligence tests developed for the purpose of assessing intellectual functioning. Many standardised tests (such as the Stanford-Binet and Wechsler) have been developed to measure the IQ (= intellectual age/chronological age $\times 100$ ) in individual patients. The IQ is generally subdivided into verbal and performance tasks. Significantly subaverage intellectual functioning is indicated by an IQ of approximately 70 or below. This upper limit is intended as a guideline and could be increased to IQ 75 or more, depending on the reliability of the intelligence test used (24).

Impairments in adaptive behaviour, as determined by clinical assessment and, usually, standardized scales (e.g Stanford-Binet and WISC (Wechsler Intelligence Scale for Children)), are defined as significant limitations in an individual's effectiveness in meeting the standards of maturation, learning, and/or social responsibility that are expected for his or her age level and cultural group (24).

The developmental period is defined as the period of time between conception and the 18th birthday (24).

In 1992, the AAMR introduced a new definition and classification system (38) that was intended to initiate a shift from a deficiency-model to a support-model of mental retardation. In the 1992 system, mental retardation refers to: "substantial limitations in present functioning. It is characterized by significantly subaverage intellectual functioning, existing concurrently with related limitations in two or more of the following applicable adaptive skill areas: communication, self-care, home living, social skills, community use, self-direction, health and safety, functional academics, leisure, and work. Mental retardation manifests before age $18^{\prime \prime}$. Under the old AAMR definition (24), mental retardation was viewed as a deficiency associated with individuals. In the new AAMR definition, mental retardation is viewed as a disabling condition resulting from the interaction of a person with his or her environment. 


\subsubsection{Incidence}

The prevalence of mental retardation is influenced by a great number of environmental factors such as age, social and ethnic background, and sex. Mental retardation (MR) is common, with an estimated incidence of $2-3 \%$ in all newborns in the USA and Europe $(8,46,48)$.

\subsubsection{Classification}

Classification of mental retardation is possible in many ways. A practical and commonly used method of classification is provided by the determination of the degree of intellectual deficit. The classification proposed by the DSM-III-R (1987) is based on the severity of symptoms; the terminology as reported in the 1968 WHO Report has been generally accepted $(2,73)$ (Table 1). The slow learners in the borderline group and the mildly retarded, educable individuals can be distinguished from the moderately retarded group, where the patients are trainable for only basic life situations, and the severely and profoundly retarded group, which usually needs professional care (68). In the mild group, patients will attend schools for children with learning disabilities. As adults, they will sometimes be employed in sheltered working places and live in sheltered homes. In the moderate group, patients will attend special schools and sheltered working places and become institutionalized at some point in their lives, depending on their home situations. The severe and profound group will need as much individual speech and motor skill training as possible, but they will be dependent on either home or institutionalized care.

Table 1

WHO classifications of the degree of mental retardation.

$\begin{array}{lll}1948 \text { terminology } & 1968 \text { terminology } & 19 \\ \text { iadiot } & \text { profound } & \text { below } 20 \text { or } 25 \\ \text { high degrea imberile } & \text { severe } & 20-25 \text { to } 35-40 \\ \text { low degree imbecile } & \text { moderate } & 35-40 \text { to } 50-55 \\ \text { feeblemindied/maron } & \text { mild } & 50-55 \text { to } 70 \\ \text { borderline } & \text { borderline } & 70-85\end{array}$

\subsubsection{Etiology}

Looking for the etiology of mental retardation is a difficult task and continuous challenge to all professionals involved in the field. In a child, the combined action of genetic and environmental influences will determine the mental and cognitive outcome. The distinction between "nature and nurture" was already noted by Plato in ancient times. In patients with mental retardation, it is not always possible to define a single etiological diagnosis; intellectual deficit may result from the interplay between many factors.

Etiological research in mental retardation started with large clinical studies. In 
1938, Penrose reported a study of 1280 patients from the Royal Eastern Counties Institution in Colchester, UK, thus inspiring others to document the clinical data on their patients in a systematic way (47).

During the past five decades, laboratory techniques have become available to study the underlying causes of mental retardation. With the discovery in 1959 of trisomy 21 in individuals with Down syndrome, a start was made with the description of many other cytogenetic abnormalities. Various cytogenetic techniques (high resolution banding, fluorescent in situ hybridization) made it possible to increase the number of autosomal chromosome aberrations to over 1000 (53). The discovery of the fragile $X$ syndrome in the "70s was a new breakthrough $(37,65)$, revealing that $X$ linked mental retardation (XLMR) indeed exists and stimulating research into the various forms of XLMR.

The concept of inherited metabolic disease was introduced with the studies in alcaptonuria and the monograph entitled "Inborn errors of metabolism" by Sir Archibald Garrod in 1909, and, in modified form, in 1923 (21). Since then, many inborn errors have been reported in connection with mental retardation. In the '70s and ' 80 s, clinical genetic centers offering genetic counseling were gradually established in university hospitals. Dysmorphology ("syndrome delineation and recognition") became an important topic for the clinical geneticist; the insight that mental retardation in combination with a specific pattern of dysmorphic features could lead to a clinical diagnosis was important for research and family genetic counseling. During the past ten years, laboratories for DNA studies were founded, and the field of molecular biology experienced rapid growth. Many disease genes were located on the human genome and an increasing number of genes could be cloned and further studied. Today, DNA linkage and gene mutation analysis is an important part of the clinical genetic workup in, for example, families with fragile X. Since an etiological diagnosis is necessary for adequate genetic counseling and prenatal diagnosis, more and more attention was focused on the problem of making a correct etiological diagnosis.

The 9th revision (1978) of the International Classification of Diseases (29), recommended by the WHO, contained ten etiological categories for mental retardation (Table 2). However, this classification had a major disadvantage: congenital/genetic causes of mental retardation were not listed as separate groups but "hidden" in every category. This has been improved in the 10th edition (1992).

Studying a population of 1560 patients in Wisconsin, USA, Opitz et al. (1978) concluded that a genetic abnormality was the cause or predisposition of severe mental retardation in some $45 \%$ of the cases (46). Several other etiological studies have been performed in a systematic manner. The reported differences in percentages of the various diagnostic categories can be explained by the bias of ascertainment in each of the studies. In a study of an institutionalized population of 1991 moderately and severely mentally retarded individuals, chromosome abnormalities were found in $21.3 \%$, Down syndrome and fragile X syndrome being the most frequent (15). Similar data were found in a systematic cytogenetic study in a population of 1170 mentally retarded and/or behaviourly disturbed patients in the Netherlands (57). In the Eighties, 
a systematic genetic-diagnostic survey was performed in a number of institutes for individuals

Table 2

WHO hist of causal factors of mential retardition (29).

c. infeetions and intoxications

1. trauma or physical agents

2. disorders of metabolism, growtlin or nulrition

3. gross brain disease (postnatal)

4 diseases and conditions due to anknown prenatat in llyatree

5. chromosonial abnormalitios

6. prenaturitity

7. major psychiatric disease

8. psycho-social (environmentaly depurivation

9 other and unspecified

with moderate and severe mental retardation in Belgium $(9,16,17,69)$. The patients were subjected to careful clinical investigation, with special attention given to dysmorphology and neurological findings, and cytogenetic analysis was performed, including screening for fragile $X$ syndrome. In addition to a systematic phenylketonuria screening, amino acid chromotography of serum and urine were performed in all individuals without precise diagnosis. Additional investigations were carried out, as indicated by the individual clinical data. Finally, an etiological classification was made. Table 3 combines data of the 4 institutes. In the institutes with more severely mentally retarded individuals $(9,16)$ the number of unclassified persons was less than in the institutes with a moderately retarded group of persons $(17,69)$. In the more severe mentally retarded group children were included (ages ranging from 1 to 44 years $(9,16))$. In the other two reports $(17,69)$ patients were adults with ages ranging from 19 to 64; males only were living in in one of these institutes (69). The contribution of genetic causes of mental retardation is significant.

Since 1990 , even more cytogenetic defects and inborn errors of metabolism has been unraveled, and molecular biology has unfolded many genes or gene locations of inherited diseases. New mechanisms of inheritance have been found, well-known examples being expanding genes (as in fragile $X$ syndrome) and uniparental disomy (as for instance in Prader-Willi syndrome and in Angelman syndrome). In the clinical genetic journals, "new" clinically recognizable syndromes are reported every month. However, despite all diagnostic efforts, still many patients with mental retardation have no etiological diagnosis, and every clinical geneticist has his "unknowns" or "private syndrome patients". 
Table 3

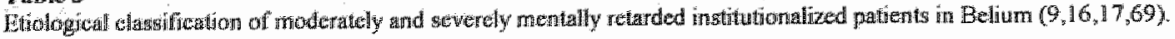

Category Perceritage

1. Gonetic

- forthomosment.

Down wyturanc 10,4

frugile $x$

other chiromosome abnomalify 2.3

- single urutanl gene 15.2

2. Multiple eongentat anomaty andromes 3.4

3. CNS malformations

4. CNS dysf functions due to prenatal or perinatal cause $\quad 213$

5. Infections pre, peri-, fordtrathal 10.0

6. Posinatal train damage $\quad 2.2$

7. Infantite psychosis and Rett syndrome 1.0

8. Üichassified $\quad 27.5$

\subsection{X-LINKED MENTAL RETARDATION}

Although Penrose, in his 1938 paper, recognized the excess of male patients in a large institute for the mentally retarded, he rejected the sex difference as being the result of $X$-linked genes because he saw no excess of retarded male sibs $(22,47)$. The sex difference was recognized by other investigators as well, but was attributed to an alleged higher susceptibility of males to environmental factors such as birth trauma or to an alleged bias of ascertainment (higher expectations of males in society) $(8,47)$. During the ' $40 \mathrm{~s}$, a small number of families with an X-linked pattern of inheritance had been reported; the Martin-Bell family with X-linked mental retardation and the Bickers-Adams family with X-linked hydrocephalus being the most well known $(5,42)$. In the early " $70 \mathrm{~s}$, the psychologist Lehrke hypothesized that X-linked genes would account for the male excess in mental retardation (36). However, it was only after the description of the fragile X syndrome by Sutherland in the Seventies (65) that the existence of X-linked mental retardation (XLMR) was really acknowledged and further research on XLMR genes was stimulated. The existence of a marker X chromosome in a family with XILMR was discovered earlier by Lubs (37). A clinical report on a large family with $X$-linked recessively inherited non-specific mental retardation was refused by two well respected medical journals before it was published in a third journal (10)! The Martin-Bell patients were shown to have the fragile $X$ syndrome $(50)$.

Several other clinically reported conditions with $\mathrm{X}$-linked mental retardation have been restudied. Clinical follow-up of the families revealed important data in new generations and on progression in time in the patients who were still alive. Linkage analysis with polymorphic markers of the $\mathrm{X}$ chromosome resulted in gene locations of the various conditions. A 6-generation family reported in 1944 by Allan, Herndon and Dudly, combining neurological manifestation with XLMR has been updated and 
linkage has been documented to Xq21 $(1,58,62)$. Affected male patients in another family, reported by Renpenning et al. in 1962 , tended to have small head circumferences and were severely retarded (49). This family was revisited and linkage analysis in this family placed the gene locus in the pericentric region between Xp12 and Xq13 $(13,59)$. Finally, the Snyder-Robinson family, reported in 1969 , was restudied $(3,61)$; linkage analysis data placed the locus at Xp21.2 (63).

Epidemiological studies in the mental retardation population have consistently indicated that the number of mentally retarded males exceeds the number of retarded femalles by 15 to $25 \%(22,67)$. The fragile $X$ syndrome, after Down syndrome the second most frequent genetic cause of mental retardation, accounts for $40 \% \mathrm{~m} 5 \%$ of the XLMR patients (68). In 10\% to $20 \%$ of the XLMR group a clinically recognizable or private syndrome can be diagnosed. The remainder is classified as nonspecific XLMR.

During recent decades, considerable progress has been made in etiological research into X-linked entities in which mental retardation is a prominent manifestation and in the clinical delineation of syndromes. In their first paper updating XLMR genes, Neri et al. listed 39 conditions (44). In their latest update, this number had increased to 127 (45). 80/127 entities had a "MIM" number (as listed in McKusick's catalogue of Mendelian inherited disorders in Man (43)). "The gene has been regionally mapped (lodscores 2.0 or more) in 53 of these conditions, and genes have been cloned in 15/53 disorders (Figures 1 and 2). Recently, a strategy aimed at identification of Xlinked mental retardation genes was suggested by Mandel (41). Collaboration between all professionals involved in (the study of) the mentally handicapped is essential to learn more about the various conditions featuring mental retardation generally and Xlinked mental retardation particularly.

\subsection{XLMR WITH COMPLICATED SPASTIC PARAPLEGIA}

Until recently, most cases of early-onset spastic paraplegia were thought to represent manifestations of "cerebral palsy", an etiologically heterogeneous symptom complex due to acquired pre-, peri-, and postnatal damage of the central nervous system. Genetic forms of spastic paraplegia are apparently rare. Familial spastic paraplegia has been divided into 2 forms, based on whether the condition is "pure" or "complicated" (66). In the pure form, no additional features are present and inheritance in general is autosomal dominant (MIM *182600)(25). DNA linkage analysis studies revealed that autosomal dominant spastic paraplegia is genetically heterogeneous: at the present time, at least 2 loci have been regionally mapped (on chromosome numbers 2 and 14) $(27,28)$. Complicated forms of spastic paraplegia with added features of mental retardation, ataxia, sensory neuropathy, retinal changes or skin abnormalities exist; in general, most families with complicated spastic paraplegia demonstrate an autosomal recessive mode of inheritance (26). 


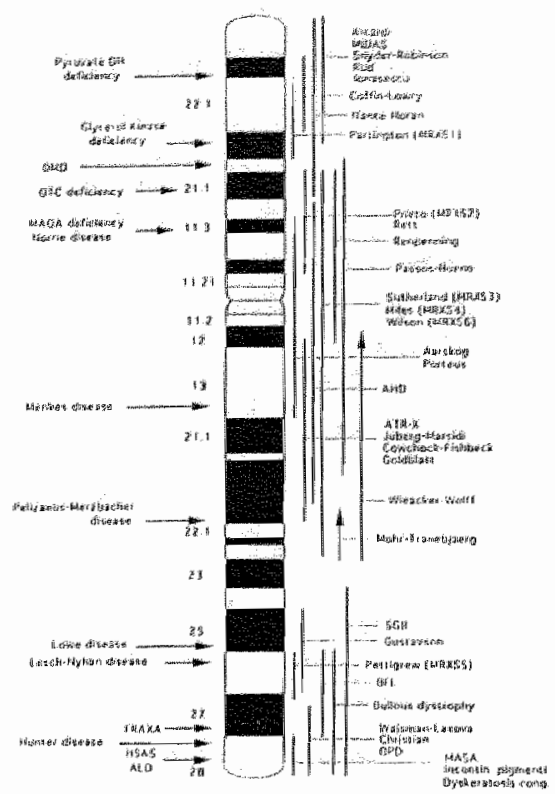

Figure 1 Map of X-linked mental retardation conditions, excluding $\mathrm{MRX}$. Horkondal arrows indicate the location of cloned genes.(neprinted wilh permission from Am J

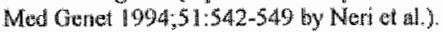

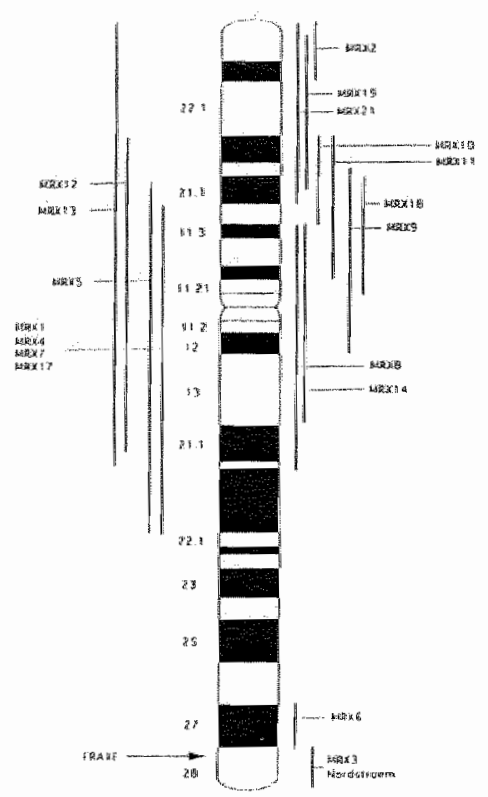

Figure 2. Linkage map of MRX. A horizontall arrow indieates the location of the partially cloned FRAXE gene. An MRX number is presently not avilable for some of the reported conditions. (reprinted with permission from Am I Med Genet 1994;51:542-549 by Neri et al.).

Several families have been reported with an X-linked complicated form of spastic paraplegia. Until 1990, two X-chromosomal loci were known to be associated with spastic paraplegia: a complicated form at Xq28, SPG1 (MIM *312900)(32) and a pure form at Xq21, SPG2 (33). Subsequently, several families with complicated spastic paraplegia, nystagmus and opticus atrophy showed linkage to the $\mathrm{Xq} 21$ region $(6,23)$, suggesting either allelic heterogeneity at the SPG2 locus or two loci for spastic paraplegia in this region (one pure, one complicated) (52). Recently, mutations in the PLP (proteolipid protein) gene have been found in two SPG2 families (34). In the same year, a mutation in the PLP locus was reported in another family with SPG2 $(6,52)$. Remarkable is the the finding that a very different disease, PelizaeusMerzbacher disease (PMD) is caused by mutations in the PLP gene as well (52). PMD is a rare $\mathrm{X}$-linked dysmyelineating disorder of the central nervous system, characterized by an early onset of nystagmus and motor developmental dellay with regression; it is usually fatal in infancy or childhood. The PLP protein is highly conservated among mammals and PLP maps to the SPG2 locus (Xq21-q22). The genetic defect involves one of the major myelin proteins, the proteolipid protein (PLP), and results in deficiencies in both myelin maturation and maintenance (34). SPG2 appears to be an 
allelic disorder with Pelizaeus-Merzbacher disease at the proteolipid protein locus (52).

SPG1, located at Xq28 (32), appeared to be the same disorder as MASA syndrome $(4,72)$. Another disorder that can present with complicated spastic paraplegia is X-linked hydrocephalus with stenosis of the aqueduct of Sylvius (HSAS) $(12,14,70)$.

\subsubsection{MASA syndrome}

In 1974, Bianchine and Lewis reported an X-linked mental retardation syndrome featuring spastic paraplegia in a brother and sister under the designation "MASA" syndrome (acronym for Mental retardation, Aphasia or slow speech development, Shuffling gait or spastic paraplegia, and Adducted thumbs) (4) (MIM *303350). Initially, it was not clear whether the MASA syndrome represented a separate disease entity. The authors stated: "We wish to refer to this heritable condition as the MASA syndrome until the basic defect is further characterized". The condition was recognized by others and additional families were reported $(20,74)$. The family with XLMR, initially reported by Kenwrick et al. as having "complicated spastic paraplegia" (SPG1) (MIM *312900) (32), later was considered to have MASA syndrome on the basis of both clinical arguments and DNA linkage analysis data (72). By the end of 1994, 13 convincing MASA-syndrome families have been reported $(4,7,18-20,31,32,40,51,54,64,72,74)$. Boyd et al. (7) reported a MASA family in which the patients presented with corpus callosum agenesis (CCA). In the reported MASA syndrome families, clinical variability was obvious both within and between families. About $90 \%$ of the patients showed spastic paraplegia and the same figure was found for adducted thumb. Clinical features such as adducted thumbs and subnormal intelligence, or even the full-blown clinical picture of MASA syndrome, were noted in female carriers and/or patients in some of the families $(4,19,31,40)$. Linkage analysis placed the "MASA" locus at Xq28 $(7,18,31,51,54,72)$.

\subsubsection{X-linked hydrocephalus with stenosis of the aqueduct of Sylvius (HSAS)}

HSAS is the most common genetic form of congenital hydrocephalus (McKusick *307000) and varies clinically from being lethal in utero or early infancy to survival with mental retardation, spastic paraplegia and adducted thumbs. In the reported HSAS families, most patients had died during pregnancy (partly due to induced labour after prenatal diagnosis), during or shortly after birth or after some weeks/months. The majority of the reported HSAS families had no affected male patients surviving the first year of life. In families with surviving affected boys, survival rate was about $50 \%$ (see chapter 3). In a number of reported families with HSAS where affected patients survive the first year of life, inter- and intrafamilial clinical variability was apparent $(12,14,60,70)$. Linkage analysis in HSAS families placed the locus at $\mathrm{Xq} 28$ as well $(30,39,60,71)$. Clinical features in these surviving HSAS patients show great overlap with the patients affected with MASA syndrome (55). 


\subsubsection{Lumping MASA syndrome and HSAS}

In 1988 a Dutch couple visited our department. They asked whether the condition present in the wife's brother and maternal uncle was inheritable; both family members were mentally retarded and had a spastic gait. A deceased distant male relative was known to have had congenital hydrocephalus; he also had adducted thumbs. Therefore, we concluded that both MASA syndrome and X-linked hydrocephalus (HSAS) concurred in this same family. Linkage to Xq28 was subsequently documented in this family (54). Shortly after this observation, a second family was reported with both phenotypes in one pedigree (18). These two cases led us to hypothesize that MASA syndrome and HSAS are variable expressions of mutations in the same gene at Xq28 $(18,55)$. We designed the present study and made a call for patients $(55,56)$.

\subsection{AIMS OF THE STUDY}

In the present study, which consisted of a clinical and a molecular section, we raised the following questions:

\subsubsection{Clinical aspects}

How variable is the clinical spectrum of X-linked hydrocephalus/MASA syndrome? What are the minimal diagnostic clinical criteria?

Is it possible to make a reliable diagnosis on clinical grounds alone?

Clinical data are reported and discussed in the chapters 2,3 and 7 .

\subsubsection{Molecular aspects}

Can all families with X-linked hydrocephalus/MASA syndrome be linked to Xq28 or is there genetic heterogeneity? Chapter 4 deals with linkage analysis studies.

\subsubsection{LiCAM gene study}

While this thesis was prepared, the first mutations in LICAM were reported in families with HSAS. LICAM is one of the molecules which appears to mediate neural cell - cell adhesion in vitro (CAM: cell adhesion molecule) (35). The gene maps to Xq28 (11). In a collaborative study with Dr.P.J.Willems (Antwerp, Belgium), our aim was to search for LICAM mutations in the families, studied in this thesis. Chapter 5 contains the results of these studies. 


\section{REFERENCES}

1. Allan W, Herndon CN, Dudley FC. Some examples of the inheritance of mental deficiency: apparently sex-linked idiocy and microcephaly. Am J Ment Defic 1944;48:325-334.

2. American Psychiatric Association: diagnostic and statistical manual of mental disorders, 3rd edition, revised. Washington, DC: American Psychiatric Association, 1987.

3. Arena JF, Schwartz C, Miller M, Stevenson $\mathbb{R}$, Garza J, Nance $M$, Lubs HA. Gene localization and clinical redefinition of the Snyder-Robinson syndrome. Am J Hum Genet (suppl) 1992,51:A181.

4. Bianchine JW, Lewis Ir RC. The MASA syndrone: a new heritable mental retardation syndxome. Clin Genet 1974;5:298-306.

5. Bickers DA, Adams RD. Hereditary stenosis of the aqueduct of Sylvius as a cause of congenital hydrocephalus. Brain 1949:72:246-262.

6. Bonneau D, Rozet J-M, Bulteau C, Berhier M, Metthey R, Munnich A, Le Merrer M. X-linked spastic paraplegia (SPG2) clinical heterogeneity at a single gene locus. J Med Genet 1993;30;381-384

7. Boyd E, Schwartz CE, Schroer RJ, May MM, Shapiro SD, Arena JF, Lubs HA, Stevenson RE. Agenesis of the corpus callosum associated with MASA syndrome. Clin Dysmorphol 1993;2:332-341.

8. Bundey $\mathrm{S}$, Carter $\mathrm{CO}$. Recurrence risks in severe undiagnosed mental deficiency. J Ment Def Res $1974 ; 18: 115-128$.

9. Dereymaeker AM, Fryns JP, Deroover J, van den Berghe H. A genetic-diagnostic survey in an institutionalized population of 158 mentally retarded patients. The Viaene experience. Clin Genet $1988 ; 34: 126-134$.

10. Deroover J, Fryns JP, Parloir C, van den Berghe H. X-linked recessively inherited non-specific mental retardation. Report of a large family. Ann Génét 1977;20:263-268.

11. Djabali M, Mattei MG, Nguyen C, Roux D, Demengeot J, Denzot F, Moos M, Schachner M, Goridis C, Jordan BR. The gene encoding L1, a neural adhesion mollecule of the immunoglobulin family, is located on the X chromosome in mouse and man. Genomics 1990; 7:587-593.

12. Edwards JH. The syndrome of sex-linked hydrocephalus Arch Dis Childh 1961;36:486-493.

13. Fox P, Fox D, Gerrard JW. X-linked mental retardation: Renpenning revisited. An \Med Genet $1980 ; 7: 491-495$.

14. Fried K. X-linked mental retardation and/or hydrocephalus. Clin Genet 1972;3:258-263.

15. Fryns JP. Genetic causes of mental retardation. Leuven, Thesis, 1986.

16. Fryns JP, Kleczkowska A, Dereymaeker A, Hoefnagels M, Herenans G, Marien J, van den Berghe $H$. A genetic-diagnostic survey in an institutionalized population of 173 severely mentally retarded patients. Clin Genet $1986 b ; 30: 315-323$.

17. Fryns JP, Volcke PH, Haspeslagh $M$, Beusen $L_{x}$ van de Berghe $H$. A genetic diagnostic survey in an institutionalized population of 262 moderately mentally retarded patients: the Borgerstein experience. $J$ Ment Defic Res 1990;34:29-40.

18. Fryns IP, Spaepen A, Cassiman JJ, van den Berghe H. Letter to the editor. X-linked complicated spastic paraplegia, MASA syndrone and X-linked hydrocephaly due to congenital stenosis of the aquaduct of Sylvius: a variable expression of the same mutation at Xq28. J Med Genet 1991:28:429-432.

19. Fryns JP, Schrander-Stumpel $C$, de Die-Smulders C, Borghigraef M, van den Berghe H. MASA syndrome: delineation of the clinical spectrum at prepubertal age. Am J Med Genet 1992;43:402-407.

20. Gareis FJ, Mason JD. X-linked mental retardation associated with bilateral clasp thumb anomaly. Am J Med Genet 1984;17:333-338.

21. Garrod AE. Inborm errors of metabolism, 2nd ed. London, Oxford University Press, 1923.

22. Glass IA X-linked mental retardation. J Med Genet 1991;28:361-371.

23. Goldblatt $J$, Ballo $R$, Sachs B, Moosa A. X-linked spastic paraplegia: evidence for homogeneity with a variable phenotype. Clin Genet 1989;35:116-120.

24. Grossman HJ (Ed). Classification in mental retardation. Washington, DC: American Association on Mental Deficiency, 1983 revision.

25. Harding AE Hereditary "pure" spastic paraplegia: a clinical and genetic study of 22 families. J Neuroll Neurosurg Psychiatry. 1981:44:871-883.

26. Harding AE Classification of the hereditary ataxias and paraplegias. Lancet 1983;1:1151-1155. 
27. Hazan J. Lamy $C$, Meiki J, Munich $A$ de Recondo J. Weistenbach J. Autosomal dominant spastic paraplegiai is genetically heterogenous and one locus maps to chromosome 14q. Nahme Genet $1993,5: 163-167$.

28. Hazan J, Fontaine B, Bruyn RPM, Lamy C, van Deutckon JCT, Rime CS, Dür A, Melki J, Lyon-Caen O. Agid Y, Munnich A, Padberg GW, de Recondo J, Frants RR, Brice A, Weissenbach J. Linkage of a new locus for a atosomial dominant familial spastic paraplegia to chromosome $2 \mathrm{p}$. Hum Mol Geneq $1994,3: 1569: 1573$.

29. International Clasisfication of Diseases, $9 \mathrm{~h}$ revision, clinicall modification. Vol.2. Aun Arbor. Michigan, U.S.A, Edwards Brothers Inc, 1978.

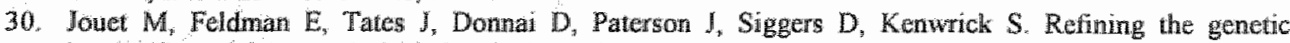
localisation of the gene for X llinked hydrocephalus within Xq28. J Med Genet 1993;30:214-217.

31. Kaepenick LA, Legias $E$, Higgins $J$, Kapur $S$. Clinical aspects of MASA syndrome in a large family including expressing females. Clin Genet 1994;45:181-185.

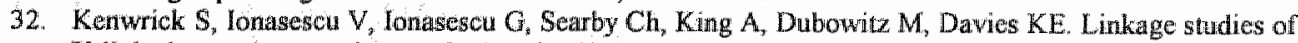
$X$-linked recessive spastic paraplegia using DNA probes. Hum Genet 1986;73:264-6.

33. Keppen LD, Leppert MF, O'Connell P, Nakamura Y, Stauffer D, Lathrop M, Lalouel $\mathrm{J}-\mathrm{M}$, White R. Etiological heterogeneity in X-Jinked spastic paraplegia Am I Hum Genet 1987; 19:933-943.

34. Kobayashi H, Hoffman EP. Marks HO. The numpshaker mutation in spastic paraplegia. Nature Genet $1994 ; 7: 351.352$.

35. Lander $\mathrm{AD}$. Understanding the molecules of neural cell contacts: emerging paiterns of structure and function. TTNS 1989:12:189:195.

36. Lehrke RG. A theory of X-linkage of major intellectual traits. An J Ment Defic 1972;76:611-619.

37. Lubs HA. A marker X chromosome. Am J Hum Genet 1969;21:231-244.

38. Luckasson R, Coulker DL, Polloway EA, Reiss S, Schalock RL, Snell ME, Spitalnik DM, Stark JA. Mental retardation: definition, classification, and systens of supports. Washington, $D C$ : American Association on Mental Retardation.

39. Lyonnet $S$, Pelet $A$, Royer $G$, Delrieu $O$, Serville $F$, Le Marec B, Gruensteudel A, Pfeiffer RA, Briard ML, Dubay C, Hors-Cayla MM, Le Merrer $M$, Munmich A. The gene for X-linked hydrocephalus maps
to Xq28, distal to DXS52. Genomics $1992 ; 14508-510$.

40. Macias VR, Day DW, King TE, Wilson G. Clasped-thumb mental retardation (MASA) syndrome: confirmation of linkage to $\mathrm{Xq} 28$. Am J Med Genet 1992;43:408-414.

41. Mandel JL. Towards identification of X-linked mental retardation genes: a proposal. Am J Med Genet $1994 ; 51: 550-552$.

42. Martin JP, Bell J. A pedigree of mental defect showing sex-linkage. I Neurol Neurosurg Psychiatry
$1943 ; 6: 154-157$.

43. McKusick V. Mendelian inheritance in man. Catalogs of autosomal dominant, autosomal recessive, and $X$-linked recessive phenotypes, $1992 ; 10$ th edition.

44. Neri G. Gurrieri F, Gal A, Lubs HA. XLMR genes: update 1990. Am J Med Genet 1991;38:186-189.

45. Neri G, Chimazai P. Arena JF, Lubs HA. XLMR Genes: update 1994. Am I Med Genet 1994;51:542.
549 . 46. Optc IM, Kaveggia GE, Durkin-Stamm MV, Pendleton E. Birth Defects: Original Aricles Serics,
$1978 ; X I V, 6 \mathrm{~B}: 1-38$. The National Foundation, March of Dimes.

47. Penrose LS. A clinical and genetic study of 1280 cases of mental defect. (The Colchester Survey) London: Medical Research Council. Special report series, No 229,1938.

48. Priest JH. Thuline HC, La Veck OD, Jarvis $\mathrm{DG}$. An approach to genetic factors in mental retardation. Studies of Camilies containing at least two siblings admitted to a state institution for the retarded. An J
Ment Defic $1961,6642-50$.

49. Renpenning H, Gerrard JW, Zaleski WA, Tabata T. Familial sex-linked mental retardation. Can Med
Assoc J 1962;87:954-956.

50. Richards BW, Sylwester PE, Brooker C. Fragile X-linked mental retardation: the Martin-Bell syndrome.
J Ment Defie Res $1981 ; 25: 253-256$.

51. Rietschel M, Friedl $W$, Uhllias $S$, Neugebauer $M$, Heimann $D$, Zerres K. MASA Syndrome; clinical wariability and linkage analysis. Am J Med Genet 1991,41:10-14. 
52. Saugier-Veber $P$, Munich $A$, Bonneau D, Rozet $J M$, Le Merrer $M$, Gil $\mathbb{R}$, Boesptlug-Tanguy $O$. $X$ Inked spastic paraplegia and Pelizaeus-Merzbacher disease are allelic disorders at the proteolipid protein locus. Nature Genet 1994;6:257-262.

53. Schinzel A. The human cytogenetic database. Oxford University Press 1994.

54. Schrander-Stumpel CTRM, Lcgius E, Fryn JP, Cassiman J. MASA syndrome : new chinical fataues and limkage analysis using DNA probes. J Med Genet 1990;27:688-692.

55. Schrander-Stumpel C, Fryns JP, Cassiman JJ, Legius E, Spaepen A, Howeler CJ. MASA syndrome (a form of complicated spastic paraplegia) and X-linked hydrocephalus: variable expression of the same mutation? Call for families. J Med Genet 1992;29:215.

56. Schrander-Stumpel C. Announcement. Call for families with MASA syndrome with or without X-linked hydrocephalus. Clin Genet 1991:40:473.

57. Schreppers-Tijdink, GAJ, Curf's LMG, Wiegers A, Kleczkowska A, Fryns JP. A systernatic cytogenetic study in a population of 1170 mentally retarded and/or behaviourally disturbed patients including fragile $\mathrm{X}$ screening. \& Gểnét Hum $1988 ; 36: 425-446$.

58. Schwartz CE, Ulmer $\mathrm{I}$, Brown A, Pancost I, Goodman HO, Stevenson RE. Allan-Herndon syndrome. II Linkage to DNA markers in Xq21. Am J Hum Genet 1990;47:454-458.

59. Schwartz CE, Ouzts L, Gibson A, Cadle R, Arena JF, Boyd E, Hall B, Lubs HA, Stevenson RE. Renpenning syndrome: evidence for pericentric location of the gene in wwo families, including the original Renpenning family. 6th Int Workshop on the Fragile $X$ and XLMR, Cairns, Australis.

60. Serville F, Lyonnet $S$, Pelet A, Reynaud $M$, Louail C, Munnich A, LeMerrer M. X-linked hydrocephalus: clinical heterogeneity at a single gene locus. Eur J Pediatr 1992;151:515-518.

61. Snyder KD, Robinson A. Recessive sex-linked mental retardation in the absence of other recognizable abnormalities. Clin Pediatr 1969;8:669-674.

62. Stevenson RE ${ }_{n}$ Goodman HO, Schwartz CE, Simensen RJ, Miclean Jr WT, Herndon CN. Allan-Herndom syndrome. I. Clinical studies. Am J Hum Genet 1990;47:446-453.

63. Stevenson $\mathbb{R E}$, Schwartz $C E$, Fernando Arena J, Lubs HA X-linked mental retardation: the early era from 1943 to 1969. Am J Med Genet 1994;51:538-541.

64. Straussberg R, Blatt I, Brand N, Kessler D, Bat-Miriam Katznelson M, Goodman RM. X-linked mental retardation with bilateral clasped thumbs: teport of another affected family. Clin Genet 1991;40:337341 .

65. Sutherland GR. Fragile sites on human chromosomes. III. Detection of Fra(X)(q27) in males with $X$ linked mental retardation and their female relatives. Hum Genet 1977;53:23-27.

66. Sutherland JM. Familial spastic paraplegia. In: Vinken PJ, Bruyn GW, eds. Handbook of clinical neurology. North Holland Publishing Company, Amsterdam 1975;22:421-431.

67. Tumer $G$. Editorial: X-linked mental retardation. Psychol Med 1982;12:471-473.

68. Veenema H. Clinical, cytogenetic and molecular aspects of the fragile X syndrome. Thesis, Leiden, 1989.

69. Volcke $P$, Dereymaeker AM, Fryns J $P$, wan den Berghe $H$. On the nosology of moderate mental retardation with special attention to X-tinked mental retardation. Genetic Counseling 1990;1:47 -56.

70. Willens PI, Brouwer OF, Dijkstra I, Wilmink J. X-Linked hydrocephalus. Am I Med Genet $1987 ; 27: 921-928$

71. Willems $\mathrm{PJ}$, Dijkstra Il, Van der Auwerda $\mathrm{BJ}$, Vits $\mathrm{L}$, Coucke $\mathrm{P}$, Raeymakers $\mathrm{P}$, van Broeckhoveti $\mathrm{C}$, Consalez GG, Freman SB, Warren ST, Brouwer OF, Brunner HG, Renier WO, van Elasen AF, Dumon JE. Assignment of X-linked hydrocephalus to Xq28 by linkage analysis Genomics $1990 ; 8: 867-870$.

72. Winter $\mathrm{RM}$, Davies $\mathrm{K}_{w}$ Bell MV, Huson SM, Paterson MN. MASA syndrome: further clinical delineation and chromosonal location. Human Genet 1989,82:367-70

73. World Health Organization: Organization of services for the mentally retarded. 15th report of the WHO Expert Committee on Mental Health. Techn Rep Ser Wld Hith Org, 392, 1968.

74. Yeatman GW. Mental retardation-clasped thumb syndrome. Am JMed Genet 1984:17:339-344. 


\section{Chapter $2 A$}

\section{MASA syndrome: new clinical features and linkage analysis using DNA probes}

Connie Schrander-Stumpel, Eric Legius, Jean Pierre Fryns, Jean Jaques Cassiman

Joumal of Medical Genetics 1990;27:688-692. 


\section{A.1 ABSTRACT}

We describe a two generation family in which two males have the $X$-linked recessive MASA syndrome (Mentall retardation, Aphasia, Shuffling gait, and Adducted thumbs). A third male in this family died at the age of 15 years from congenital hydrocephalus. In the present family cerebral abnormalities are reported for the first time. Linkage analysis confirms the chromosome localisation at $\mathrm{Xq28}$. A crossover between the coagulation factor VIII locus (F8C) and MASA syndrome, but not with DXS52 and DXS305, locates the gene on the same side of F8C as DXS52 and DXS305. The possible relationship between MASA syndrome and X-linked hydrocephalus is discussed.

\section{$2 A .2$ INTRODUCTION}

Hereditary spastic paraplegia is a disorder characterised by progressive spasticity of the legs. Intelligence in this pure form is normal. Inheritance is usually autosomal dominant, but X-linked recessive inheritance in families has been reported (10). In the complex form, the spasticity may be seen in combination with mental retardation, microcephaly, epilepsy, or ocular symptoms $(5,11)$. The MASA syndrome is an Xlinked disorder first reported in 1974 (1). Affected males show a combination of mental retardation, delayed speech (aphasia), spastic paraplegia (shuffling gait), and adducted thumbs. Since then, four families have been reported $(3,7,15,16)$. In two families linkage analysis located the gene in the region of Xq28 $(7,15)$. In this paper we describe a family with three affected males and the clinical features in MASA syndrome are extended. The third male in this family died from congenital lrydrocephalus. Linkage analysis confirmed the localisation at $\mathrm{Xq} 28$, and more precisely located MASA syndrome on the same side of F8C as DXS52 and DXS305.

\section{A.3 PATIENTS AND METHODS}

\section{A.3.1 Patient reports}

Patient 1 (III:2, Fig.1) was born in 1944 after an unremarkable pregnancy; the birth and perinatal history were normal. His psychomotor development was generally delayed. He walked at the age of 5 years and started to speak a few words at the age of about 4 years. At a young age he was treated for fits that might have been of epileptic origin. Recent evaluation at the age of 45 years showed a cooperative, moderatively retarded man. He had simple speech and could not read or write. He was employed in a sheltered environment. He had a normal height, but was overweight. His OculoFrontal Circumerence (OFC) was $59 \mathrm{~cm}$ ( $1 \mathrm{~cm}$ above the 98 th centile). He had a spastic gait. He stood with anteverted hips, bowed knees, and anteverted shoulders (Fig.2). Apart from the macrocephaly, no facial dysmorphism was present. His left eye showed divergent strabismus. The pupils were irregularly shaped but did 


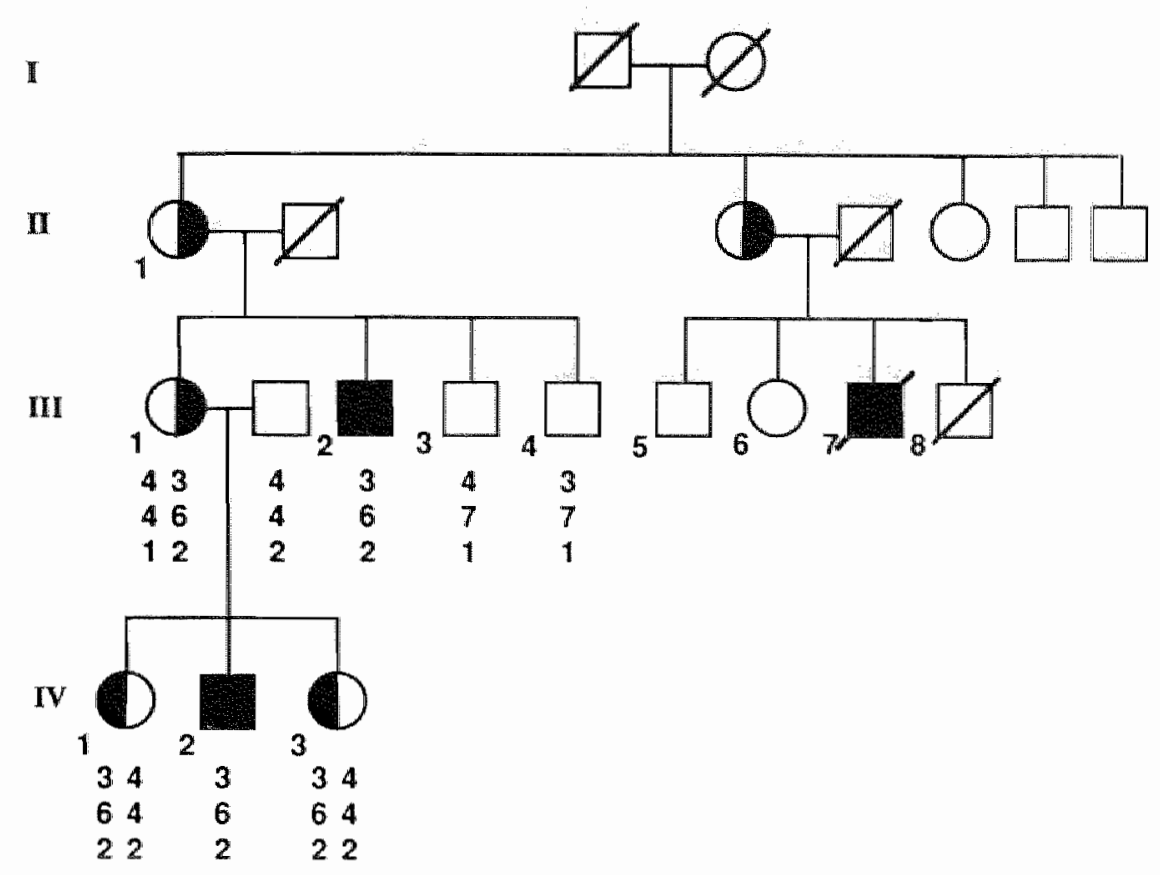

Figure 1 Pedigree of the farnily with informative DNA markers (F8C, St14, S135). The site of the shaded region in the femtle carriers' symbols corresponds to the parental origin (mother left, father right) of the haplotypes.

react to light. He held both thumbs in flexion-adduction (Fig.3) and the function of the abductor pollicis longus muscle was clinically absent. The fifth fingers showed camptodactyly. Neurological examination showed a mild dysarthria and a spastic paraplegia of the legs. Chromosomes were normal male $(46, X Y)$ and fragile $X$ screening was negative. CT scan of the brain showed asymmetry of the skull and brain and extensive widening of the lateral ventricles; the third ventricle was moderately enlarged and the fourth ventricle was normal. The lateral ventricles were irregularly shaped (Fig.4).Patient 2 (IV:2) (Fig. 1), the nephew of patient 1, was born in 1970 after a normal, term pregnancy. Birth weight and length were normal. There were no perinatal problems, but development was delayed. He started to walk at the age of 4 years, but with bowed knees. He spoke his first words at the age of 4 years. Neurological evaluation at the age of 5 years howed generally delayed development; the tendon reflexes were normal, including the plantar responses. EEG and EMG were normal. His IQ was 50. At the age of 6 years his reflexes were noted to be increased with an extensor plantar response. At the age of 19 years, he was a friendly, mildly retarded boy with a spastic gait. There was a remarkable general resemb]ance to his maternal 
uncle. He attended a special school and would soon be working in sheltered employ-ent. Height was $165 \mathrm{~cm}$, weight $85 \mathrm{~kg}$, and OFC $58 \mathrm{~cm}$ (98th centile). Apart from epicanthic folds and relative macrocephaly, no facial dysmorphism was present. Both thumbs were flexed and adducted and the fingers showed distal tapering. Neurological examination showed a spastic paraplegia of the legs. Ellectromyography of the thumb muscles showed adduction of the thumb when the abductor pollicis longus muscle was stimulated; CT scan of the forearm musculature, however, failed to show any abnormality. On ophthalmological examination, myo-pia and astigmatism were found and divergent strabismus of the left eye was present. The media and fun-dus of both eyes were normal. Chromosome study was normal male $(46, X Y)$ and the fragile site at $\mathrm{Xq} 27.3$ was negative. $\mathrm{CT}$

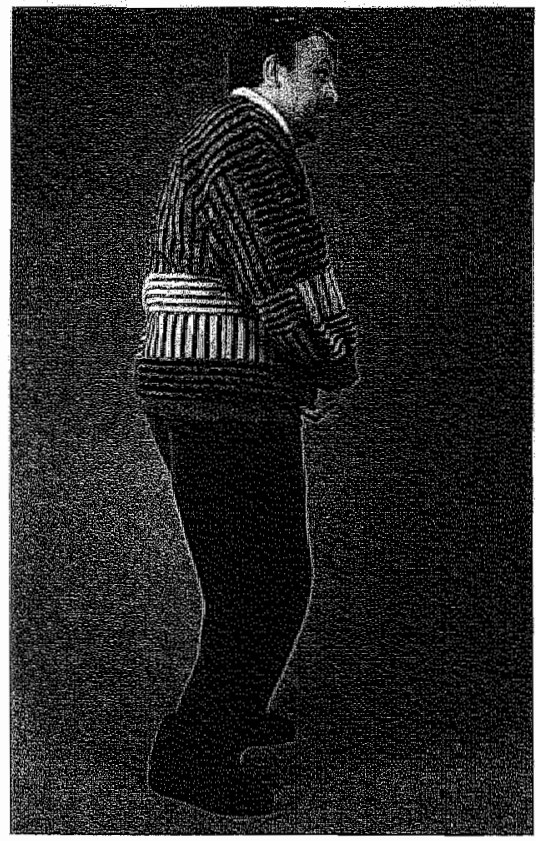

Figure 2. Patient $L$. Note the anteverted hips, bowed knees, and anteverted shoulders scan of the brain showed the same abnormalities as seen in his maternal uncle but less pronounced.

Patient 3 (III:7) (Fig. 1), a maternal cousin of patient 1, was born in 1936 with apparent hydrocephalus. He had severe mental and motor retardation and died at the age of 15 years in an institute for severely retarded patients.

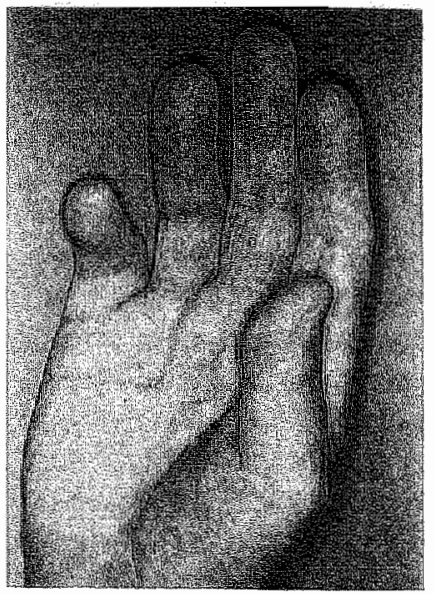

Figure 3 Hand of patient $\llbracket$ showing adducted and hexed thisubs and camptodatyly of the finth tinger

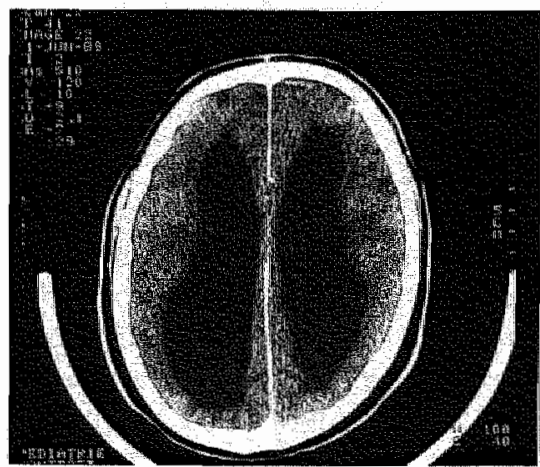

Figure $4 \mathrm{CT}$ scan of the brain of patient 1: note the irreguharly shaped wide ventricles. 
Family history

The family was examined when the older sister of patient 2 presented for genetic counseling. The mother and maternal grandmother, both obligate heterozygotes, showed no signs of the syndrome and their neurological reflexes were normal. Neither of the sisters of patient 2 has any clinical signs of the syndrome.

\section{A.3.2 DNA studies}

DNA was extracted from peripheral venous blood samples. After restriction enzyme digestion the resulting fragments were size separated by agarose gel electrophoresis and alkali blotted on Hybrid $\mathrm{N}$ plus membranes. These membranes were hybridised with the following probes: F9, F8, pX58dillc (DX599), U6.2 (DXS304), DX13 (DXS 15), St14.1 (DXS52) and St35.691 (DXS305). The computer program MENDEL was used to compare lod scores (K Lange, $\mathrm{D}$ Weelss, Boenke). Only three markers were informative in all meioses: St14.1 (DXS52), St35.691 (DXS305), and F8C (Xbal/KpnI polymorphism) (Fig 1). Lod scores for the present family and the families reported by Kenwrick et al. (7) and Winter et al. (15) are given in the table.

MASA syndrome can be unambiguously assigned to Xq.28 because there are no recombinations between St14.1 and MASA syndrome in the two reported families and in the present family. This gives a total lod score of 5.97 at theta $=0.0$. Moreover a recombination apparently occurred in the meiosis of II: 1 resulting in III:4 between the MASA locus and F8C but not DXS52 or DXS305. This places the MASA locus on the same side of F8C as DXS52 en DXS305, which are closely linked (12).

\begin{tabular}{|c|c|c|c|c|c|c|}
\hline & \multicolumn{6}{|c|}{ Lodd scōte (theter). } \\
\hline & 0.0 & 0.05 & 0.10 & 0.20 & 0.30 & 0.40 \\
\hline Present fomily & 1.204 & 1.093 & 0.975 & 0.721 & 0.444 & 0.173 \\
\hline Three families connbined & $5.98 *$ & 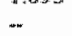 & 4.85 & 3.64 & 2.33 & 0.95 \\
\hline
\end{tabular}

* The $95 \%$ confidence limits for theta were between 0 and 0.09

\section{$2 A .4$ DISCUSSION}

The two males in the present family show the clinical features of the MASA syndrome, an acronym for mental retardation, aphasia (delayed speech), shuffling gait (spastic paraplegia), and adducted thumbs. A third male relative died from congenital hydrocephalus. The mental retardation in the older male (patient 1) is more severe than in the younger (patient 2). It is not clear whether this is a real difference owing to variation within the syndrome, as the provision of special education for the mentally 
retarded in the 1940s was clearly different from the facilities that could now be offered to patient 2 . On the other hand, the neurological and brain abnormalities in patient 1 are more severe than in patient 2 , and this may be an indication of a progression of the spastic paraplegia and CNS (Central Nervous System) abnomalities with age. The lowest reported IQ in MASA syndrone is 40 (7). A review of the clinical signs in the syndrome was recently reported by Winter et al. (15). In the present patients, ocular findings were non-specific. Additional important findings in this family were the abnormal $\mathrm{CT}$ findings in the brain with gross enlargement of the lateral ventricles. So far, a CT scan of the brain in a male with MASA syndrome has been reported only once and was normal (16). This ventricular widening is an interesting finding in view of the dead male relative with congenital hydrocephalus. In the differential diagnosis of MASA syndrome, congenital hydrocephalus has to be considered; this can occur as an $X$-linked recessive trait and is known to be associated with adducted thumbs in about $50 \%$ of patients $(6,10)$.

The adducted thumbs in MASA syndrome are thought to be caused by hypoplasia or absence of the extensor pollicis longis and/or brevis muscles; this assumption has been proven once by surgical exploration (16). The clasped thumbs in X-linked hydrocephalus are thought to be a developmental defect of the abductor and/or extensor muscles as well, shown by electrophysiological and surgical findings (9). In the present patient 2, electrophysiological examination of the thumb muscles showed evidence of an abnormality of the abductor pollicis longus muscles, which could not be confirmed on the CT scan of the forearm musculature. Pyramidal tract anomalies as seen in the present two males are a common finding in necropsy records of dead males with $X$-linked hydrocephalus (6). In families with $\mathrm{X}$-linked hydrocephalus, surviving male relatives have been described with non-specific mental retardation with or without spastic paraplegia (13). In the present family with two males with MASA syndrome, a third male relative had congenital hydrocephalus.

On clinical grounds it is not clear whether the X-linked hydrocephalus and the Xlinked MASA syndrome represent different entities; the present family illustrates the hypothesis that both disorders could be closely related. Moreover, the three patients reported by Winter et al. (15) all showed marked macrocrania (OFC $>97$ th centile). Genetic linkage analysis in the present family supports close linkage with DXS52 on Xq28 and more precisely locates MASA syndrome on the same side of F8C as DXS52 and DXS305. The preliminary results of genetic linkage analysis in families with $X$ linked congenital hydrocephalus also suggest linkage with Xq28 markers (DXS52, F8C) (14). The results of the linkage analysis, together with the clinical findings (dilated ventricles, macrocrania, and lethal hydrocephalus) strongly suggest that MASA syndrome and X-linked hydrocephalus are allelic variants.

The uncomplicated form of $X$-linked spastic paraplegia is clinically different and linkage has been found with loci in the $\mathrm{Xq} 21-22$ region $(2,8)$. Croldblatt et al. (4) reported a family with the complex form of X-linked spastic paraplegia with linkage to $\mathrm{Xq} 13-21.2$. The affected males in this family also presented varying degrees of mental retardation in addition to the spastic paraparesis, but abducted thumbs were absent and macrocrania was not mentioned. This indicates that the nosology of $\mathrm{X}$-linked spastic 
paraplegia, MASA syndrome, and X-linked hydrocephatus still remains a difficult problem. This question may only be resolved by the study of more families, including DNA studies together with careful clinical descriptions.

\section{Acknowledgments}

The authors wish to thank Dr. C.J. Höweler for neurological examination of patients 1 and 2. This work was supported by the Inter-University Network for Fundamental Research sponsored by the Belgian Govemment (1987-1991) and by a grant 'Geconcerteerde Acties' from the Belgian Government. 


\section{REFERENCES}

1. Bianchine JW, Lewis RC Jr. The MASA syndrome: a new theritable mental retardation syndrome. Clin Genet 1974,5:298-306.

2. Fishbeck KH, Shi $Y$, Ritter A, Bird T, Jancovic J, Pucketi C. Linkage studies in X-linked spastic paraplegia. Aun J Hum Genet 1987,41:Al65.

3. Gareis F, Mason ID: X-linked mental retardation associated with bilateral clasp thumb anomaly. Am J Med Genet 1984;17:333-338.

4. Coldblatt $J$, Ballo $R_{6}$ Sachs $B$, Moose A. X-linked spastic paraplegia: evidence for homogeneity with a variable phenotype Clin Genet 1989; $35: 116-120$.

5. Harding $A E$. The hereditary ataxias and related disorders. Edinburgh: Churchill Livingstone 1984:174204.

6. Halliday J, Chow CW. Wallace D, Danks DM. X-linked hydrocephalus: a survey of a 20 year period in Victoria, Australia. J Med Genet 1986,23:23-31.

7. Kenwrick $\mathrm{S}_{\mathrm{x}}$ Ionasescu V, Ionasescu $\mathrm{G}$, Searby Ch, King A, Dubowitz M, Davies KE. Linkage studies of X-linked recessive spastic paraplegia using DNA probes. Hum Genet 1986; 76:264-266.

8. Keppen LD, Leppert MF, O'Connell $P$, Nakamura $Y$, Stauffer D, Lathrop M, Lalouel J-M, White R. Etiological heterogeneify in X-linked spastic paraplegia. Am J Hum Genet 1987;41:933-943.

9. Landrieu $P$, Ninane $J$, Ferrierer $G$, Lyon $G$. Aquaductal stenosis in X-linked hydrocephalus: a secondary phenomenon? Developm Med Child Neurol 1979;21:637-652.

10. MeKusick VA. Mendelian inheritance in man. 8th ed. Baltimore: Johns Hopkins University Press, 1988:1378.

11. Sutherland GR, Gedeon AK, Haan EA, Woodroffe P, Mulley JC. Linkage studies with the gene for an Xlinked syndrome of mental retardation, microcephaly and spastic diplegia (MRX2). An J Med Genet $1988 ; 30 ; 493-508$.

12. Vincent A, Kretz C, Oberle $\mathrm{I}$, Mandel JL. A new polymorphic marker very closely linked to DXS52 in the $q 28$ region of the human $X$ chromosome. Hum Genet 1989:82:85-86.

13. Willems PJ, Browwer OF, Dijkstra I, Wilmink I. X-linked hydrocephalus. Am J Med Genet $1987: 27: 921-928$.

14. Willems PJ, Dijkstta $I_{\text {a }}$ Van der Auwera BJ, Vits L, Coucke P. Raeymakers $\mathrm{P}$, van Broeckhoven $\mathrm{C}_{*}$ Consalez GG, Freenian SB, Warren ST, Brouwer OF, Brunner HG, Renier WO, wan Elasen AF, Dumon JE. Assignnent of X-linked hydrocephalus to Xq28. Am J Hum Genet 1989;45:A352.

15. Winter RM, Davies K, Bell MV, Huson SM, Paterson MN. MASA syndrome: further elinical delineation and chromosomal location. Hum Genet 1989;82:367-370.

16. Yeatman GW. Mental retardation-clasped thumb syndrome. Am J Med Genet 1984;17:339-343. 


\section{Chapter 2B}

\section{MASA syndrome: delineation of the clinical spectrum at prepubertal age}

Jean Pierre Fryns, Connie Schrander-Stumpel, Christine de Die-Smulders, Martine Borghgraef, Herman Van Den Berghe 


\section{B: ARSTRAT}

Here we describe the clinical and neurological findings in 2 brothers with MASA (Mentat retardation, Aphasia, Shuffling gait and Adducted thumbs) syndrome and the changes phenotypic and neurological findings during the prepubertal period. MASA syndrone seems to be an X-linked mental retardation syndrome with progressively appearing manifestations and neurological signs, making clinical diagnosis before age 4 years difficult.

\section{$2 \mathrm{~B} .2$ NTRODUCTION}

Within the group of socalled specific forms of X-linked mental retardation (XLMR) interest in the nosology of X-linked complicated spastic paraplegia has increased rapidly in the past few years (4). Few data on the prepubertal symptoms and signs in MASA syndrome have been reported.

\subsection{PATIENTS AND METHODS}

\section{B.3.1 Clinical reports}

M.l. and M.M., are 2 brothers, now 12 and 5 years old. They are the only children of healthy, unrelated parents. The eldest brother, M.I, was born after a nomal pregnancy and term delivery. Birthweight was $3.15 \mathrm{~kg}$ and length $49 \mathrm{~cm}$. A severe equinovarus position of both feet was noted in the neonatal period. Between the age of 6 months and 2 years three orthopedic corrections were unsuccessful. At age 2.5 years internal strabismus and a left inguinal hernia were corrected. From the age of 6 months on a delay in psychomotor development was noted. The boy could sit without support at age 11 months and walked at age 3.5 years. Speech development was severely retarded and psychodiagnostic evaluation at age 4 years showed a developmental level of 2.5 years (IQ 54 Terman scale). Clinical examination at that age (height $102 \mathrm{~cm}-3 \mathrm{rd}$ centile; weight $17 \mathrm{~kg}$; 50 th centile; OFC (Occipito Fronto Circumferenc) $52 \mathrm{~cm}-75$ th- 97 th centile) documented a relatively macrocephalic boy with relatively brachycephalic head, flat occiput, deeply-set eyes, relative maxillary hypoplasia, colobomata alae nasi, small mouth, short philtrum, thin upper lip, and small retrognathic chin. The hands were relatively small. Both thumbs were short with hypoplastic thenar muscles and reduced active mobility $\left(20^{\circ}\right.$ adduction, $10^{\circ}$ abduction). Both feet were in a fixed equinovarus position and the legs showed marked distal muscular hypotrophy. The gait was shuffling with broad intermalleolar distance $(8 \mathrm{~cm})$. Tonus and reflexes were normal. At age 6 years he was admitted to a special school for the moderately mentally retarded. He was reevaluated at age 12 years (weight $44 \mathrm{~kg}-75$ th centile; height $144 \mathrm{~cm}-25$ th centile; OFC $54 \mathrm{~cm}-50$ th centile). In addition to the craniofacial changes (Fig.1), the hypotrophic thumbs and 


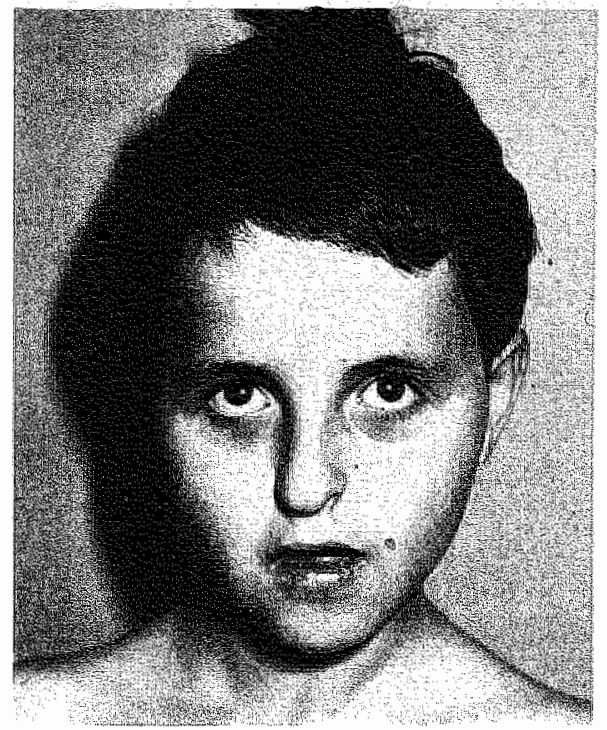

Figure 1 The craniofacial dysmorfism in the eldest brother.

serum and urine were normal.

The youngest brother, M.M., was born normally at term. Birthweight was $4.03 \mathrm{~kg}$ and length $51 \mathrm{~cm}$. Feeding difficulties were present in the first months of life with poor suck reflexes. Clinical and neurological examination was normal in the neonatal period. A small midfrontal neavus flammeus was the only notable finding. Clinical reevaluation at age one year showed relative hypotonia. The boy could hardly sit without support. There was a relative hypotrophy of the distal legs with normal tendon-reflexes and hands were small with hypotrophic thumbs and reduced thenar muscle mass. His facial appearance was similar to that of this brother with relatively large, square shaped cranium, small midface with maxillary hypoplasia, short philtrum, thin lips, colobomata alae nasi and microretrognathia. He started to walk the distal hypotrophy of the legs with equinovarus position of both feet, he now presented a typical habitus with flexed knees, anteverted shoulders and thoracic hyperkyphosis (Fig.2). He had spastic paraplegia with increased tone and increased reflexes with an extensor plantar response. His gait was spastic and shuffling and speech delay was still severe. CT-scan of the brain showed bilateral ventricular dilatation with enlarged third and fourth ventricles without other structural anomalies. Ophthalmological examination and electromyography were normal. Chromosomes were normal male $(46, X Y)$; fragile $X$ screening was negative $(100$ cells of a M199 culture). Routine biochemical and metabolic screening including aminoacid chromatography of

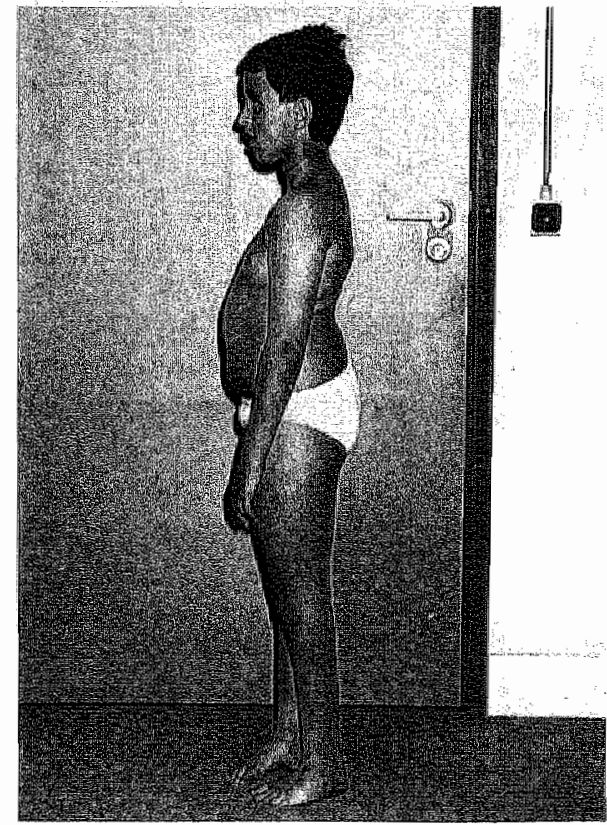

Figure 2 Typiciat habius with arteserted hips, bowed knows and antewerted shoulder an the elderit brother 


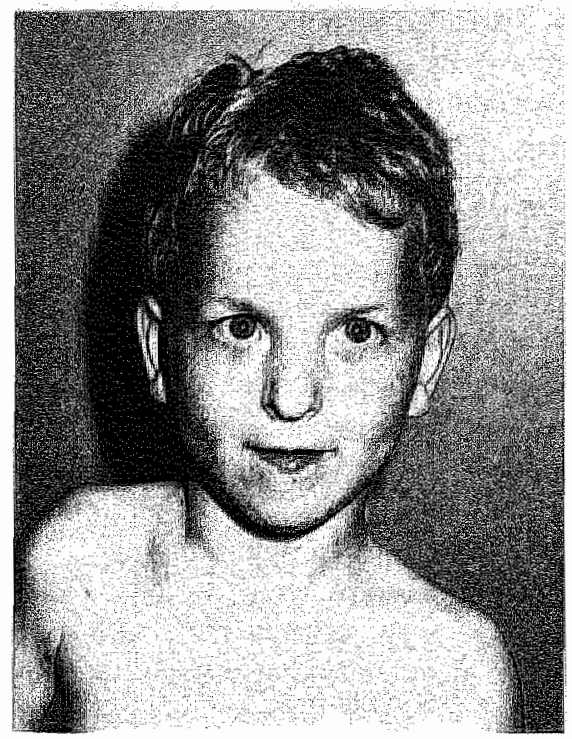

Figure 3 Younger brother: similar eranofacial rnding

without support after age 2.5 years but his gait remained unstable and shuffling. Speech development was severely retarded and at age 4 years he could only speak a few words and had serious articulation problems. A delay in mental development became more and more evident and psychological evaluation at age 4 years documented slight mental retardation (IQ 69 - Terman scale). Gross motor development was markedly delayed with unstable gait, poor equilibrium, inversion of both feet, distal muscle hypotrophy with increased muscle tone and hyperreflexia with an extensor plantar response. He had a typical habitus with anteverted shoulders, hyperkyphosis and bowed knees. Weight was $14 \mathrm{~kg}$ (75th centile), height $89 \mathrm{~cm}$ (50th centile) and OFC $50 \mathrm{~cm}$ (50th centile). CT-scan of the brain showed enlargement of both ventricles, normal cortical sulci and absence of other structural anomalies. Chromosomes were normal, and fragile $X$ screening was negative (100 cells of a M199 culture). Ophthalmological examination, electromyography, routine biochemical and metabolic screening were normal. Between the ages of 4 and 5 years (Figs.3 and 4) progression of motor abilities and skills were almost nil despite an extensive training program and speech therapy resulted in an almost nonsignificant progress of verbal performance with persistent poor articulation.

\section{B.3.2 Family History}

The mother was the fourth born in a family of 5 children. Her 3 brothers and her sister are mentally and physically normal. Family history is otherwise unremarkable. Clinical evaluation of the mother showed a 37-year-old borderline intelligent female (height $167 \mathrm{~cm}$,

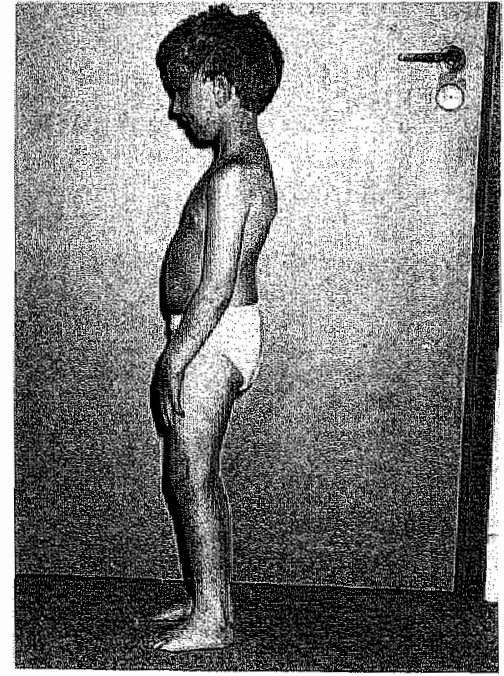

Figure 4 Younger brother: same general habitus. 
weight $55 \mathrm{~kg}$, OFC $55 \mathrm{~cm}$ ) with relatively small midface as seen in her two sons (maxillary hypoplasia, colobomata alae nasi, short philtrum, thin upper lip, microretrognathia). She attended a secondary school for the slightly mentally retarded. Now, she is socially well integrated but her speech is slow with important articulation problems.

\section{B.4 DISCUSSION}

Hereditary 'pure" spastic paraplegia is a disorder characterized by progressive spasticity of the legs in otherwise normal individuals (7); in most families pedigree data are in accordance with autosomal dominant inheritance, but X-linked recessive transmission has also been documented (6). In the 'complicated' form the spasticity may be combined with a variety of one or more symptoms i.e. mental retardation, abnormal headsize, epilepsy and ocular symptoms (5). In 1974, Bianchine and Lewis (2) delineated, on the basis of clinical and neurological symptoms, a clinically distinct $X$-linked pleiotropic form: affected males show the combination of Mental retardation, Aphasia, Shuffling gait and Adducted thumbs i.e. the so-called MASA syndrome. DNA-linkage studies performed in 4 families located the gene in the region of $\mathrm{Xq} 28$ $(6,8)$. Moreover, in one of the reported families $(10)$ affected males had true macrocephaly, and in the family reported by Schrander-Stumpel et al. (8) two affected males had extensive widening of the lateral ventricles and one male relative died at young age from progressive hydrocephaly. $X$-linked hydrocephalus with aqueductal stenosis and short, flexed thumbs was first described by Bickers and Adams (1) and Edwards (3). In families with $\mathrm{X}$-linked hydrocephalus surviving male relatives have been documented with nonspecific mental retardation with or without spastic paraplegia (9) and, moreover, genetic linkage analysis assigned X-linked hydrocephaly to Xq28. All these combined data i.e the available pedigree data, the clinical and neurological findings in the affected males and the results of genetic linkage analysis therefore strongly suggested that the MASA syndrome and X-linked hydrocephaly may be allelic variants. Recently, we had the occasion to perform clinical and DNA-linkage studies in another large four generations family (4). In this family 5 males presented a mental retardation syndrome with neurological abnormalities which varied greatly in severity and clinical expression: 2 brothers died at young age and presented hydrocephaly with aqueductal stenosis, one moderately mentally retarded maternal uncle had clinical and neurological abnormalities compatible with the diagnosis of MASA syndrome and 2 other borderline intelligent to slightly mentally retarded maternal uncles presented severe complicated spastic paraplegia. The findings in these 5 affected males strongly support the evidence that the $3 \mathrm{X}$-linked conditions i.e. Xlinked complicated spastic paraplegia (SPG1 - McKusick *312900), MASA syndrome (McKusick *303350) and X-linked hydrocephaly due to congenital stenosis of the aqueduct of Sylvius (McKusick *307000) are either variable clinical maifestations of the same mutation at $\mathrm{Xq} 28$ or could represent different mutations of the same locus. Combining the clinical and neurological findings of the affected adult males of these 2 families, two additional observations were made: a relationship between the degree of 
mental retardation and the neurological symptoms seemed to exist i.e. severe spastic paraparesis was seen in the more severely mentally retarded males and, furthermore, the neurological impairment was more evident with increasing age.

Up to now, few data were published on prepubertal patients with the MASA syndrome. Winter et al. (10) reported a family where 2 adult brothers and their nephew had the phenotype of the MASA syndrome. He noted: 'The diagnosis in the index case at $\mathbb{I}$ year (the affected nephew) would have been extremely difficult, if not impossible, without the family history". The 2 brothers of the present report, 12 and 6 years old at the last clinical evaluation, presented a combination of clinical and neurological findings fully compatible with the diagnosis of MASA syndrome. They were slightly to moderately mentally retarded with serious delay in speech development and poor articulation, their gait was shuffling with spasticity and increased reflexes and their thumbs were small with hypoplastic thenar muscles. CT scans revealed marked widening of the lateral ventricles with normal cortical sulci and without other CNS anomalies in both of them. We had the opportunity to follow the youngest brother from birth on. In the neonatal period clinical and neurological examinations were strictly normal. At age one year a mild delay in motor development was noted together with a relative hypotrophy of the lower legs and small thumbs with reduced thenar muscle mass. Reflexes were normal and the boy was rather hypotonic. From that age on the impairment of motor development became more and more evident and he started to walk with a broad, unstable gait after age 2.5 years. Speech development was severely retarded with serious articulation problems. At age 4 years the inverted position of the feet became evident for the first time with more marked distal hypotrophy of the lower legs and first signs of spastic paraplegia with hypertonicity, increased tendon reflexes and extensor plantar response appeared. Also at that moment the typical habitus with bowed knees and anteverted shoulders was noted. During the following year the motor development was almost non-existent, and verbal performances did not progress significantly. These follow-up data confirm our previous suggestion (4) that the neurological symptoms become more evident with increasing age and support the finding of Winter (10) in the 1-year-old affected nephew of this family.

The mental delay in the elder brother of the present family was more serious than in the younger brother. A severe rockerbottom type deformity of both feet with marked distal hypotrophy of the lower legs was already present from birth on. The general delay of motor- and language development had always been more striking than in his slightly mentally retarded younger brother. These findings seem to confirm that the neurological symptoms, and their progression with age, are more striking in the more severely mentally retarded affected males.

Few data have been reported on the phenotype of female heterozygotes. In the family reported by Schrander-Stumpel et al. (8) we did not observe clinicall or 
neurological abnormalities in the 2 female obligate heterozygotes. The mother of the present 2 affected boys was of borderline intelligence and had a remarkably similar craniofacial appearance as seen in her sons. However, neurological status was normal. Particular attention to the mental status, phenotype and neurological sympotoms in female heterozygotes of this type of X-linked mental retardation should therefore be given in order to confirm the present observation and to establish the incidence of partial clinical expression in heterozygotes. 


\section{REFERENCES}

1. Bickers DS, Adams RD. The syndrome of X-linked hydrocephalus. Arch Dis Childh 1949;36:486-489.

2. Bianchine W, Lewis RC Sr. The MASA syndrome: A new heritable mental retardation syndrome. Clin Genet 1974,5:289-306.

3. Edwards JH: The syndrome of X-linked hydrocephalus: Arch Dis Childh 1961;36:486-489.

4. Fryns IP, Spaepen $A$, Cassiman J. Van Den Berghe $\mathrm{H}$. $X$ linked complicated spastic paraplegia, MASA gyndrome, and X linked hydrocephalus owing to congenital stenosis of the aqueduct of Sylvius: variable expression of the same mutation at Xq28. I Med Genet 1991;28:429-432.

5. Harding AE. The Hereditary Ataxias and Related Disiorders, 1st ed. Edinburgh: Churchill Livingstone, $1978: 174-204$.

6. Keppen LD, Leppert MF, O'Connell $P_{*}$ Nakamura $Y$, Stauffer $D_{*}$ Lathrop $M_{\text {, Lalonal }} \mathrm{M}_{*}$, White $\mathrm{R}$. Etiological heterogeneity in X-limked spastic paraplegia. Am J Hum Genet 1987;41:933-943.

7. Mckusick VA. Mendelian Inheritance in Marn: Catalogs of Autosomal Dominant, Autosomal recessive, and X-linked Phenotypes, 9th ed. Baltimore and London: The Johns Hopkins University Press 1990.

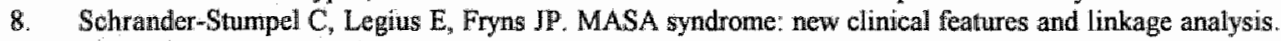
J Med Genet 1990;27:688-692.

9. Willems $\mathrm{PJ}_{\mathrm{v}}$ Brouwer OFD, Dijkstra I. X-linked hydrocephalus. An J Med Genet 1987;27:921-928.

10. Winter RM, Davies $K$, Bell MV. MASA syndrome: further clinical delineation and chromosomal location. Hum Genet 1990;82:367-370. 


\section{Chapter 3}

\section{The spectrum of X-linked hydrocephalus (HSAS), MASA}

syndrome, and complicated spastic paraplegia (SPG1): clinical review with six additional families.

Connie Schrander-Stumpel, Chris Höweler, Marilyn Jones, Annemarie Sommer, Cathy Stevens, Sigrid Tỉnschert, Jeanette Israel, Jean Pierre Fryns. 


\section{II ABSTRACT}

X-linked Hydrocephalus with Stenosis of the Aquaduct of Sylvius ((HSAS)(MIM *307000), MASA syndrome (acronym for Mental retardation, Aphasia (indicating slow speech development), Shuffling gait (meaning spastic paraplegia) and Adducted thumbs)(MIM *303350), and complicated spastic paraplegia (SPG1)(MIM *312900) are closely related. Soon after delineation, SPG1 was incorporated in the spectrum of MASA syndrome. HSAS and MASA syndrome show great clinical overlap; DNA linkage analysis places the loci at $\mathrm{Xq} 28$. In an increasing number of families with MASA syndrome or HSAS mutations in L1CAM, a gene located at Xq28, have been reported. In order to further delineate the clinical spectrum, we studied 6 families with male patients presenting with MASA syndrome, HSAS or a mixed phenotype. We summarized data from the previous reports and compare them with our data. Clinical variability appears to be great, even within families. Problems in genetic counseling and prenatal diagnosis, the possible overlap with $\mathrm{X}$-linked corpus callosum agenesis and FG syndrome, and the different forms of X-linked complicated spastic paraplegia are discussed. Since adducted thumbs and spastic paraplegia are found in $90 \%$ of the patients, the condition may be present in males with nonspecific mental retardation. We propose to abandon the designation MASA syndrome and use the term HSASMASA spectrum, incorporating SPG1.

\subsection{INTRODUCTION}

In a recent update on X-linked mental retardation (XLMR) genes, Neri et al. listed 127 conditions in which MR is consistently present (46). The conditions were subdivided into 5 categories: syndromes, dominant disorders, metabolic disorders, neuromuscular disorders, and nonspecific mental retardation. 80 Conditions have a MIM number (43); for 53 the gene has been regionally mapped, and for 15 of these the gene has been cloned (46).

Spastic paraplegia is a neurologic condition, divided into "pure" (spastic paraplegia as sole clinical manifestation, MIM *182600) and "complicated" (spastic paraplegia in combination with other clinical signs) forms. Inheritance in the pure form is generally autosomal dominant, although recessive cases have been reported (23). Pedigrees with pure X-linked spastic paraplegia (MIM *312920) have been reported in only few families $(4,49,78)$. Two distinct loci for $X$-linked hereditary spastic paraplegia, SPG1 and SPG2, have been identified: SPG1 at Xq28 (33) and $S P G 2$ at $X q 2 \rrbracket-q 22$ (35). Recently, in a familie with $S P G 2$ a point mutation was found in the PLP (proteolipid protein) gene (53).

When performing a computer search on the combination of XLMR and spastic paraplegia (an example of "complicated spastic paraplegia") 33 conditions were found, including metabolic diseases (2). One of these conditions is the so-called "MASA" syndrome (MIM *303350), reported as a new entity by Bianchine and Lewis in 1974 (3). A family with XLMR reported as having "complicated spastic paraplegia" (SPG1)(MIM *312900) by Kenwrick et al. (33) was considered to have MASA syn- 
drome on both clinical arguments and DNA linkage analysis data (76). In this paper we further incorporate SPG1 in the spectrum of MASA syndrome. DNA linkage analysis placed the "MASA" locus at Xq28 $(7,17,33,39,41,50,54,76)$. Boyd et al. (7) reported a MASA family where the patients presented with agenesis of the corpus callosum (CCA).

HSAS is the most common genetic form of congenital hydrocephalus (MIM *307000) and varies clinically from being lethal in utero or early infancy to survival with mental retardation, spastic paraplegia, and adducted thumbs. In families with HSAS inter- and intrafamilial clinical variability is well-known $(11,16,59,72)$. Linkage analysis in HSAS families placed the locus at Xq28 as well $(27,40,59,73,74)$.

Some years ago, reports appeared of 2 families in which males had both MASA. syndrome and HSAS; DNA linkage analysis in these families also placed the locus at $\mathrm{Xq} 28$, leading to the hypothesis that MASA syndrome and X-linked hydrocephalus, due to stenosis of the aquaduct of Sylvius (HSAS) may be variable expressions of the same gene at Xq28 (17,54). A further family, reported as MASA syndrome family, supported this observation (29). Clinical comparison between males with MASA syndrome and affected males surviving the first year in HSAS families showed many simillarities $(56,57)$.

In some of the families with HSAS, MASA syndrome, or a mixed phenotype, different mutations have been reported in the gene encoding for $\mathrm{LICAM}$, a neural cell adhesion molecule $(14,28,34,51,65,68)$. This gene has been mapped to Xq28 (10).

In summary, clinical findings in patients with MASA syndrome and in surviving patients (beyond the age of 1 year) in HSAS families show great overlap. DNA linkage analysis in both types of families places the locus at $\mathrm{Xq} 28$, and in a growing number of families with HSAS, MASA syndrome, or mixed phenotype, mutations in LICAM have been reported.

In order to further delineate the clinical spectrum of HSAS/MASA syndrome, we initiated a call for families $(55,56)$. We wondered whether the spectrum could be defined more specifically, based on clinical findings. In this paper we report the clinical data in 6 additional families. We summarize data from the literature, and we discuss genetic as well as clinical issues, including genetic counseling and prenatal diagnosis, the overlap with X-linked CCA and (possibly) FG syndrome, and the different forms of $\mathrm{X}$-linked complicated spastic paraplegia.

\subsection{CLINICAL REPORTS}

Six families were studied. HSAS was diagnosed when the proband presented with hydrocephalus. MASA syndrome was diagnosed using the clinical criteria of mental retardation, adducted thumbs, spastic paraparesis and slow speech development, or in general speech problems. However, when brain imaging manifested hydrocephalus, diagnosis was reclassified as HSAS. An X-linked pattern of inheritance was suspected with 2 affected brothers when the parents were not consanguineous; X-linked inheritance was assumed when the pedigree contained at least 2 affected male patients in at least 2 generations, related through females. The total of affected males was 18. 
Three HSAS cases were diagnosed prenatally by ultrasound examination, and pregnancies were terminated. In one further fetus, aborted for social reasons in an HSAS family, the diagnosis was based on a subsequent molecular investigation. Four affected males with HSAS died at birth or neonatally. In each of the 6 families detailed clinical information was available; altogether, data were available on 2 fetuses and 10 patients. On 6 deceased affected males only anamnestic data were available; these cases are present in the pedigrees, but not in the clinical reports. In all ten affected males surviving the first year of life, cytogenetic studies were normal and fragile $\mathrm{X}$ syndrome was excluded by DNA mutation analysis. DNA linkage analysis data in families B-F are reported elsewhere (58). The clinical data are summarized in Table 1.

\section{Table 1}

Clinical findings in presently reported families A-E, each with 2 patients ( 1 and 2 ).

\begin{tabular}{|c|c|c|c|c|c|c|c|c|c|c|c|c|}
\hline \multirow[t]{2}{*}{ Finding } & \multicolumn{2}{|c|}{ Framilly } & \multicolumn{2}{|c|}{ Wamily $\mathrm{B}$} & \multicolumn{2}{|c|}{ Eiamily $\mathrm{C}$} & \multicolumn{2}{|c|}{ Fumily D } & \multicolumn{2}{|c|}{ Family $\mathrm{E}$} & \multicolumn{2}{|c|}{ Familly F } \\
\hline & 1 & 28 & 1 & 2 & 1 & 2 & $!$ & 2 & 1 & 2 & 1 & 2 \\
\hline Gest. age (wiektsi) & & & & & 24 & & 22 & & & & & \\
\hline Age (gyegrisi) & 22 & 16 & nid & nd & & 4 & & 22 & 5 & 1 & 10 & 1 \\
\hline Olec at birth (P) & 20714 & $297 \mathrm{th}$ & 50 th & $97 \mathrm{ih}$ & P97h & nod & $397 \mathrm{th}$ & nd & nd & and & 397 th & 397 th \\
\hline OFC postnatial ( & $\times 07 \mathrm{th}$ & $>97 \mathrm{th}$ & 2004 & 50 th & & $501 \mathrm{~h}$ & & soth & $>07$ th & $>97 \mathrm{~h}$ & 97 th & $>97 \%$ \\
\hline Mental retardation & + & + & \# & + & & + & & $*$ & + & fa & 。 & 4 \\
\hline Level & & & Mild: & Mild & & Profound & & Severe & Severe & Mild & & nd \\
\hline Age at walking (yr) & 2 & 2 & 3 & 2 & & - & & - & nd & ny & 1.2 & 1.5 \\
\hline $\begin{array}{l}\text { Spastie puraplegin or } \\
\text { hyperreflexin }\end{array}$ & H & to & + & + & & 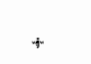 & & + & $*$ & - & - & + \\
\hline Age an talking & "SI & & & & & & & & & $\mathbb{1}$ & Dita & yed \\
\hline Speech quality & & & "Prot & lents" & & & & & & & thearing & g losis) \\
\hline No ippeseti & & & & & & $*$ & & + & + & & & \\
\hline Adducted athumilosi & \pm & $k^{*}$ & + & \# & & . & & + & + & 4 & 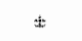 & it \\
\hline Hyilroctephthilus & + & * & nd & nd & + & * & * & + & $*$ & . & + & . \\
\hline $\mathrm{CCA}$ & * & - & ned & nd & + & . & $*$ & ndt & $*$ & - & $\therefore$ & . \\
\hline Diagnos is / phowetyos & $\mathrm{H}$ & $\mathrm{M}$ & $M$ & $M$ & H & $\mathrm{H}$ & HI & $\mathrm{H}$ & $\mathrm{H}$ & $\mathrm{M}$ & $\mathrm{H}$ & $\mathrm{H}$ \\
\hline
\end{tabular}

Pedigree A (Fig.1) consists of a family with 2 brothers (III:1 and III:2) with MASA syndrome. The mother (II:2) and 2 healthy sisters (III: 3 and III:4) had no signs of the syndrome. The mother had 3 healthy brothers and 3 healthy sisters. Her father 

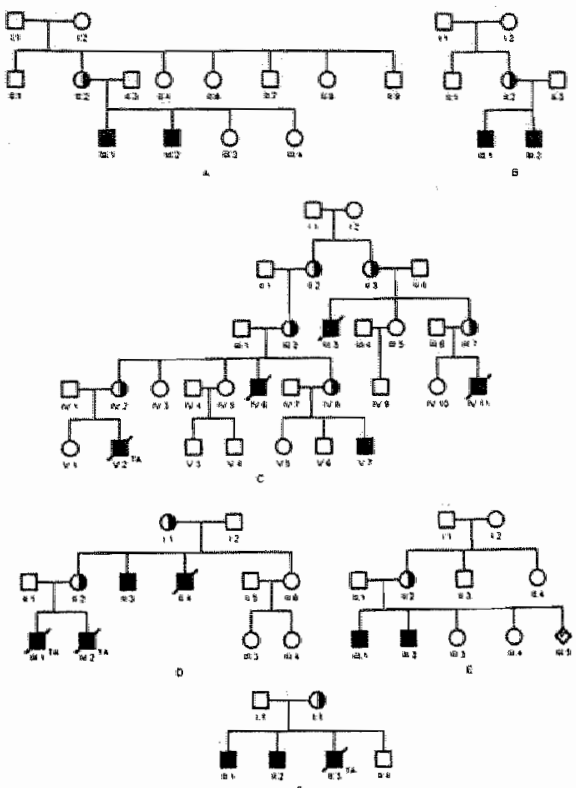

Figure 1 Pedigrces of families A - F.

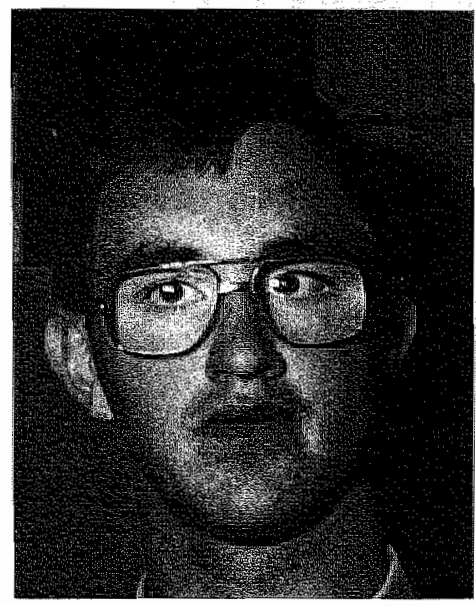

Figure 2 Patient III: I and IIT: 2 (pedigree A) macrocephaly in the older brother (right) and norispecific phonotype in the younger (len):

He had a typical habitus with shoulders in anteversion, thumbs adducted, hips in antever-sion and knees were slightly flexed.(Fig.3).His gait was shuffling. OFC was $62.5 \mathrm{~cm}$ ( $>98$ th centile). His lower limbs were hypertonic, with clonic knee and ankle jerks and extensor plantar responses. Brain CT scan showed large ventricles; the

was 43 years old at the time of her birth, her mother was 42 . Pregnancy, birth and perinatal periods were normal in both affected boys; occipitofrontal circumference (OFC) in both boys was a-bove the 90 th centile $(37.5$ $\mathrm{cm})$. They were both developmentally delayed: walking started around age 2 years. Speech development was slow. Mental retardation be-came evident with IQ's of 30-40; they live in a sheltered home. In both patients, the neurological manifestations became clearly evident only after puberty. Results of re-peat chromosome studies were normal male, $46, X Y$, fragile $X$ negative. Metabolic screening was normal, as were ophthalmologic investigation and EEG. At age 22 years, patient III: 1 was a friendly, macrocephalic, mentally retarded man (Fig.2).

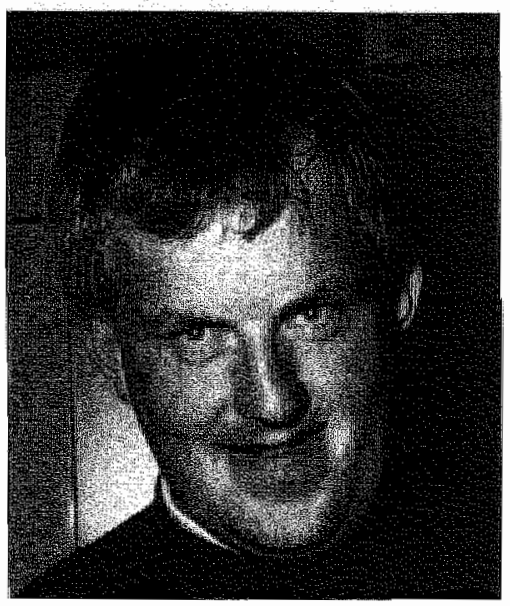




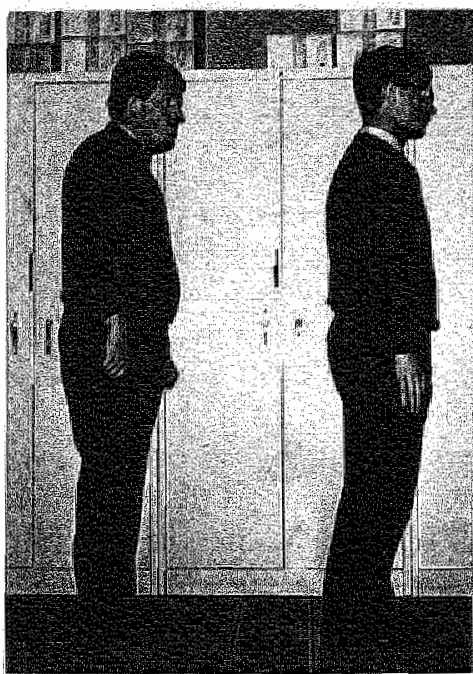

Figure 3 Posture of brothers III: 1 and III 2 (pedigree A). Note the wancolation in the shoulders, prenation of the forcerms, aryd flexion in the knees. compus callosum was present and there was no cor-tical atrophy. This patient was reclassified as HSAS. Patient III:2 presented at the age of 7 months with macrocephaly (45 cm); reflexes were normal. Pneumoencephalogram showed normal Jateral ventricles and a broad septum pellucidum. At the age of 11 months he could not yet sit and he had extensor plantar reflexes. A repeat pneumoencephalogram revealed broad frontal horns and a large 3rd ventricle. At age 16 years, he was a macrocephalic, mentally retarded adult (Fig 2) with a habitus similar to that of his brother (Fig. 3). OFC was $61 \mathrm{~cm}$ (>98th centile). He had hyperreflexia and indifferent plantar reflexes. Brain CT scan showed no apparent abnormalities.

Pedigree B (Fig. 1) consists of a

family with 2 brothers (III:1 and III:2) clinically affected with MASA syndrome (Figs.4 and 5). "The mother (II:2) had 1 healthy brother. The parents were not consanguineous. The older boy was born at term with normal growth parameters. He took his first step at age 3 years, and at the age of 13 years had an ataxic, shuffling gait. His speech was ataxic and hesitant. The younger brother walked at 2 1/2 years and spoke single words at 20 months. Delays in gross motor skills and expressive language were noted early on. Both children had very brisk deep tendon reflexes; the younger brother had a slightly less ataxic gait. They had mumerous orthopedic procedures on hands and feet and still wear leg braces. They are both in special education classes (mild MR) and do very well in this setting. They have significant myopia. They were not macrocephalic, although the younger brother"s OFC was at the 98 th centile during his first year of life; imaging of the CNS was not avallable in either

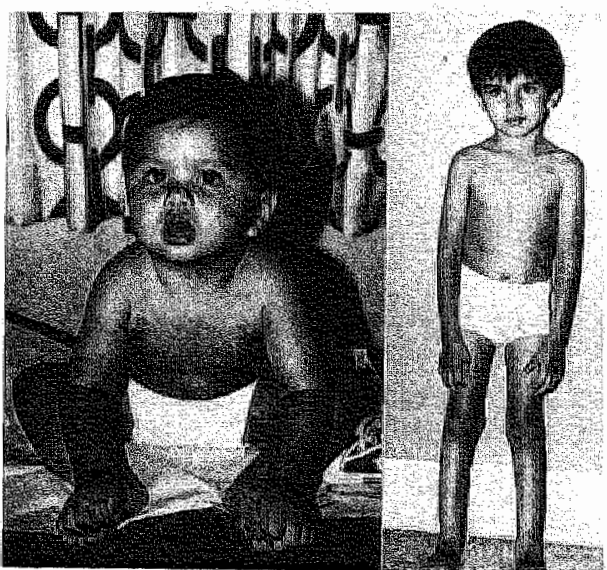

Figure 4 Probands MI: 1 and II:2 (pedigree B), 1 and 4 years old: macrecephatic, hypotonis younger brother, posture with anterotated shoulders in the older brother. 


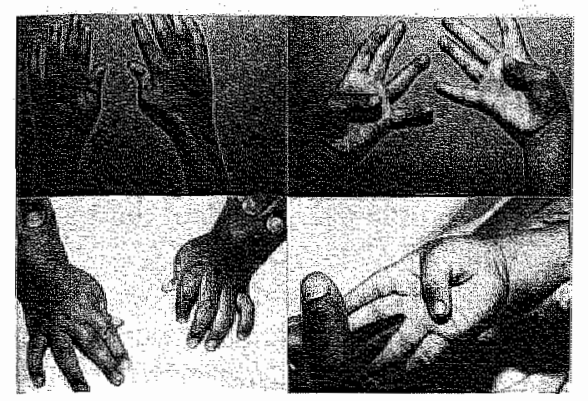

Figure 5 Hands in probands DI: 1 and III 2 (pedigree B), showing adducted thumbs. of them.

Pedigree $\mathrm{C}(\mathrm{Fig} 1)$ consists of a 5 generation family with 2 male patients (V:2 and V:7) with HSAS: Proband V:2 was diagnosed by fetal ultrasound study at 24 weeks gestation; the pregnancy was terminated and the diagnosis of severe hydrocephalus was confinmed; cortex was thin and both the lateral ventricles, third ventricle, and cisterna magna were dilated. Thumbs were normal. The deceased male IV:6 was

stillborn and said to have a large head (no clinical data available). Proband $V: 7$ was born at 38 weeks of gestation by caesarean section due to a very large head; he had severe hydrocephalus and was shunted at age 3 days. At age 4 years he was profoundly developmentally delayed and wheelchair-bound, with horizontal and vertical nystagmus but normal thumbs. Speech development was absent. 2 Male relatives (III:3 and $V: 11$ ) died from congenital hydrocephalus (no further information available).

Pedigree $D$ (Fig. 1) consists of a 3 generation family; the proband (11:1) presented with HSAS. Patient $\Pi: 3$ is a severely mentally retarded male. He was boin with hydrocephalus and was shumted at age one year. When examined at age 22 years (Fig.6), he had spastic tetraplegia with the legs more severely affected than the arms; thumbs were adducted with a hypoplastic left thumb. He could not sit or walk and was unable to speak; he had urinary and bowel incontinence. Head circumference was 55.5 $\mathrm{cm}$ (50th centile). The ophthalmologic exam documented an atrophic optic nerve. Affected male II:4 died shortly after birth. He had an extremelly large head; no further information is available. Fietus III: 1 was aborted at 22 weeks of amenorrhea because of severe hydrocephalus on repeat ultrasound examination. At autopsy, internal hydrocephalus was found, especially of the lateral ventricles; the aqueduct was not stenotic. The corpus callosum was absent. The right ventricle of the heart was hypoplastic. Fetus III:2 was aborted for social reasons at 14 weeks gestation; chromosomes were $46, \mathrm{XY}$ and DNA linkage analysis showed the risk haplotype (58, and personal followup by S.Tinschert and C.SchranderStumpel).

In pedigree E (Fig. 1), proband III:1 presented with $\mathrm{MSAS}$, and his brother (III:2) with MASA syndrome. The mother (II:2) had a healthy brother

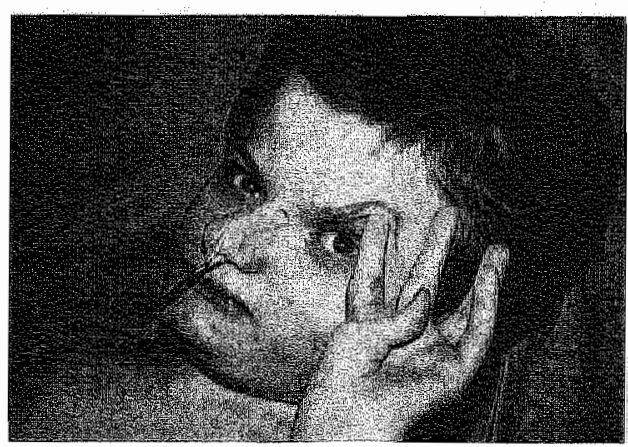

Figure 6 HSAS patient II 3 (pediggee D): atererely mentally retarded patient witty adducted thumb. 
and sister. The parents were not consanguineous. Proband III: 1 was diagnosed with hydrocephalus at age 4 months and a shunt was placed. At age 5 years, he was developmentally delayed, and had an abnormal gait and adducted thumbs. Proband III: 2 , at 14 months, had an OFC at the 98th centille without apparent signs of hydrocephalus on the MRI scan. He was developmentally delayed and had adducted thumbs.

Pedigree $F$ (Fig. 1) was a family with 2 affected brothers (II:1 and II:2) presenting with HSAS. There is 1 healthy brother. The parents were not consanguineous. In the younger brother (III:2), fetal ultrasound at 32 weeks gestation demonstrated hydrocephalus; at birth, OFC was $36 \mathrm{~cm}$; a shunt operation was not performed. At age 1 year the legs were hypertonic and psychomotor development was mildly delayed. Thumbs were adducted. He had a hearing loss (familial trait). The older affected brother (II:1), 10 years old, was shunted after birth because of apparent hydrocephalus. He also had a hearing loss; , his intelligence was normal. Adducted thumbs were present in early childhood. A male fetus (II:3) was aborted at 26 weeks of gestation because of severe hydrocephalus seen on fetal ultrasound study (no autopsy data available).

\subsection{LITERATURE DATA}

We reviewed the clinical data on 13 families, previously reported as having MASA syndrome; there was a total of 98 patients $(3,7,17,18,19,29,33,41,50,54,63,76,77)$.

In most reported families with HSAS, patients die during pregnancy (partly due to induced labour after prenatal diagnosis), during or shortly after birth, or after some weeks/months. We were able to review 25 HSAS families with data on 70 patients with survival beyond 1 year (out of a total of 145 affected patients) $(6,11,13,16,24,-25,32,36,38,42,45,-52,59,61,66,67,72)$. Within the total of 145 affected male patients, 11 cases of prenatal diagnosis of an affected male fetus with termination of the pregnancy were documented $(32,60,66,67)$. The data are summarized in Table 2. When comparing literature clinical data in MASA syndrome patients with affected males surviving beyong 1 year from HSAS families we found a great overlap: hydrocephalus was present in $60 \%$ of the documented MASA patients (9/16) and in $50 \%$ of the documented surviving HSAS patients (35/70). OFC tended to be larger in the HSAS group. 2 normal OFC's were the result of early shunting procedures for hydrocephalus. All but one patient were mentally retarded, with variation from mild to severe; normal intelligence in HSAS was reported once (52). IQ's, when reported, tended to be lower in the HSAS group.

Spastic paraplegia was present in $92 \%$ in the MASA group and in $85 \%$ in the HSAS group. Adducted thumbs were present in $93 \%$ and $87 \%$, respectively; this latter percentage is much higher than the $25-44 \%$, previously reported in patients with HSAS $(13,22,25)$.

The reports on speech disorders in MASA patients have documented a wide range of speech pathology rather than one specific disorder. The literature on speech pathology in HSAS is sparse. 
Mental retardation, adducted thumbs, and spastic paraplegia were equally present in both groups with or without manifest hydrocephalus.

Table 2

Clinical manifastations in families from literature, reported as having MASA symdromo or HSAS (patients surviving boyond the age of 1 year?.

\begin{tabular}{|c|c|c|}
\hline winding & $\begin{array}{l}\text { MASA syndrome }(n=98) \\
\text { Posilinf }\end{array}$ & $\begin{array}{l}\text { HSAS }\left(n^{2} 70\right) \\
\text { Poserinf }\end{array}$ \\
\hline Male: female ratio & 935 & $70: 0$ \\
\hline OFC in centilles & $(n-25)$ & $(\pi=41)$ \\
\hline$<\mathrm{P3}$ & - & 1. \\
\hline$P_{3}-1 \times 50$ & 12 & 5 \\
\hline$P 50$ & 7 & $6(2 \times$ shunted $)$ \\
\hline P50-P98 & 6 & 9 \\
\hline$>\mathrm{Pg} 9$ & - & 20 \\
\hline Mentall retardation. & $9898\left(100^{\circ} \%\right)$ & $6970(98 \%)$ \\
\hline 10 & $(n=30)$ & $(t y=36)$ \\
\hline$<20$ (profound) & - & 7 \\
\hline $20-35$ (severe) & 2 & 17 \\
\hline 35.50 (moderate) & 10 & 7 \\
\hline $50-70($ mild $)$ & 9 & 2 \\
\hline $70-85$ (borderline) & 9 & 1. (1985) \\
\hline Spastic paraplegia & $58163(92 \%)$ & $35 \% 1(85 \%)$ \\
\hline Speech delay & $45 / 50(90 \%)$ & ? \\
\hline Adducted thumbs & $63.68(93 \%)$ & $2731(87 \%)$ \\
\hline \multicolumn{3}{|l|}{ Brain abnomality } \\
\hline Hyddoephalus & $9 / 17(5,3 \%)$ & $30 / 70(43 \%)$ \\
\hline Corpus callosum agenesis & $4 / 13(31 \%)$ & Common \\
\hline
\end{tabular}

Posinf: number of positive data compared to number of informative patients. ?: not reported in general Edwards, 1961 ; Visekul et al, 1975 ; Willems et al, 1987 ; Kelley et al, 1988; Serville et al, 1992.

\subsection{DISCUSSION}

In order to further delineate the clinical spectrum of the closely related $X$-linked hydrocephalus (HSAS)(MIM *307000), MASA syndrome (MIM *303350), and Xlinked complicated spastic paraplegia (SPG1)(MIM*312900), we studied families diagnosed as HSAS or MASA syndrome depending on the phenotypic and neurological findings in the respective index patient. In Jiterature a family is called MASA syndrome or HSAS regarding the index patient, explaining for instance the absence of hydrocephalus in a number of "HSAS" patients. Being aware of the clinical spectrum, and knowing that clinical subdivision has become artificial, we have tried to define the phenotype in each individual patient instead of classifying the whole family.

Clinical data regarding the 10 patients and 2 fetuses are listed in Table 1. Clinical diagnosis (HSAS or MASA) was listed for each patient personally. Four HSAS patients died during fetal life: in 3 cases the pregnancy was terminated after prenatal ultrasound diagnosis; one fetus, aborted for social reasons, appeared to have the risk haplotype. Four affected males died perinatally or neonatally. In 1 of 2 fetuses in whom autopsy was performed, CCA was found. In six males HSAS was diagnosed, and in four, MASA syndrome. 
Spastic paraplegia was found in $8 / 10$ of our patients, with literature data giving an incidence of about $90 \%$. In young or even prepubertal boys, spastic paraplegia may be absent or very mild, and the diagnosis would be difficult in the absence of at family history $(18,76$; present families $\mathrm{A}$ and $\mathrm{E}$ ). Progression of spastic paraplegia in time was evident in several families (17,54 (with personal follow-up of the patients); present families $A$ and $B$ ).

Kenwrick et al. (33) noted IQ's to be lower in older patients when compared to IQ's in younger patients. The severity of mental handicap and the neurologic findings could be related to more serious CNS involvement in 2 families $(7,54)$. Unfortunately, no brain imaging was availlable in family 2 in this report. In our patients, mental retardation was the rule except for 1 HSAS patient (pedigree $1 \mathrm{~F}$, III:1), where the brother had the complete HSAS phenotype and a male fetus was aborted because of severe hydrocephalus. Hydrocephalus is not a constant finding in MASA and HSAS patients: literature data show $60 \%$ and $50 \%$ respectively (Table 2 ). In 2 males with clinical MASA syndrome, macrocephaly was present without apparent signs of hydrocephaly on the brain imaging (pedigree $A, I I I: 2$; pedigree $E, I I I: 2$ ). On the contrary, males have been reported with smal! or normal OFCs and enlarged cerebral ventricles, thus showing signs of hydrocephalus $(29,32,72)$. These data underline the need for brain imaging in these patients. They also illustrate that there is no strict relation between $\mathrm{OFC}$ and the presence/absence of hydrocephaly. Mental retardation is present independent of OFC.

Adducted thumbs, a major criterion for the clinical diagnosis of MASA syndrome, were found in $93 \%$ of the patients in the literature and in our 4 patients. Im HSAS patients in general it has been reported to occur in $25-44 \%$ of patients $(13,22,25)$. In the reports we collected (families with survival of affected males beyond age 1 year), we found a much higher incidence of $87 \%$, and we saw adducted thumbs in $5 / 6$ of our patients (Tables 1 and 2). As an isolated trait the condition was reported by Crawford et al. (8). Weckesser et al. (71) reported a family with sexlinked inheritance of adducted thumbs; further clinical data were not given. The adducted thumb may be present in a number of other conditions: congenital arthrogryposis, Freeman-Sheldon syndrome (15), Christian syndrome (9), or traumatic after birth. The cause of adducted thumbs in HSAS/MASA syndrome is not clear: it could be due to cortical tract involvement, or to a concomitant anomaly (37). In MASA syndrome as well in HSAS, adducted thumbs appear not to be related to a concomitant hydrocephalus $(3,77$; present study, Table 1). In one report, direct exploration demonstrated a/hypoplasia of the extensor muscle of the thumb (77).

The families in this report confirm the extensive overlap between MASA syndrome and HSAS (Table 1), suggesting a common cause. The data also show great clinical variability, even within families. In about $10 \%$ of patients spastic paraplegia and/or adducted thumbs are absent, indicating that the condition can present as nonspecific XLMR. In this respect, the families reported by Gedeon et al. (20) and by Nordström et al. (47) are of possible importance. In both families male relatives presented with nonspecific XLMR, and linkage to Xq28 was found (MRX3). In the family in Gedeon et al., 2/5 males had OFCs at the 90-97th centiles with normal CT 
scans; in the family in Nordström et al., no clinical data were given. The question of whether MRX3 should be incorporated in the HSAS/MASA spectrum will depend on further molecular studies in these 2 families.

\subsubsection{Genetic counseling}

Obligate female carriers in families with MASA syndrome and/or HSAS in general show no clinical abnormalities. However, in the family reported by Kaepernick et al. (29), 3 obligate carriers had leaming problems or mild mental retardation, and 2 obligate carriers presented with adducted thumbs. In the same family, 3 females born to obligate carriers presented with lethal hydrocephalus (due to skewed X-inactivation during lyonisation?). Affected girls have been reported in a few other families $(3,41)$.

Prenatal ultrasound diagnosis of MASA syndrome in a male fetus is not possible. Prenatal diagnosis by ultrasound of HSAS is possible but not reliable, because of the variable clinical spectrum of the disorder $(12,74)$. For these reasons, DNA linkage analysis is of great importance for genetic counseling, and to offer families the possibility of early prenatal diagnosis by chorionic. villus sampling (60). DNA linkage analysis maps the locus for both MASA syndrome and HSAS at Xq28. In some families with HSAS/MASA syndrome (various) LICAM mutations have been reported (see introduction). DNA linkage analysis studies in families B-F are reported elsewhere (58). In small families, DNA linkage analysis is not higly reliable (58).

\subsubsection{Overlap with $\mathrm{X}$-linked complicated CCA.}

The family reported by Boyd et al. (7) as having MASA syndrome, presented with CCA in $4 / 4$ patients; $1 / 4$ also had hydrocephalus. CCA is commonly reported in patients with HSAS. Reviewing the literature on familial CCA we found at least 7 reports dealing with possible X-linked complicated CCA $(30,31,44,69,70,75,79)$. The boy reported by Kaplan (31) had adducted thumbs and Hirschprung's disease, while his maternal uncle had none of these additional features; the uncle could not walk, and OFCs were at the 3rd-10th centiles. The 2 brothers and uncle/nephew reported by Vles et al. (69) combined CCA with irregular widening of the cerebral ventricles; they were severely mentally retarded and had spastic paraplegia. No information was given regarding the thumbs; DNA linkage analysis with distal Xq probes was not performed. Two male infants of a heterozygote triplet pregnancy presented with developmental delay and hyperreflexia; cerebral CT scan showed CCA and irregular widening of the lateral ventricles (70). Possibly these male patients fit into the HSAS/MASA spectrum.

CCA is present in about $25 \%$ of male patients affected with $\mathrm{FG}$ syndrome (48). Some clinical overlap between FG syndrome and HSAS/MASA spectrum has been suggested; both conditions share XLMR, macrocephaly and shuffling gait (R.D.Clark, personal communication). Although thumb anomalies are reported in FG syndrome, adducted thumbs are not common; anus abnormality or severe constipation 
is not present in HSAS/MASA spectrum. In FG syndrome, no linkage analysis data are available yet.

\subsubsection{X-linked complicated spastic paraplegia.}

In spastic paraplegia, additional clinical features such as ataxia, dysarthria, nystagmus, macrocephaly, microcephaly, and ophthalmologic abnormalities may be present (23). Until 1990, 2 X-chromosomal loci were known to be associated with spastic paraplegia: a pure form at $\mathrm{Xq} 21, \mathrm{SPG} 2$ (35), and a complicated (incorporated into MASA syndrome) at Xq28, SPG1 $(33,76)$.

Recently, linkage analysis data confirmed a second locus for complicated spastic paraplegia on the $\mathrm{X}$ chromosome at $\mathrm{Xq} 21$ (5). In this family, great clinical variability was noticed, ranging from mental retardation with severe spastic paraplegia nystagmus, and ataxia to mild pyramidal tract involvement with normal gait and intelligence. The same clinical variability and linkage to $\mathrm{Xq} 21$ markers were found in the complicated spastic paraplegia family, reported by Goldblatt et al. (21). Probably the same entity was described in the papers by Johnston and McKusick (26) and Ulkü et al. (64). Linkage with Xq21 in the X-linked "pure" spastic paraplegia (35) raised the possibility of allelic heterogeneity or the close proximity of 2 loci for spastic paraplegia (5). Recently, in the family reported by Bonneau et al. (5), a mutation was reported in the proteolipid protein (PLP) gene, mapped at the long arm of the $\mathrm{X}$ chromosome $(\mathrm{Xq} 21-\mathrm{q} 22)$ (53). With the reports on mutations in L1CAM, the first hypothesis is becoming evident, at least in some of the reported families, for HSAS $(51,65,73)$, and MASA syndrome $(14,34,76)$.

\subsection{CONCLUSION}

HSAS, MASA syndrome, and complicated spastic paraplegia (SPG1) appear to be part of a clinical "spectrum", with both MASA syndrome or HSAS reported in a same pedigree. SPG1 (33) was incorporated in MASA syndrome (76). Clinical features range from lethality during pregnancy or in the perinatal period to survival with mental retardation, spastic paraplegia, adducted thumbs, (and speech retardation). Clinical delineation of the spectrum can be difficult since in about $10 \%$ of patients spastic paraplegia and/or adducted thumbs are absent. Even mental retardation can (exceptionally) be absent, even in the presence of male relatives with the "full-blown" phenotype $(52$, present family $\mathbb{E})$.

In males with non-specific mental retardation, family history (deceased males with hydrocephalus?) and brain imaging (hydrocephalus, CCA?) might be useful. In families with HSAS/MASA spectrum DNA linkage analysis may be of benefit in genetic counseling and in offering prenatal diagnosis. However, especially in small families or in young patients, where clinical diagnosis is difficult and DNA linkage analysis data are less reliable, genetic heterogeneity cannot be ruled out.

At least one further locus on the $\mathrm{X}$ chromosome $(\mathrm{Xq} 21)$ has been reported to be correlated with a condition similar to the HSAS/MASA spectrum (5). 
In a small number of HSAS/MASA families, different mutations have been reported in L1CAM, located at $\mathrm{Xq} 28$. It is not yet clear whether all of these families have mutations in this gene.

Finally, we suggest abandoning the acronym "MASA" syndrome, designated by Bianchine and Lewis (3) to describe the cardinal manifestations in their affected patients. In the abstract of their paper they stated: "We wish to refer to this heritable condition as the MASA syndrome until the basic defect is further characterized". With the clinical findings, the DNA linkage analysis data, and the L1 mutations being present in some families with both phenotypes, a more appropriate term seems necessary. For practical reasons we propose the clinical term: "HSAS/MASA spectrum"', in which the complicated spastic paraplegia (SPG1) is incorporated.

\section{Acknowlegdements}

We thank the families who participated in this study for their cooperation. We also thank Francis van der Lubbe for the figures. 


\section{REFERENCES}

1. Baar HS, Gabriel AM. Sex-linlied spastic paraplegia. Am J Ment Defic 1966;71:13-18.

2. Baraitser $M_{4}$ Winter $\mathbb{R} M$. The London Neurology Database Oxford University Press, 1993.

3. Bianchine $N W$. Lewis It RC The MASA syndrome: a new heritable mental retardation syndrome. Clin Genet 1974,5:298-306

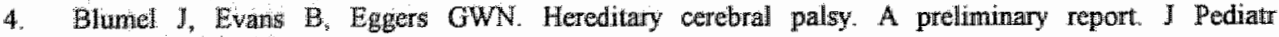
$1957,50 \cdot 454-458$.

5. Bonneau D, Rozet J-M, Bulteau C Berhiex M, Metthey R, Munnich A. Le Merrer M. X-linked spastic parapliegia (SPC2): clintical heterogeneity at a single gene locus. J Med Genet 1993;30:381-384.

6. Borle A. Sur l'etiologie de l'hydroesphalie congénitale à propos d'un cas d'hydrocéphalie concordante chè des jumcaux uniwitellins. J Génét Hum 1953;2:157-202.

7. Boyd E, Schwartz CE, Schroer RJ, May MM, Shapiro SD, Arena JF, Lubs HA, Stevenson RE. Agenesis of the corpus callosum associated with MASA syndrome. Clin Dysmorphol 1993;2;332-341.

8. Crawford $\mathrm{HH}_{0}$ Horton $\mathrm{CE}$, Adanson JE. Congenital aplasia or hypoplasia of the thumb and finger extensor tendons. J Bone and Joint Surg 1966;48-A82-91.

9. Christian JC, Andrews PA, Conneally PM, Muller J. The adducted thumbs syndrome. Chin Genet $1971 ; 2: 95-103$.

10. Djabali M, Mattei MG, Nguyen $C$, Roux D, Demengeot $J$, Denzot F, Moos M, Schachner M, Goridis C, Jordan BR. The gene encoding $\mathrm{L} 1$, a neural adhesion molecule of the immunoglobulin fanuly. is located on the $X$ chromosome in mouse and man. Genomics $1990 ; 7: 587-593$.

11. Edwards JH. The syndrome of sex-linked hydrocephalus. Arch Dis Childh 1961;36:486-493.

12. wan Egmond-Linden A, Wladimiroff JW, Jahoda MGJ, Niermeyer MF, Sachs ES, Stefanko S. Prenatal diagnosis of $X$-linked hydrocephaly. Prenatal Diagnosis 1983;3:245-248.

13. Faivre J, Lernarec B, Bretagne $J$, Pecker $J$. X-linked hydrocephalus, with aquaductal stenosis, mental retardation, and adduction-flexion deformity of the thumbs. Child's Brain 1976;2:226-233.

14. Fransen E, Schrander-Stumpel C, Vits $L$, Coucke P, Van Camp G, Willerns PJ. X-linked hydrocephallus and MASA syndrome present in one family are due to a single missense mutation in exon 28 of the LICAM gene. Hum Mol Genet 1994:3:2255-2256.

15. Freeman EA, Sheldon IH. Cranio-carpo-tarsal dystrophy - an undescribed congenital malformation. Arch Dis Childh 1938;13:277-283.

16. Fried K. X-linked mental retardation and/or hydrocephalus. Clin Genet 1972;3:258-263.

17. Fryns JP, Spaepen $A$, Cassiman $J$, van den Berghe $H$. Letter to the editor. X-linked complicated spastic paraplegia, MASA syndrome and $X$-linked hydrocephaly due to congenital stenosis of the aquaduct of Sylvius: a variable expression of the same mutation at Xq28. J Med Genet 1991:28:429-432.

18. Fryns JP, Schrander-Stumpel $C_{\text {, }}$ de Die-Smulders $C$, Borghgraef $M$, Van Den Berghe $H_{.}$MASA syndrome: delineation of the clinical spectrum at prepubertal age. Am J Med Genet 1992;43:402-407.

19. Gareis FJ, Mason JD. X.linked mental retardation associated with bilateral clasp thumb anomaly. Am J Med Genet 1984;17,333-338.

20. Gedeon A, Kerr B, Mulley J, Turner $G$. Localisation of the MRX3 gene for nonspecific X-linked mental retardation. Am J Med Genet 1991;28:372-377

21. Goldblatt J. Ballo R, Sachs B, Moosa A. X-linked spastic paraplegia: evidence for homogeneity with a wariable phenotype. Clin Genet 1989,35:116-120.

22. Halliday $J_{\mathrm{i}}$ Chow $C W$. Wallace D, Danks DM. X-linked hydrocephalus: a survey of a 20 year period in Victoria, Australia. J Med Genet 1986;23:23-31.

23. Harding AE. The hereditary ataxias and related disorders. Edinburgh, Churchill Livingstone 1984:174204.

24. Holteman RNN, Garcai $L$, Koenigsberger R. Hydroceplualus and congenital clasped thumbs: a case report with electromyographic evaluation. Developm Med Child Neurol 1976;18:521-527.

25. Jansen J. Sex-linked hydrocephalus. Developm Med Child Neurol 1975;17:633-640.

26. Johnston AW, McKusick VA A sex-linked recessive form of spastic paraplegia. Am I Hum Genet. $1962 ; 14: 83-94$.

27. Jouet $M$, Feldman $\mathbb{E}$, Tates $J$, Donnai $D$, Paterson J, Siggers $D$, Kenwrick S. Refining the genetic localisation of the gene for X-linked hydrocephalus within Xq28. J Med Genet 1993;30:214-217. 
28. Jowet M, Rosenthal A, MacFarlane J, Kenwrick $S$, Donnat D A missense motation confirms the L1 deffect in X-linked hydrocephalus (HSAS). Nature Genet 1993,4331.

29. Kaepernick LA, Legius E, Higgins $J_{\text {, }}$ Kapur $S$. Clinical aspects of MASA syndrome in a large family including expressing females. Clin Genet 1994;45;181-185.

30. Kang WM, Huang CC, Lin SJ. X-linked recessiwe inheritance of dysgenesis of corpus callosum in a Chinese family. Am J Med Genet 1992;44:619-623.

31. Kaplan P. X-linked recessive inheritance of agenesis of the corpus callosum. I Med Genet 1983;20:122. 134.

32. Kelley RI, Mennuti MT, Hickey WF, Zakhai EH. X-linked recessive aqueductal stenosis withoui macrocephaly. Clin Genet 1988;33:390-394.

33. Kenwrick $S_{x}$ lonasescu $V$, Ionasescu $G_{n}$ Searby $C h$, King A, Dubowitz $M$, Davies KE. Linkage studies of X-linked recessive spastic paraplegia using DNA probes. Hum Genet 1986;73:264-6.

34. Kenwrick S, Jouet $M$, Rosenthal A, Donnai D. Mutations in the LI gene in HSAS and MASA syndrome patients. Am J Hum Genet 1993;53 suppl 148.

35. Keppen LD, Leppert MF, O'Connell P, Nakamura Y, Stauffer D, Lathrop M, Lalouel J-M, White R. Etiological heterogeneity in X-linked spastic paraplegia. Am J Hum Genet 1987;41:933-943.

36. Klein D. Cas observé: hydrocéphalie a hérédité liée au sexe. J Génét Hum 1954;3:147-148.

37. Kuzniecky RI, Watters GV, Watters L, Meagher-Villemure. X-linked lydrocephalus. Can I Neur Sciences 1987; 13:344-346.

38. Landrieu $P$, Ninane $J_{3}$ Ferrière, Lyon $G$. Aqueductal stenosis in X-linked hydrocephalus: a secondary phenomenon? Dexelopm Med Child Neurol 1979;21:637-652.

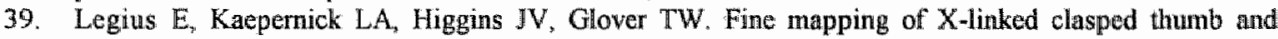
mental retardation (MASA syndrome) in Xq28. Clin Genet 1994,45:165-168.

40. Lyonnet $S$, Pelet $A$, Royer $G$, Delrieu $O$, Serville $F$, Le Marec $\mathbb{B}_{v}$ Gruensteudel $A$, Pfeiffer RA, Briard ML, Dubay C, Hors-Cayla MM, Le Merrer M, Munnich A. The gene for X-linked hydrocephalus maps to Xq28, distal to DXS52. Genomics 1992;14:508-510.

41. Macias VR, Day DW, King TE, Wilson $G$. Clasped-thumb mentall retardation (MASA) syndrome: confirmation of linkage to Xq28. An J Med Genet 1992;43:408-414.

42. Martin $\mathrm{C}$, Got M., Babin JP, Cazauran JM. Hydrocéphalie familiale, maladie héréditaire recessive gonosomique. Arch Franc Péd 1971:28:971-974.

43. McKusick V. Mendelian inheritance in man. Catalogs of autosomal dominant, autosomal recessiwe, and X-linked recessive phenotypes, 1992;10th edition.

44. Menkes JH, Philippart M, Clark DB. Hereditary partial agenesis of corpus callosum. Arch Neurol 1964; 11:198-208.

45. Needleman HL, Root AW. Sex-linked hydrocephalus. Report of two families, with chromosomal study of two cases. Pediatries 1963;31:396-399.

46. Neri $G$, Chinrazxi $P$, Arena F, Lubs HA. XLMR Genes: update 1994. Am J Med Genet 1994,51:542549.

47. Nordström $A M$. Penttinen $M$, van Koskull $H$. Linkage to $\mathrm{Xq} 28$ in a family with nonspecific X-linked mental retardation. Hum Genet 1992;90:263-266.

48. Opitz IM, Richieri-da Costa A, Aase JM, Berke PJ. FG syndrome updata 1988: note of 5 new patients and bibliography. Am J Med Genet 1988;30:309-328.

49. Raggio JF, Thurmon TF, Anderson EE. X-linked hereditary spastic paraplegia. J Louisiana Stat Med Soc $1973 ; 125: 4-6$.

50. Rietschel $M$. Fried W, Uhlhaas $S$, Neugebauer M, Heimann D, Zerres K. MASA syndrome: clinical variability and linkage analysis. Am J Med Genet 1991;41:10-14.

51. Rosenthal A, Jouet $M$, Kenwrick S. Aberrant splicing of neural cell adhesion molecule L1 mRNA in a family with X-linked hydrocephaluss. Nature Genet 1992;2:107-112.

52. Sajid $\mathrm{MH}$, Copple PJ. Familiar aqueductal stenosis and basilar impression. Neurol 1968;18:260-262.

53. Saugier-Veber P, Munnich A, Bonneau D, Rozet JM, Le Merrer M, Gil R, Boespflug-Tanguy O. Xlinked spastic paraplegia and Pelizaeus-Merzbacher disease are allelic disorders at the proteolipid protein locus. Nature Genet 1994:6:257-262.

54. Schrander-Stumpel CTRM. Legius $E_{0}$ Fryns JP, Cassiman JJ. MASA syndrome : new clinical features and linkage analysis using DNA probes. J Med Genet 1990;27:688-692 
55. Schrander-Stumpel C. Announcement. Call for families with MASA syndrome with or without X-linked hydrocephalus. Clin Genei 1991;40:473.

56. Schrander-Stumpel C, Fryns JP, Cassiman JI, Legius E, Spaepen A, Höweler CJ MASA syndrome (a form of complicated spastic paraplegia) and $X$-linked hydrocephalus: variable expression of the same mutation? Call for fumilies. J Med Genet 1992;29:215.

57. Schrander-Stumpel C, Fryns JP. MASA syndrome. Clin Genet 1992:42:102-103.

58. Schrander-Stumpel $C$, Meyer $H_{3}$ Merckx D, Jones M., Israel J, Sommer A, Stevens C, Tinschert S, Wilson $G$, Willems P, Legius $E$, Fryns JP. The spectrum of "complicated spastic paraplegia, MASA syndrome and $X$-linked hydrocephalus". Contribution of DNA linkage analysis in genetic counseling of individual families. Genetic Counseling 1994;5:1-10.

59. Serville F, Lyonnet $\mathrm{S}_{*}$ Pelet A, Reynand $\mathrm{M}$, Louail C, Munnich A, LeMerrer M. X-linked hydrocephalius: clinical heterogeneity at a single gene locus. Eur J Pediatr 1992;151:515-518.

60. Serville $F$, Benit $P$, Saugier P, Vibert M, Royer G, Pelet A, Chery M, Munnich A, Lyonnet S. Prenatal exclusion of X-linked hydrocephalus-stenosis of the aquaduct of Sylvius sequence using closely linked DNA markers. Prenatal Diagnosis 1993;13:435-439.

61. Shannon MW, Nadler HL. X-linked hydrocephalus. I Med Genet 1965;5:326-328.

62. Strain $\mathrm{L}_{\mathrm{v}}$ Gosden DI ${ }$ Brock DJH. Bonthron DT. Genetic heterogeneity in X-linked hydrocephalus: linkage to markers within Xq27.3. Am J Hum Genet 1994;54:236-243.

63. Straussberg R, Blatt I, Brand N, Kessler D, Bat-Miriam Katznelson M, Goodman RM. X-linked mental retardation with bilateral clasped thumbs: report of another affected family. Clin Genet 1991;40:337341.

64. Ulki A, Karasoy H, Karaktepe A, Gökcay F. X-linked spastic paraplegia. Acta Neurol Scand $1991 ; 83: 403-406$.

65. Van Camp G, Vits L, Coucke P, Lyomnet $S_{n}$ Schrander-Stumpel C, Darby J, Holden J, Munnich A, Willems P. A duplication in the LICAM gene asociated with X-linked hydrocephalus. Nature Genet $1993: 4: 421-425$

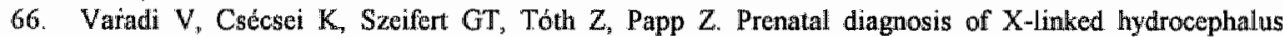
without aquaductal stenosis. J Med Genet 1987;24:207-209.

67. Viseskul C. Gilbert E, Opitz JM.X-linked hydrocephalus. Further observations. Zeitsclir Kinderheilk 1975;119:111-121.

68. Vits L, Van Camp $G_{s}$ Coucke P, Wilson G, Schrander-Stumpel C, Schwartz C, Willems P. MASA syndrome is due to mutations in the LICAM gene. Nature Genet 1994;7:408-414.

69. Vles JSH, Fryns JP, Folmer $\mathrm{K}$, Boon P, Buttiens: M, Grubben C, Janevski B. Corpus callosum agenesis, spastic quadriparesis and irregular lining of the lateral ventricles on CT-scan. A distinct X-linked mental retardation syndrome? Genetic Counseling 1992;3:97-102.

70. Vles JSH, de Die-Smulders C, van der Hoeven M, Fryns JP. Corpus callosum agenesis in two male infants of a heterozygotic triplet pregnancy. Genetic Counselling 1993;4:239-240.

71. Weckesser EC, Reed JR, Heilple KG. Congenital clasped thumb (congenital flexion-adduction deformity of the thumb). A syndrome, not a specific entity. J Bone Joint Surg 1968;50-A:1417-1428.

72. Willems PJ, Brouwer OF, Dijkstra I, Wilmink J. X-Linked hydrocephalus. An J Med Genet $1987 ; 27: 921-928$

73. Willems Pr, Dijkstra I, Van der Auwerda BJ, Vits L, Coucke P, Raeyrnakers P, van Broeckhoven C, Consalez GG, Freeman SB, Warren ST, Brouwer OF, Brunner HG, Renier WO, van Elasen AF, Dumon JE. Assignment of X-linked hydrocephalus to Xq28 by linkage analysis. Genomics 1990;8:867-870.

74. Willems JP, Vits L, Raymaekers P, Benten J, Coucke P, Holden JJA, van Broeckhoven C, Warren ST, Sagi M, Robinson D, Dennis N, Friedman KS, Magnay D, Lyonnet $S$, White BN, Wittwer BH, Aylsworth AS, Reicke $S$. Further localization of $X$-linked hydrocephalus in the chromosomal region Xq28. Am J Hum Genet 1992;51;307-315.

75. Wilson WG, Kennaugh JM, Kugler JP, Reynolds JF. Agenesis of the corpus callosum in two brothers. J Med Genet 1983;20:416-418.

76. Winter $\mathrm{RM}_{6}$ Davies $\mathbb{K}$. Bell MV, Huson SM, Paterson MN. MASA syndrome: further climical delineation and chromosomal location. Human Genet 1989;82:367-70.

77. Yeatman GW. Mental retardation-clasped thumb syndrome. Am J Med Genet 1984;17:339-344. 
78. Zatz M, Penha-Serrano C, Otto PA. X-linked recessive type of pure spastic paraplegia in a large pedigree: absence of detectable linkage with $\mathrm{Xg}$.J Med Genet 1976;13:217-222.

79. Zellweger H. Agenesia corporis callosi. Zeitschr Kinderheilk $1952 ; 2: 136-155$. 



\section{Chapter 4}

The spectrum of X-linked hydrocephalus (HSAS), MASA syndrome and complicated spastic paraplegia (SPG1): contribution of DNA linkage analysis in genetic counseling of individual families.

Connie Schrander-Stumpel, Henk Meyer, Diane Merckx, Marilyn Jones, Jeanette Israël, Annemarie Sommer, Cathy Stevens, Sigrid Tinschert, Golder Wilson, Patrick J.Willems, Eric Legius, Jean Pierre Fryns.

Genetic Counseling 1994;5:1-10. 


\subsection{ABSTRACT}

$X$-linked hydrocephalus with stenosis of the aqueduct of Sylvius (HSAS) and the Xlinked MASA syndrome (Mental retardation, Aphasia, Shuffling gait and Adducted thumbs) both have a variable clinical spectrum with great overlap. Data from DNA linkage analysis placed the locus for both conditions at Xq28. On clinical and molecular grounds it has been hypothesized that both MASA syndrome and HSAS are caused by a mutation in the same gene at $\mathrm{Xq} 28$. There is no significant clinical marker in the obligate female carriers and prenatal diagnosis by ultrasound is not reliable. DNA analysis can offer improved genetic family counseling and more reliable prenatal diagnosis. In the gene encoding for $\mathrm{Ll}$, a neural cell adhesion molecule located at Xq28, several different mutations have been reported in HSAS families and in a MASA family. We report data on DNA linkage analysis in 6 families with HSAS/MASA syndrome. These data illustrate the importance of DNA linkage analysis in the individual family; they also show, however, the problem of studying small families. Genetic heterogeneity cannot be excluded.

\subsection{INTRODUCTION}

In the 1992 update on XLMR (X-linked mental retardation), at least 77 X-linked conditions were listed in which MR is the primary or major component (16). Mental retardation in combination with spastic paraplegia is present in the so-called "MASA" syndrome, acronym for Mental retardation, Aphasia (slow speech development), Shuffling gait (spastic paraplegia), and Adducted thumbs)(1). DNA linkage analysis mapped the locus for the condition at Xq28 $(3,6,13,15,17,19,29)$. The family reported as "complicated X-linked spastic paraplegia" (SPGI)(McKusick number MIM *312900) showed linkage to the same chromosomal region (11); clinical diagnosis in this family is compatible with MASA syndrome (29). Several families have been reported with male patients presenting with either MASA syndrome or HSAS; DNA linkage to $\mathrm{Xq} 28$ was present in these families, leading to the hypothesis that both clinical conditions are variable expressions of the same mutation at $\mathrm{Xq} 28(6,19$,27,28). An additional family supported this hypothesis (10). In HSAS families,clinical variability is a well-known feature even within families $(4,5,26)$. Clinical comparison between males with MASA syndrome and surviving affected males in HSAS families shows many similarities $(21,22)$. In a clinical review, both spastic paraplegia and adducted thumbs appeared not to be obligate: in about $10 \%$ of the affected males these features are absent, posing possible diagnostic problems (22). Clinical diagnosis at a young age can be difficult, especially when there is no positive family history $(7,29)$. Linkage analysis in HSAS families places the locus to Xq28 as well $(8,14,23,27,28)$. In 1992, the first mutation in the candidate gene encoding for L1 (a neural cell adhesion molecule) was described in an HSAS family (18); additional mutations in this gene have been reported in HSAS $(9,25)$ and in MASA syndrome (12).

Obligate carrier females generally show no clinical features of the disease; prenatal ultrasound diagnosis is possible, but unreliable in case of normal findings 
because hydrocephalus might develop after birth or might not be part of the disease (27). Thus, DNA linkage analysis providing carrier detection and a reliable prenatal test will be of great help to individual families (24). Here we report DNA linkage analysis data in 6 families with the "complicated spastic paraplegia (SPG1)/MASA syndrome/HSAS" spectrum.

\subsection{PATIENTS AND METHODS}

\subsection{Families}

A call for "MASA" or "HSAS" families was placed in several journals $(20,21)$. Families were referred from the Netherlands, Germany, and the United States of America. Six families with MASA syndrome and/or HSAS were studied (pedigrees A-F, Figure 1). MASA syndrome was diagnosed on the basis of the clinical criteria of mental retardation, adducted thumbs (not obligate), spastic paraparesis (not obligate) and slow speech development (21). A family was called an "HSAS family" when the proband presented with manifest hydrocephalus. Both phenotypes can be present in one and the same pedigree. An X-linked pattern of inheritance was suspected with 2 affected male sibs whose parents were not consanguineous; X-linked inheritance was assumed when the pedigree contained at least 2 affected male patients in at least 2 generations, related through females.

Pedigree A (Fig. 1A. MASA syndrome) was the subject of a previous ublication(15). In this family, 14 affected patients (1 female) expressed the typical features of MASA syndrome. CT scans of the brain were not available. DNA analysis was performed in 6 affected patients (II:5, II:6, III:1, III:2, III:3, and III:7), 3 obligate carriers (I:2, II:2 and II:8) and 4 females at risk of being a carrier (II:4, III:4, III:5, and III:6).

Pedigree B (Fig. 1B, MASA syndrome) consisted of a family with 2 affected male sibs (III: 1 and III:2). The boys presented with mild mental retardation, speech problems, spastic paraplegia and adducted thumbs. They were not macrocephalic, although in one of the brothers OFC was at the 97 th centile in the first year of life; CT scans of their brains were not available. DNA analysis was performed on the patients (III:1 and III:2), their mother (II:3), maternal uncle (II:1) and maternal grandparents (I:1 and $\mathrm{I}: 2$ ). 

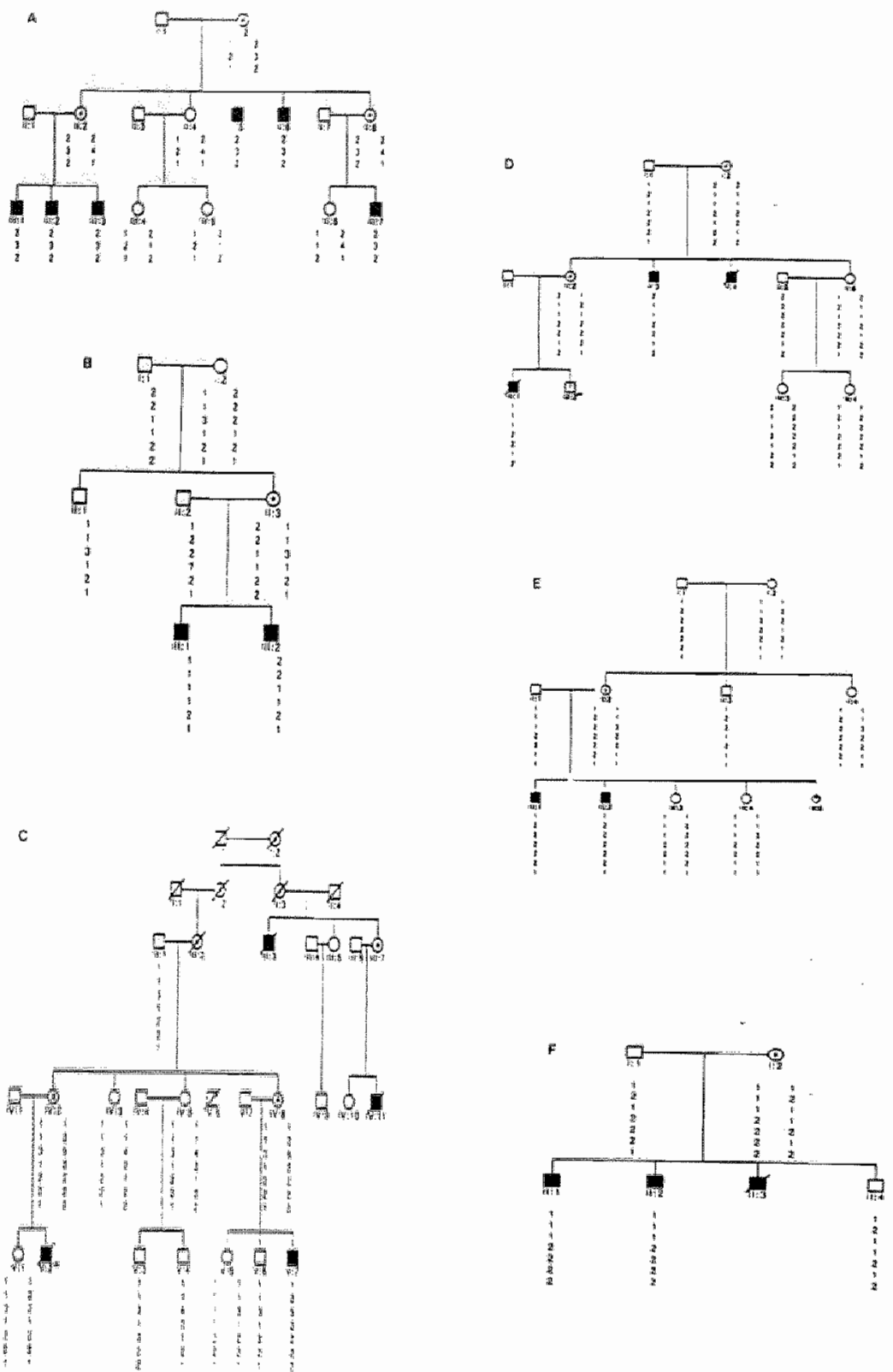

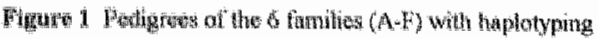


Pedigree $\mathrm{C}$ (Fig.1C, HSAS) had at least 2 affected probandi (V:2 and V:7). Proband V:2 was diagnosed by fetal ultrasound at 24 weeks gestation; the pregnancy was induced and diagnosis of severe hydrocephalus was confirmed; cortex was thin, lateral ventricles, third ventricle and cisterna magna were dilated. Thumbs were apparently normal. The deceased male IV:6 was stillborn and said to have a large head. Two other males (III:3 and IV:11) died from congenital hydrocephalus. Proband V:7 was born at 38 weeks gestation by Caesarean section due to a very large head; he had a severe hydrocephalus and was shunted 3 days after birth. At the age of 4 years he was a wheelchair-bound boy whose development was profoundly delayed; he exhibited horizontal and vertical nystagmus and normal thumbs. DNA analysis was done in 11 individuals: proband $V: 7,2$ obligate carriers (IV:2 and IV:8), 4 females at $50 \%$ risk of being carriers (IV:3, IV:5, V:1 and V:5), 1 healthy son of an obligate carrier (V:6), 2 healthy sons of a possible female carrier $(V: 3$ and $V: 4)$ and the maternal grandfather (III:1).

Pedigree D (Fig.1D, HSAS) had 3 affected male patients (II:3, II:4 and III:1). At the age of 22 years, patient II:3 was severely mentally retarded, had spastic paraplegia of the legs and adducted thumbs, the left thumb being hypoplastic. He could not sit or walk and had no speech development; bladder and sphincter control were insufficient. Head circumference was $55.5 \mathrm{~cm}$ (normal). Affected male II:4 died shortly after birth; he had an extremely large head; no further data were available. The fetus III:1 was aborted at 22 weeks gestation because of hydrocephalus. At autopsy there was a hydrocephalus internus, especially of the lateral ventricles; corpus callosum was absent. The aqueductus was not stenotic. The right ventricle of the heart was hypoplastic. DNA analysis was performed in 2 patients (II:3 and III:1), 2 obligate carriers (I:2 and II: 2 ) and 3 females at risk of being carriers (II:6, III:3, and III:4).

Pedigree E (Fig.1E, HSAS/MASA syndrome) had 2 affected patients (III: 1 and III:2). Proband III: 1 was diagnosed as hydrocephalic at the age of 4 months; a shunt was placed. At the age of 5 years, he was developmentally delayed, had a "shuffling" gait and clasped thumbs. Proband III:2, 14 months old, had an OFC above P98 without signs of hydrocephalus on the MRI scan. He was developmentally delayed and had clasped thumbs. DNA analysis was performed in the 2 probandi (III: 1 and III:2), 1 obligate carrier (II:2), the maternal uncle (II:3), 3 females at risk of being carriers (II:4, MI:3 and III:4), and the maternal grandparents (I:1 and I:2).

Pedigree F (Fig. 1F) was a family with 2 affected male sibs presenting with HSAS (II: 1 and II:2). There was 1 healthy brother (II:4). A male fetus (II:3) was aborted because of severe hydrocephalus (no autopsy data available). The parents were not consanguineous. In the younger brother (II:2) fetal ultrasound at 32 weeks gestation revealed hydrocephalus; at birth $O F C$ was $36 \mathrm{~cm}$; a shunt operation was not indicated. At the age of 5 months height was $69 \mathrm{~cm}$ (90th centile), OFC $46 \mathrm{~cm}(1 \mathrm{~cm}$ above 97th centile). Legs were hypertonic and psychomotor development was generally delayed. Thumbs were clasped. He had a hearing loss (familial trait; abnormal brain-evoked responses). The older affected brother (III:1), 9 years old, did need a shunt after birth because of apparent hydrocephalus. He also had a hearing loss, intelligence appeared to be normal. Thumbs were clasped. In this family DNA 
studies were performed in both affected males (II 1 and II:2), their mother (I:2) and father (I:1), and their healthy brother (II:4).

\subsubsection{Molecular studies}

Genomic DNA was isolated from peripheral blood of patients and relatives by means of the high salt extraction method or sent directly to us by one of the coauthors. The following probes recognizing polymorphic loci mapped to chromosome Xq27-q28 were used in this study: U 6.2 (DXS304), 1A1 (DXS374), F8.14 (DXS52), DX13 (DXS15), 2-55 (PCR), 2-19 (PCR) and F8C. Loci are shown in their map position (16.28). Probes were obtained from ATCC, except for 2-55 and 2-19, which are PCRRFLP's. RFLP analysis was performed using standard procedures.

\subsection{RESULTS}

In family D, one crossover was detected with DXS304, which indicated that the MASA/HSAS locus is distal to this locus. In family $B$, three recombination events can be deduced. In patient $\mathrm{IL}: 1$, a crossover distal to DXS374 and proximal to F8C was evident, whereas in patient III: 2 one crossover proximal to F8C was evident. The combined data from families 2 and 4 confirm the localisation of the MASA/HSAS locus distal to $\mathrm{DXS374}$ and proximal to $\mathrm{F8C}$.

In family $\mathrm{A}$, only $\mathrm{F} 8 \mathrm{C}$ was tested in the original report (15); female III:6 could not be informed about her status. In the present study, DXS52 and F8C were selected for risk calculation. Female II: 4 was excluded from having the risk haplotype ( $>99.9 \%$ normal). Female III:6 could also be excluded in this respect ( $>99.9 \%$ normal).

In pedigree B (Fig. 1B) the haplotype of the maternal grandfather was recognized in his grandsons (germline mutation in the grandfather or in the mother?).

In pedigree $C$, using flanking markers DXS52 and $\mathrm{F} 8 \mathrm{C}$, females IV:3, IV:5, $V: 1$ and $V: 5$ did not exhibit the risk haplotype with a probability of $>99.9 \%$, so they could be reassured about the recurrence risk in future children.

In pedigree D, risk analysis was performed using DXS374 and 2-19 as flanking markers. Female II:6 was excluded from having the risk haplotype $(>99.8 \%)$ normal) and thus the two daughters could also be reassured.

In pedigree $\mathbb{E}$, the haplotype of patients III- 1 and III-2 was recognized in the maternal grandfather ( $1: 2$ ), but also in the maternal aunt (II:4). It was thus not possible to inform the sister (II:4) of obligate carrier II:2 about her situa-tion.

Finally, in pedigree F (Fig. IF), the haplotype of the affected males (II:I and II:2) was present in the mother (I:1); the healthy brother (II:4) had inherited the other allele of the mother ( $1: 2)$. 


\subsection{DISCUSSION}

The MASA syndrome (MIM *303350) is a clinically recognizable XIMR syndrome with variable expression, as is HSAS (MIM *307000). Both clinical phenotypes have been reported within the same families $(4,5,6,10,19,23,26)$. In one of these families, the males with MASA syndrome showed extensive widening of the lateral ventricles, demonstrating the clinical overlap (19). DNA linkage analysis placed the locus for both MASA syndrome and HSAS in Xq28 $(6,8,11,13,14,15,17,19,23,27-29)$. Obligate female carriers in general show no clinical abnormalities; some females, however, show mild mental retardation and/or adducted thumbs (10). In pregnancy, a clinical diagnosis of MASA syndrome in a male fetus is not possible; prenatal diagnosis by ultrasound in HSAS carriers is not reliable because of the variable clinical spectrum of the disease. For these reasons, DNA linkage analysis is of major importance to enable carrier detection and prenatal diagnosis on chorionic villus material (24).

The MASA/HSAS locus was previously placed between the DXS52 and F8C $(8,13,14,19,27,28)$. In 1992 a mutation (aberrant splicing defect) in the neural cell adhesion molecule L1 (LICAM) was reported in one out of four HSAS families (18). In 2 additional HSAS families, different mutations in $L 1$ were found, as well as in a MASA syndrome family, indicating that MASA syndrome and HSAS are phenotypic variations of mutations in the same gene $(9,12,25)$.

Up to now, all reported families with MASA syndrome/HSAS show linkage to the same distal X markers. Recently, however, a family with X-linked complicated spastic paraplegia has been reported in which the locus was shown to be linked to Xq21 (2). This leaves the possibility of linkage heterogeneity open in the "complicated spastic paraparesis/MASA syndrome/HSAS" families. In genetic counseling, especially in small families, genetic heterogeneity should be kept in mind. The presently reported families B and D are examples of the difficulties in interpreting the linkage analysis data: in these families we can not discriminate between germline mosaicism and genetic heterogeneity.

Finally, in our opinion the time has come to abandon the acronym "MASA syndrome", as suggested by Bianchine and Lewis in 1974: "We wish to refer to this heritable condition as the MASA syndrome until the basic defect is further characterized" (1). From a historical point of view, we propose the clinical term "HSAS/MASA spectrum". 


\section{REFERENCES}

1. Bianchine IW, Lewis Jr RC. The MASA syndrome A new heritable mental retardation syndrome. Clin Genet 1974;5:298-306.

2. Boniteau D, Rozet J-M, Bulteau C, Berhicr M, Methey R, Munnich A., Le Merrer M.: X-linked spastic paraplegia (SPG2): clinical heterogeneity at a single gene locus. J Med Genet 1993;30:381 -384.

3. Bioyd E, Schwartz CE, Schroer Ft, May MM, Shapiro SD, Arena JF, Lubs HA, Stevenson RE. Agenesis of the corpus callosum associated with MASA syndrome. Clin Dysmorphol 1993;2:332-341.

4. Edwards JH. The syndrome of sex-linked hydrocephalus. Arch Dis Childh 1961;36:486-493.

5. Fried K. X-linked mental retardation and/or hydrocephalus. Clin Genet 1972;3:258-263.

6. Fryns IP. Spaepen A, Cassiman JJ, van den Berghe H. Letter to the editor. X-linked complicated spastic paraplegian, MASA syndrome and X-linked hydrocephallus due to congenital stenosis of the aquaduct of Sylvius: a variablle expression of the same mutation at Xq28. J Med Genet 1991;28:429-431.

7 . Fryns JP, Schrander-Stumpel $C$, de Die-Sinulders $C$, Borghgraef $M$, van den Berghe $H$. MASA syndrome: delineation of the clinical spectrum at prepubertal age. Arm J Med Genet 1992;43:402-407.

8. Jouet $\mathrm{M}_{n}$ Feldmen E, Yates J, Donmai $\mathrm{D}$, Paterson J, Siggers D, Kenwrick $\mathrm{S}$. Refining the genetic location of the gene for X-finked hydrocephalus within Xq28. J Med Genet 1993;30:214-217.

9. Jouet $M_{8}$ Rosenthal $A$, MacFarlane J, Kenwrick S, Donmai D. A missense mutation confirms the L1 defect in X-linked hydrocephalus (HSAS). Nature Genet 1993;4:331.

10. Kaepernick LA, Legius E, Higgins JV, Kapur S. Clinical aspects of MASA syndrome in a large family, including expressing females. Clin Genet 1994;45:18:1-185.

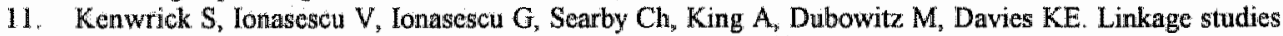
of X-linked recessive spastic paraplegia using DNA probes. Hum Genet 1986; 73:264-266.

12. Kenwrick $S$, Jotuet $M$, Rosenthal $A$, Donnai $D$. Mutations in the Ll gene in HSAS and MASA syndrome patients. Am J Hum Genet 1993;53 suppl: 148.

13. Legius E, Kaepernick LA, Higgins JV, Glover TW. Fine mapping of X-linked clasped thumb and mental retardation (MASA syndrome) in Xq28. Clin Genet 1994;45;165-168.

14. Lyonnet $S$, Pelet A, Royer G, Delrieu $\mathrm{O}$, Serville F, Le Mare $B_{*}$ Gruensteudel A, Pfeifler RA, Briard $M L$, Dubay $C$, Hors-Cayla $M_{s}$ Le Merrer M, Munnich A. The gene for X-linked hydrocephalus maps: to Xq28, distal to DXS52. Genomics 1992;14:508-510.

15. Macias $\mathrm{VR}$, Day DW, King TE, Wilson $\mathrm{G}$. Claspad-thumb mental retardation (MASA) syndrome: confirmation of linkage to Xq28. Am J Med Genet 1992;43:408-414.

16. Neri $G$, Chiurazai $\mathbb{P}$, Arena $F$, Lubs HA, Glass IA. XLMR Genes: Update 1992. Am J Med Genet $1992 ; 43 ; 373-382$

17. Rietschel M, Fried W, Uhlhaas S, Neugebauer M, Heimann D, Zerres K. MASA Syndrome: Clinical Variability and Linkage Analysis. Am. Med Genet $1991: 41: 10-14$.

18. Rosenthal A, Jowet M, Kenwrick S. Aberrant splicing of neural cell adhesion molecule LI mRNA in a family with X-linked hydrocephalus. Nature Genet 1992;2:107-112.

19. Schrander-Stumpel C, Legius E, Fryns JP, Cassiman JJ. MASA syndrome : new clinical features and linkage analysis using DNA probes. J Med Genet 1990,27:688-692.

20. Schrander-Stumpel C. Announcement. Call for families with MASA syndrome with or without $X$-linked hydrocephaluss. Ctim Gener 1991;40:473.

21. Schrander-Stumpel C, Fryng JP, Cassiman J, Legius E, Spaepen A, Höweler CI. MASA syndrome (a lorm of complicated spastic paraplegia) and X-linked hydrocephalus: variable expression of the same mutation"? Call for families. J Med Genet 1992;29:215

22. Schrander-Stumpel C. Fryns JP. MASA syndrome. Clin Genet 1992;42:102-103.

23. Serville F, Lyonnet $S$, Pelet $A$, Reynaud $M$, Lowail $C$, Murnich $A$, le Merrer $M$. X-linked hydrocephaIus: clinical heterogeneity at a single gene locus. Eur I Pediatr 1992; 151:515-518.

24. Serville F, Benit P, Saugier P, Vibert M, Royer G, Pelet A, Chery M, Munnich A, Lyonnet S. Prenatal exclusion of $\mathrm{X}$-linked hydrocephalus-stenosis of the aquaduct of Sylvius sequence using closely linked DNA markers. Prenatal Diagnosis 1993; 13:435-439.

25. Van Canp $G$, Vits $L$, Coucke $P$, Lyonnet $S$, Schrander-Stumpel C, Darby J, Holden $J$, Munnich $A$. Willems $P$. A duplication in the LICAM gene associated with X-linked hydrocephalus. Nature Genet $1993,4: 421-425$ 
26. Willems PJ, Brouwer OF, Dijkstra I, Wilmink J. X-Linked hydrocephalus. Am J Med Genet $1987 ; 27: 921-928$.

27. Willems PJ. Dijkstra I, van der Auwera BJ, Vits L, Coucke P, Raeymakers P, van Broeckhoven C, Consalez, GG, Freeman SB, Warren ST, Brouwer OF, Brumer $\mathrm{HG}_{\mathrm{r}}$, Renter WO, van Elasen AF, Dumon JE. Assignment of X-linked hydrocephalus to Xq28 by linkage analysis. Genomics 1990;8:367-370.

28. Willems PJ, Vits L, Raymaekers $P$, Beuten J, Coucke P, Holden J JA, van Broeckhoven $C$, Warnen ST, Sagi M, Robinson D, Dennis N, Friedman KS, Magnay D, Lyonnet S, White BN, Wittwer BH, Aylsworth AS, Reicke S. Further Localization of X-linked Hydrocephalus in the Chromosomal Region Xq28. Am J Hum Genet 1992;51:307-315.

29. Winter RM, Davies $\mathrm{K}$, Bell MV, Huson SM, Paterson MN. MASA syndrone: further dinical delineation and chromosomal location. Hum Genet 1989;82:367-370. 



\section{Chapter $5 A$}

\section{Duplication in the L1CAM gene associated with X-linked hydrocephalus}

Guy Van Camp, Lieve Vits, Paul Coucke, Stanislas Lyonnet, Connie SchranderStumpel, John Darby, Jeanette Holden, Arnold Munnich, Patrick J. Willems

Nature Genetics 1993:4:421-425. 


\section{SA.1 ABSTRACT}

Recently, a mutation in the gene for the neural cell adhesion molecule LICAM, located at $\mathrm{Xq} 28$, was found in a family with $\mathrm{X}$-linked hydrocephalus (HSAS). However, as the LICAM mutation could only be identified in one HSAS family, it remained unclear whether or not LICAM was the gene responsible for HSAS. We have conducted a mutation analysis of LICAM in 25 HSAS families. The mutation reported previously was not found in any of these families. In one family, however, a 1.3 kilobase $(\mathrm{kb})$ genomic duplication was identified, cosegregating with HSAS and significantly changing the intracellular domain of the LICAM protein. These results confirm that L1CAM is the HSAS gene.

\section{A.2 INTRODUCTION}

X-linked hydrocephalus with stenosis of the aqueduct of Sylvius (HSAS, MIM *307000)(16) is the most common genetic form of hydrocephalus. It may accounts for almost $25 \%$ of male patients with hydrocephaly not associated with neural tube defects (3), and its overall frequency has been estimated at $1 / 30,000$ male births (8). However, its true frequency may be higher as HSAS can present with atypical features and even without hydrocephaly $(6,25,27)$. In its most typical form, HSAS is characterized by hydrocephalus with stenosis of the aqueduct of Sylvius, moderate to severe mental retardation, clasped thumbs, spastic paraparesis of the lower extremities and a wide spectrum of structural brain anomalies including aplasia or hypoplasia of the corpus callosum $(2,4,5,6,13,25,27)$.

With linkage analysis in four families we localised HSAS to Xq28 (28). This has been confirmed in additional families $(7,11,12,15,19,25,29)$. Collectively, these data indicate linkage of HSAS to Xq28 in a total of 20 families. Multipoint linkage analysis and the localization of key recombinational events in HSAS families has indicated that HSAS lies within a 2 megabase (Mb) between DXS52 and F8C within the $\mathrm{Xq} 28$ locus (29). Since the only known $\mathrm{Xq} 28$ gene with a function in neurological tissue was LICAM, a gene coding for a neural cell adhesion molecule, this gene was considered as a candidate gene for HSAS (29). Although a mutation in LICAM segregating with HSAS, was recently identified, it was unclear, whether or not LICAM mutations were responsible for HSAS, as LICAM mutations could not be found in other HSAS families (23).

We have conducted a mutation analysis of LICAM in 25 unrelated HSAS patients or obligate carriers. In one family, a duplication in the 3' region of the LICAM gene, cosegrega-tes with HSAS. This second finding of an LICAM mutation in HSAS confirms LICAM as the HSAS gene. 


\section{A.3 METHODOLOGY}

\section{A.3.1 HSAS patients}

Twenty-five HSAS families from different ethnic background were studied (Table 1). Only families containing at least two patients with hydrocephalus and inental retardation in at least

Table I

ISAS families included in this study

\begin{tabular}{|c|c|c|c|}
\hline Pedigree & Country of Origin & Analysis." & References \\
\hline HSAS I & The Netherlands & $\mathrm{S}, \mathrm{P}$ & 27,29 \\
\hline HSAS 2 & United Kingdom & $\mathrm{S}, \mathrm{P}$ & 4,29 \\
\hline HSAS 3 & United States & $\mathrm{S}, \mathrm{P}$ & 29 \\
\hline HSAS 4 & The Netherlands & $\mathrm{s}, \mathrm{P}$ & 21,29 \\
\hline HSAS 5 & Israel & $\mathrm{S}, \mathrm{P}$ & 29 \\
\hline HSAS 6 & United Kingdom & $\mathrm{P}$ & 5,29 \\
\hline HSAS 7 & United States & $\mathbb{P}$ & 7,29 \\
\hline HSAS 8 & United States & $\mathbb{P}$ & 11,29 \\
\hline HSAS 10 & United States & $\mathbb{P}$ & 11,29 \\
\hline HSAS 11 & Germany & $\mathrm{S}, \mathrm{p}$ & 29 \\
\hline HSAS 12 & Germany & $\mathrm{s}, \mathrm{P}$ & 19,29 \\
\hline HSAS 14 & United Kingdom & $\mathrm{S}, \mathrm{P}$ & \\
\hline HSAS 16 & Germany & $\mathrm{S}, \mathrm{P}$ & \\
\hline HSAS 19 & Hungary & $\mathrm{s}, \mathrm{p}$ & 26 \\
\hline HSAS 21 & The Netherlands & $\mathrm{s}, \mathrm{P}$ & \\
\hline HSAS 22 & Belgium & $\mathrm{s}, \mathrm{p}$ & 13 \\
\hline HSAS 23 & Israel & $\mathrm{S}, \mathrm{P}$ & \\
\hline HSAS 24 & The Netherlands & $\mathbf{s}_{n} \mathrm{P}^{n}$ & \\
\hline HSAS 25 & United States & $\mathrm{s}, \mathrm{p}$ & \\
\hline IISAS 26 & United States & $\mathrm{P}$ & \\
\hline MSAS 29 & United States & $\mathrm{P}$ & \\
\hline HSAS 30 & Beligium & $\mathrm{s}, \mathrm{p}$ & \\
\hline HSAS 32 & United Kingdam & $\mathrm{P}$ & \\
\hline MSAS 33 & Germany & $p^{m}$ & \\
\hline HSAS 34 & The Netherlands & $\mathbb{s}_{*} \mathrm{P}$ & \\
\hline
\end{tabular}

"S: Analyzed by Southern blotting using the LICAM CDNA clone. P: Anlalyzed by PCR to screen for the prowiously reported point mutation (23) for the 1.3 kb L. ICAM duplication present in family HSAS1.

two generations consistent with X-linked inheritance, were included in this study. Linkage analysis performed on families HSAS 1 to 12 , has been described previously $(28,29)$. Clinical details of family HSAS 1 have also been described previously $(27)$. Briefly, all HSAS patients in this family show moderate to severe mental retardation and the majority of them have adducted thumbs and spastic paraparesis of the lower extremities. The spectrum of hydrocephalus in this family is very large ranging from severe prenatal hydrocephalus with grossly elevated occipitofrontal circumference necessitating perinatal drainage, to minimal dilatation of the lateral ventricles. Multipoint linkage analysis in family HSAS 1 with Xq28 markers DXS52 and F8 gave a peak lodscore of 3.18 with HSAS. 


\section{A.3.2 Southern blot analysis}

DNA isolation, Southern blotting and hybridization were performed using standard protocols. For Southern blot analysis, a plasmid clone containing approximately 3800 bp coding for L1CAM protein without any $3^{\prime}$ untranslated sequences (10), was used as a probe. For the delineation of the duplication, this clone was digested with PstI after excision of the insert from the pBluescript vector with HindIII and XbaI. From the resulting four L1CAM cDNA fragments, the smallest one $(530 \mathrm{bp})$ containing the 3'terminal region of the ORF, was found to hybridize to the novel fragments associated with the duplication.

\section{A.3.3 mRNA and cDNA preparation}

mRNA was isolated from EBV-transformed lymphoblastoid cell lines from two HSAS 1 patients and from controls. mRNA was isolated using the QuickPrep Micro mRNA Purification Kit (Pharmacia) starting from $10^{6}$ cells. This mRNA was suspended in 400 $\mu \mathrm{l}$ water. Thirteen $\mu 1$ of mRNA was transcribed into cDNA using a Superscript kit (Life Technologies). After diluting this reaction to $40 \mu \mathrm{l}, 1 \mu \mathrm{l}$ of cDNA was used for PCR amplification.

\section{A.3.4 PCR amplification}

Genomic PCR reactions were performed under the conditions recommended in the Geneamp PCR kit (Perkin-Elmer). The position of the different primers is indicated in Fig. 1 and primer sequences are given in Table 2. PCR products were visualized by ethidium bromide staining. An annealing temperature of $60^{\circ} \mathrm{C}$. The first amplification with primers F5-R3 used 35 cycles. and agarose or polyacrylamide gel electrophoresis. Genomic PCR used $300 \mathrm{ng}$ DNA and 30 cycles. For primer pairs F2-R1, F3-R2 and F7-R5 the annealing temperatures were $65^{\circ} \mathrm{C}, 62^{\circ} \mathrm{C}$ and $60^{\circ} \mathrm{C}$, respectively. Amplification of LICAM CDNA was done by nested PCR with $1 \mu \mathrm{l}$ of a 25 -fold dilution of the first PCR was reamplified ( 25 cycles) in a second PCR reaction with primer sets F3-R3, F3-R2, F7-R2 and F6-R2. 

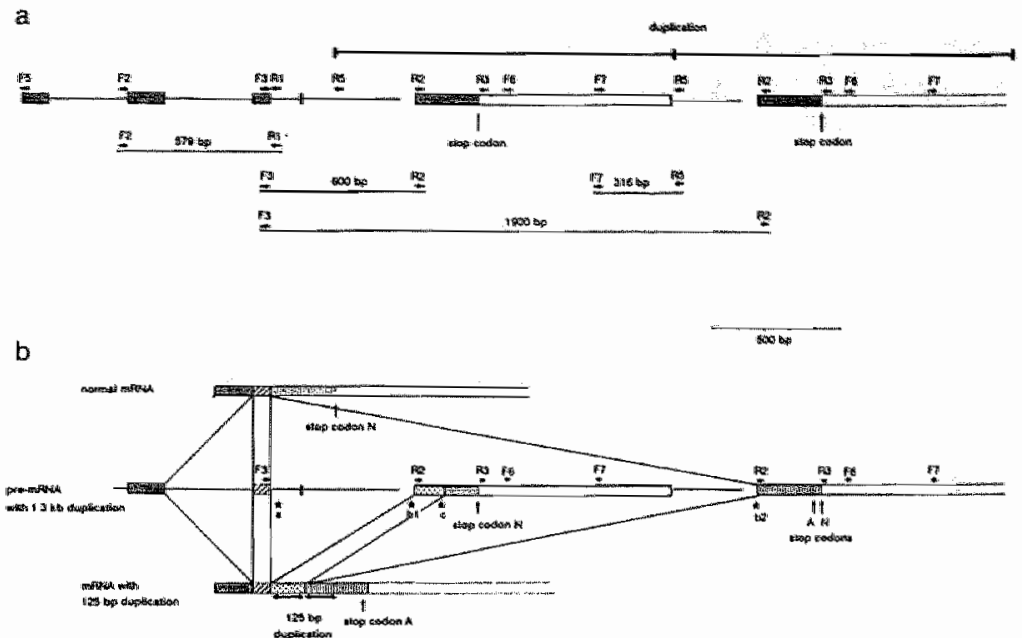

Figure 1a Genomic structure of the 3'-region of the LICAM gene in family HSAS 1 . Introns are represented by theis, exons by baxes. The ORF is hatched. The relative positions of the oligonucleotide primers used in this study are indicated by anrows. Dotted lines indicate regions of unknown sequence. b: Splicing of pre-mRNA containing the $1.3 \mathrm{~kb}$ duplication in EBV-transformed B-cell lines generating mature mRNA with the 125 bp duplication and nomal mRNA. The normal stop codon (N) and the alternative stop codon (A) are marked with vertical arrows. The normal S'-splice site (a), the nonnal 3'-splice site (b1), the duplicated 3'-splice site (b2), and the cryptic \$'-splice site (c) are indicated by asterisks, "The 12 bp excon between splice sites a and bl, represented by a small solid bo $x_{2}$ is only present in brain L.1CAM mRNA due to allernative splicing $(9,10,18,20)$.

Table 2

Primer sequences used in genomic PCR and RT-PCR.

primer sequence $\left(5^{\prime}-3^{n}\right)$

5

16

F2

$\sqrt{13}$

F5

16.

N7

EI

$\mathrm{R} 2$

R3

R5

\author{
CCAGCACGGCACTTOAGTTO \\ CAGGAAGAGATCTTGAGACCATGC \\ GGGCHGGTGTCTCACCCTCAO \\ ATOAGACGITCGGCGAGTAGAG \\ TCCTACACGCAGTGCGACCI \\ AGGAGAACTTOCTOCCTCGOAI" \\ TTGCCAICTCTOCTCCAACCO \\ CCACTCC TGCACCOGC ICAC \\ GOCTOCTGCCAMAGGCCTTCTC \\ AGCATCTCCTGTCCGTACTOCA \\ CAGTGOAOGTATCTGTGTOGAG
}

The position of the primers is indicaled in Fig. 1. Primers 5 and 16 have been sescribed previously $(23)$.

\section{A.3.5 DNA sequencing}

PCR products were cloned into pUC18 plasmid by blunt-end ligation. Recombinant plasmids were sequenced using a Sequenase kit (USB, Cleveland Ohio) according to the manufacturer's instructions. A C-rich region in the genomic PCR fragment F7-R5 which was difficult to sequence using the Sequenase kit, was also sequenced with a Circumvent kit (Biolabs). 


\section{A.4 RESULTS}

\section{A.4.1 Screening LICAM for a branch point signal mutation}

We first investigated whether the point mutation reported previously in the LICAM intron 19 bp upstream of exon Q (23) was present in our HSAS families. This point mutation creates a new restriction site for the enzyme MaelI. Presence of this site can be identified by genomic polymerase chain reaction (PCR) amplification using primers

2

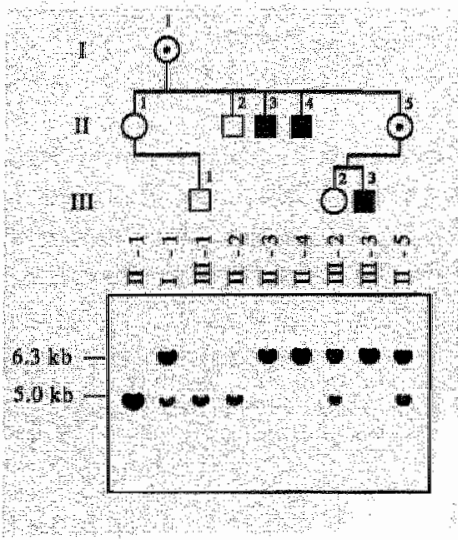

b

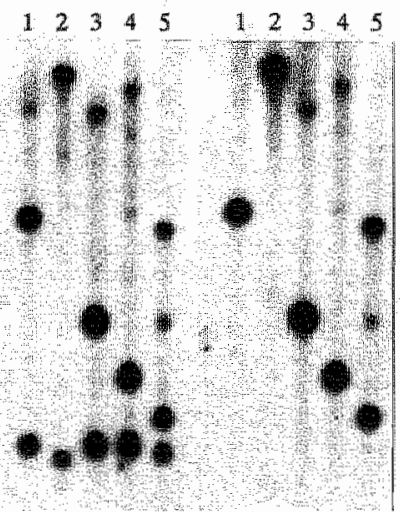

Figure 2 Detection of the L1CAM duplication in fumily HSAS I by Southern blot analysis using a fragment of the LICAM cDNA containing the $3^{4}$ end of the ORF $(530 \mathrm{bp})$, a: TaqI blot for part of furrily HSAS 1 . The pedigree with male patients (filled squares), obligate carriers (doited eircles), healthy males (open squares) and possible carriers (open circles) is indicated above the Southem blot. In healthy persons, a normal $5.0 \mathrm{~kb}$ band is present, while in affected individuals $26.3 \mathrm{~kb}$ band is present das to the $1.3 \mathrm{~kb}$ duplication. In carriers, both bands are present. b: Southern blot analysis of patients $\Pi$-4 (A) and MI-3 (B) of family HSAS 1 and a healthy control (C) using restriction enzymes Bgll (lane 1), Bamill (lane 2), Pwall (Uane 3), Ssu (lane 4) and Pst] (lane 5). For all enzynes, extra bands of approximately 1.3 kb are present in both patients. The novel bands.

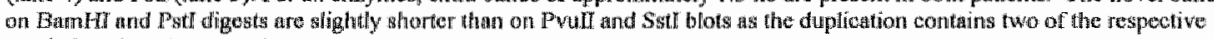
restriction siltas close together.

5 and 16 (Table 2), followed by digestion of the PCR product with MaelI and polyacrylamide gel electrophoresis, as previously described (23). One patient or obligate carrier from each of the 25 HSAS families, of different ethnic background (Table 1), was tested. The mutation was absent from all HSAS families.

\section{A.4.2 Mutation analysis by Southern blotting}

To identify gross DNA rearrangements in L1CAM, Southern blotting was used to analyze subset of 17 families (Table 1), for which enough DNA was available. Restriction enzymes BamHI, BgIII, EcoRI, HindIII, PstI and Taql were used to generate Southern blots containing DNA samples from one patient or obligate carrier from each family and a number of controls. These were hybridized with a cDNA probe 
containing the complete LICAM open reading frame (ORF). A difference in banding pattern between patients and controls was observed in family HSAS 1, which showed aberrant bands for all restriction enzymes tested. Subsequently all members of this family were analyzed by Southern hybridization of TaqI generated blots. The normal $5.0 \mathrm{~kb}$ band was replaced by a novel $6.3 \mathrm{~kb}$ band in three patients, whereas both bands were present in three female carriers (Fig. $2 \mathrm{a}$ ). Complete cosegregation of the novel 6.3 $\mathrm{kb}$ band with the HSAS mutation is seen in this family. Both EcoRI and HindIII blots showed a band of approximately $20 \mathrm{~kb}$ in controls, whereas a slightly larger band (data not shown) was seen in HSAS patients. On BamHI, PstI and Bglll blots, a single extra band of approximately $1.3 \mathrm{~kb}$ was observed in patients and carriers. In order to exclude the possibility of an LICAM polymorphism segregating with the disease in family HSAS 1., $129 \mathrm{X}$-chromosomes, from healthy controls were analyzed on TaqI Southern blots. The novel $6.3 \mathrm{~kb}$ band was absent from all controls tested.

\section{A.4.3 A $1.3 \mathrm{~kb}$ duplication in L1CAM}

The extra band of approximately $1.3 \mathrm{~kb}$, on BamHI, Pstll, and BglII Southern blots of patients of the HSAS 1 family was also present on Pvull and SstI blots, suggesting a duplication of this size in family HSAS 1 . In general, a restriction enzyme cutting once in a duplicated region gives rise to an extra band of exactly the length of this duplication. To investigate in which part of the gene the presumed duplication was located, Southern blot hybridization was carried out using probes containing different fragments of the LICAM CDNA. A fragment containing the last $530 \mathrm{bp}$ upstream of the stop codon hybridized to the abnormal bands in HSAS 1 family members (Fig. 2b), localizing the duplication to the $3^{3}$-end of the LICAM ORF (Open Reading Frame).

Combining the sequence information of the LICAM CDNA (10) with the genomic sequence $(20,22)$, allowed us to construct a genomic map of the $3^{\prime}$-end of the

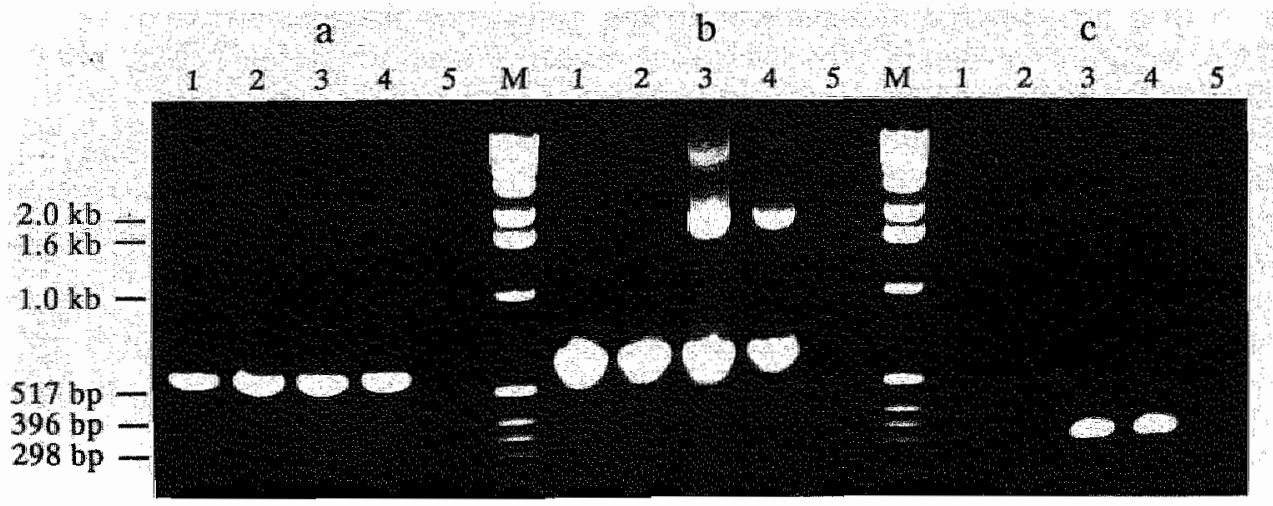

Figure 3 Genomic PCR of controls (lanes 1 and 2), HSAS I patients I-4 (lane 3) and III-3 (lane 4), and a blank (lane 5). With primer set F2-R 1 an, only the normal band of 579 bp is observed in both patients and controls. With primer set $13-R 2 b$, a nommal bard of 600 bp is present in all lames and a band of about 1,900 bp is preserit only in the patients duce

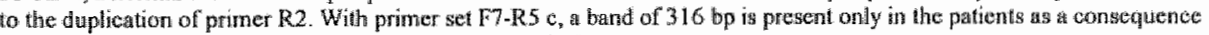
of a second annealing site for primer RS downstream of primer $F 7$. 
LICAM gene, and design nine PCR primers from this region (Table 2). To narrow the region containing the putative duplication, $\mathrm{PCR}$ amplification was carried out on genomic DNA using overlapping primer sets (Fig. la). If at least one of the primers of a given primer set is located in the duplication, a novel fragment will be generated in addition to the normall fragment, due to the presence of a duplicate annealing site for the appropriate primer. Amplification using primer combination F2-R1 gave a band of the expected length (roughly $580 \mathrm{bp}$ ) both in patients of family HSAS 1 and in healthy controls (Fig. 3a). Primers F3-R2 also gave a band of the expected size (roughly 600 bp) in family HSAS 1 and in controls, but DNA from family HSAS 1 also gave rise to a second band of about $1.9 \mathrm{~kb}$ (Fig.3b). This analysis located the 5 -end of the duplicated region to between the regions complementary to primers R1 and R2. The 5'end of the duplication was further localized by genomic PCR using primers F7-R5 (Fig.3c). In healthy controls, these two primers are directed away from each other, and consequently no PCR product is formed. In the HSAS 1 patients, however, a fragment of about $300 \mathrm{bp}$ was amplified, suggesting that primer R5 is located within the duplication. This implies that a second annealing site for this primer is present downstream of primer F7, making the amplification of the $300 \mathrm{bp}$ fragment possible. To localize the exact $5^{\prime}$ and $3^{\prime}$ end of the duplicated region, the nucleotide sequence of the R5-F7 fragment was determined. The sequence extending from primer F7 was identical to the 3' untranslated sequence of L1CAM over $246 \mathrm{bp}$, but extended $24 \mathrm{bp}$ further than the sequence reported by Hlavin and Lemmon (10) and was followed by 3 bp of intronic sequence immediately upstream of primer R5. The sequence extending from primer $\mathrm{R} 5$ was identical to the expected intron sequence for only $3 \mathrm{bp}$. This analysis places the $5^{\prime \prime}$-end of the duplication 3 bp upstream from primer R5, and the $3^{\prime \prime}-$ end of the duplication $756 \mathrm{bp}$ after the stop codon of the LICAM ORF, resulting in a total duplicated region of roughly $1,300 \mathrm{bp}$.

To investigate whether this duplication was also present in those HSAS families which were not analyzed by Southern blotting, patients or obligate carriers of all 25 HSAS families were amplified by PCR using primers F3 and R2. A fragment of about $600 \mathrm{bp}$ was present in all patients tested (data not shown). Only in patients from family HSAS 1 was the extra band of $1.9 \mathrm{~kb}$ observed, demonstrating that HSAS 1 is the only family, out of the 25 , with this duplication in the L1CAM.

\section{A.4.4 Aberrant splicing of LICAM mRNA}

We performed PCR analysis of cDNA from two patients from HSAS 1 and two controls, to examine the effect of the duplication on LICAM mRNA. As LICAM mRNA levels in EBV-transformed lymphoblastoid cell lines are very low, nested reverse transcriptase PCR (RT-PCR) on mRNA was used. After a first amplification with primers F5 and R3, a second hemi-nested amplification was performed using primers F3 and R3. A normal band of 276 bp was generated from both patients and controls. In both patients, however, a second band of approximately the same intensity and a length of approximately $400 \mathrm{bp}$ was generated (data not shown). Sequencing of the latter fragment showed a 125 bp duplication, starting immediately after primer F3. 
This duplication alters the reading frame and leads to the use of a different stop codon. This results in the substitution of the normal 35 amino acids at the carboxyl terminal of the LICAM protein with a new 75 amino acids sequence. This new LICAM MRNA is likely generated by an aberrant splicing event (Fig. 1 b). The primary transeript probably contains a 1,300 bp duplication in which the $3^{3}$-splice site of the intron upstream of the last coding exon (marked b1 and b2 in Fig. 1 b) is duplicated. Since the $5^{\prime}$ splice site of this intron is not duplicated, the duplicated intron can not be spliced out correctly. Splicing using the 3'-splice site b2 and a cryptic 5 -splice site o at bp 125 of the last coding exon (Fig.1b) could generate this 125 bp mRNA duplication. Comparison of the sequence at the cryptic 5'-splice site c (TGGTTCGT) showed three mismatches with the consensus 5'-splice site AGGTAAGT, while the normal 5'-splice site a (AGGTGAGC) contains two mismatches.

Since the PCR amplification with primer pair F3-R3 on the LICAM CDNA of both patients of family HSAS 1 also generated fragments of normal length ( $276 \mathrm{bp}$ ), the cryptic splice site is not used for all LICAM pre-mRNA molecules. A possible explanation for the occurrence of this PCR fragment of normal length is a splicing event between the duplicated 3 "-splice site $\mathrm{b} 2$ and the normal 5 '-splice site a (Fig. 1b). In this case, the complete $1.3 \mathrm{~kb}$ duplication is spliced out, generating a normal mRNA molecule. To test this hypothesis, RT-PCR was performed on mRNA from both HSAS 1 patients using primers F5 and R3, followed by several nested primer pairs. No amplifi-cation was found with nested primer sets F7-R2 and F6-R2 on cDNA, although genomic DNA from the HSAS 1 patients, used as a control, showed good amplification (data not shown). Nested primer sets F3-R3 and F3-R2 showed amplification products of normal length on CDNA, as well as bands $125 \mathrm{bp}$ larger. Although there is no formal proof for the hypothetical exon-skipping splicing event generating a normal mRNA in the HSAS 1 patients, it is a likely explanation for the observed PCR results.

\section{A.5 DISCUSSION}

Recently a point mutation of LICAM has been identified in an X-linked hydrocephalus patient, suggesting that LICAM is the HSAS gene (23). However, this point mutation was only demonstrated in one HSAS family and the effect of the mutation at the protein level was not studied, although both normal LICAM message and aberrantly spliced mRNA products were found (23). Furthermore, transgenic mice carrying a L1CAM knock-out do not show hydrocephalus (P. Soriano, pers. comm.). Therefore, proof that LICAM is the HSAS gene, has awaited other LICAM mutations identified in HSAS families.

In a search for LICAM mutations, we first looked for gross DNA rearrangements by hybridization of Southern blots to a cDNA probe containing the complete LICAM ORF. In only one out of 17 families was such a mutation found, indicating that large rearrangements visible on Southern blots represent a small proportion of mutations in HSAS families. Additional mutation analysis is now being performed in the remaining HSAS families. Exon-by-exon mutation analysis in LICAM is compli- 
cated by the lack of information on the LICAM genomic structure and exon-intron boundaries. RT-PCR of LICAM mRNA is hampered by the fact that fresh brain tissue from patients is not available whereas the level of LICAM mRNA in EBV-transformed lymphoblastoid cell lines is very low necessitating the use of nested PCR.

In family HSAS 1 we identified a 1,300 bp duplication comprising the $3^{\prime}$-end of the L1CAM ORF, part of the upstream intron, and 756 bp of $3^{*}$ untranslated sequence. Evidence that this mutation causes the disease is: (i) the duplication cosegregates with HSAS in this family; (ii) the duplication was shown not to be a common polymorphism as it was not found in the control population and (iii) the duplication gives rise to aberrant splicing of L1CAM mRNA and translation of the new mRNA replaces the 35 carboxyl terminal amino acids of the LICAM protein with a new 75 amino acid sequence. As this is the second LICAM mutation found in HSAS, there remains little doubt that LICAM is indeed the X-linked hydrocephalus gene.

Our results indicate the possibility that the aberrant splicing of primary mRNA transcripts of LICAM in this family results in both abnormal mRNA with a $125 \mathrm{bp}$ duplication and normal LICAM mRNA. However, the presence of normal LICAM mRNA can not be confirmed using other techniques such as northern or western blotting on EBV-transformed B-cell lines since high expression levels of L1CAM is exclusively restricted to cells of neuronal origin (17). It is possible that splicing of the pre-mRNA containing the $1.3 \mathrm{~kb}$ duplication is performed differently in brain and Bcell lines and that no normal mRNA is present in the brain of the HSAS 1 patients. It has been previously shown that LICAM mRNA undergoes differential splicing in peripheral nervous tissue and non-neuronal tissue, compared to brain which contains an extra 12 bp exon $(9,10,17,20)$. As this exon is located between 5 -splice site a and 3 '-splice site bl (Fig. 1b), splicing of the mutant mRNA in brain is unclear. If there is normal LICAM mRNA in the brain of HSAS $\mathbb{1}$ patients, then this mutation could be analogous, in its effect, to the previously identified mutation (23), in which normal LICAM mRNA was present in addition to abnormally spliced products. By competing for LICAM ligands, the presence of non-functional LICAM species on the cell memorane coula disrupt the tunction of normal LICAM.

The presence of normal mRNA in affected patients could be understood in the light of a dominant-negative effect of this mutation. As LICAM is a membrane protein, interaction between LICAM molecules or competitive ligand binding of mutant LICAM could lead to impaired LICAM function in all cells of affected males. As the obligate carriers of this mutation would carry normal LICAM in those cells with the mutant LICAM gene inactivated by the lyonisation process, approximately $50 \%$ of the cells may still have normal LICAM function. This may explain why HSAS in this family is transmitted as a pure X-linked recessive trait, whereas at the cellular level the mutation exhibits a dominant-negative effect.

LICAM is a member of the immunoglobulin superfamily of neural adhesion molecules (24) and has been implicated in neural migration $(1,18)$ and neurite outgrowth $(14,30)$. LICAM encodes a membrane bound protein with extra and intracellular domains linked by a transmembrane region. The high degree of conservation between the cytoplasmic portion of human LICAM and its homologues in mouse, rat 
and chicken suggests an important role for this region $(9,10)$. Translation of the aberrantly spliced LICAM mRNA in family HSAS 1 gives rise to a protein with significant changes in the cytoplasmic domain. Although the extracellular region of the protein probably remains intact, the intracellular function of the LICAM protein must be altered by this mutation, although a precise understanding of how impairment L1CAM function causes HSAS is awaited. 


\section{REFERENCES}

1. Asou $H_{2}$, Miura $M$, Kobayashi $M$, Uyemura $\mathbb{K}_{\text {, }}$ loh $K$. Cell adhesion mollecule $L 1$ guides cell migration in primary reaggegregation cultures of mouse cerebellar cells. Neurosci Lett 1992;144:221-224.

2. Bickers DS, Adans RD. Hereditary stenosis of the aqueduct of Sylvius as a cause of congenital hydrocephalus. Brain 1949;72;246-262.

3. Burton BK. Recurrence risk for congenital hydrocephalus. Clin Genet 1979;16:47-53 (1979).

4. Cassic R, Boon AR. Sex-linked hydrocephalus. J Med Genet 1977;14:72-73.

5. Edwards $\mathrm{JH}_{\text {n }}$ Norman RM. Roberts JM. Sex-linked hydrocephalus: report of a family with 15 affected members. Arch Dis Childh 1961;36:481-485.

6. Fried K. X-linked mental retardation and/or hydrocephalus. Clin Genet 1972;32258-263.

7. Friedman $K J$. Linkage studies in a four generation family with $X$-linked hydrocephalus associated with flexed index fingers. Proceedings of the $23 \mathrm{~d}$ annual March of Dimes Clinical Genetics conference (Vancouver, July 7-10 1991).

8. Halliday $J$, Chow $C W$, Wallace $D$, Danks DM. X-linked hydrocephalus: A survey of a 20 year period in Victoria, Australia. J Med Genet 1986;23:23-31.

9. Harper JR, Prince JT, Healy PA, Stuart JK, Nauman SI, Stallup WB. Isolation and sequence of partial cDNA clones of human LI - homology of human and rodent $\mathrm{LI}$ in the cytoplasmic region. I Neurochem 1991;56:797-804.

10. Hlavin ML, Lenmon V. Molecular structure and functional testing of human L1. Genomics $1991: 11: 416-423$.

11. Holden JJA, Ridgway P, White $B N$, Young JC, Chalifoux M, DiTullio $K$, Wiens $\mathbb{R}$, Holmes A, French $B$, Kurczynski. Further evidence localizing the $\mathrm{X}$-linked hydrocephalus locus to $\mathrm{Xq} 28$. Am J Med Genet 1990,47 Suppl:A.183.

12. Jouet $M$, Feldman $\mathbb{E}$, Tates $\mathrm{J}$, Donnai $\mathrm{D}$, Paterson $\mathbb{J}$, Siggers $\mathrm{D}$, Kenwrick $\mathrm{S}$. Refining the genetic localisation of the gene for X-linked hydrocephalus within Xq28. J Med Genet 1993;30:214-217.

13. Landrieu P. Ninane J. Ferrière G, Lyon G. Aqueductal stenosis in X-linked hydrocephalus: a secondary phenomenon? Developm Med Child Neurol 1979;21:637-652.

14. Lemmon V, Farr KL, Lagenaur $\mathrm{C} . \mathbb{L} 1$-mediated axon outgrowth occurs via a homophilic binding mechanism. Neuron $1989 ; 2: 1597-1603$

15. Lyonnet S, Pelet A, Royer G, Delrieu O, Serville F, Le Marec B, Gruenstendel A, Pfeiffer RA, Briard ML, Dubay C, Hors-Cayla MM, Le Merrer M, Munnich A. The gene for X-linked hydrocephalus maps to Xq28, distal to DXS52. Genomics 1992;14:508-510.

16. McKusick VA. Mendelian Inheritance in Man: Catalogs of autosomal dominant, autosomal recessive and X-linked phenotypes, 8 th edition. John Hopkins University Press, Baltimore 1988.

17. Miura $M$, Kobayashi $M$, Asou $H$, Uyemura $K$. Molceular cloning of cDNA encoding the rat neurall cell adhesion molecule $\mathrm{Ll}$ - two LI isoforms in the cytoplasmie region are produced by differential splicing. FEBS Lett 1991:289911-95.

18. Miura M, Asou H, Kobayashi M, Uyemura K. Functional expression of a full-length cDNA coding for rat neural cell adhesion molecule L1 mediates homophilic intercellular adhesion and migration of cerebellar newrons. J Biol Chem 1992;267:10752-10758

19. Orth U, Enders $H_{3}$ Reicke $S$, Schwinger $\mathrm{E}_{\mathrm{b}}$ Gal A. Gene of X-linked hydrocephalus is closely linked to DXS52 and DXS115 in Xq28. Cytogenet Cell Genet 1991;58:2079.

20. Reid RA, Henperly JI. Variants of human L. 1 -cell adhesion molecule arise through alternate splicing of RNA. J Mol Neurosci 1992;3:127-135.

21. Renier WO, Ter Haar BOA, Sloof JL, Hustinckx TWJ, Gabreëls FJM. X-linked congenital hydrocephalus. Clin Neurol Neurosturg 1982,84:113-123.

22. Rosenthal A, Mackinnon RN, Jones DCS. PCR walking from microdissection clone M54 identifies three exons from the human gene lor the neural cell adliesion molecule LI (CAM-LI). Nucleic Acids Res $1991: 19: 5395-5401$

23. Rosenthal A, Jouet M, Kenwrick $S$. Aberrant splicing of neural cell adhesion molecule L1 mRNA in a family with X-linked hydrocephalus. Nature Genel 1992;2:107-112.

24. Schachner M. Neural recognition molecules and their influence on cellular functions. In "The Nerve Growth Cone" (Ruwen Press Litd., New York, 1992). 
25. Serville $\mathbb{E}$, Lyonnet $S$, Pelet A, Reynaud M, Louail $C$, Munnich A, LeMerrer M. X-linked hydrocephalus: clinical heterogeneity at a single gene locus. Eur J Pediatr 1992;151:515-518.

26. Váradi V, Csécsei K. Szeifert GT, Tóth Z, Papp Z. Prenatal diagnosis of X-linked hydrocephalus without aqueductal stenosis. J Med Genet 1987;24:207-209.

27. Willems PJ. Brouwer $O F$, Dijkstra $\mathbb{I}_{3}$ Wilmink J. X-linked hydrocephalus. Am I Med Genet $1987 ; 27: 921-928$

28. Willems PJ, Dijkstra I, Van der Auwerda BJ, Vits L, Coucke P, Raeymakers $P$, wain Broeckhoven $C$, Consalez GG, Freeman SB, Warren ST, Brouwer OF, Brunner HG, Renier WO, van Elasen AF, Dumon $\mathrm{JE}$. Assignment of X-linked hydrocephalus to Xq28 by linkage analysis. Genomics 1990;8:867-870.

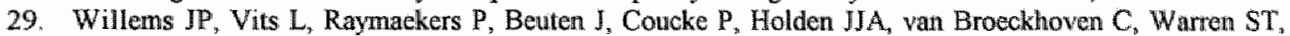
Sagi $M$, Robinson $D$, Dennis $N$, Friedman KS, Magnay D, Lyonnet $S$, White BN, Wittwer BH, Aylsworth AS, Reicke S. Further localization of X-linked hydrocephalus in the chromosomal region Xq28. Ann J Hum Genet 1992;51;307-315.

30. Williams EJ, Doherdy P, Tumer G, Reid A, Hemperly IJ, Walsh FS. Calcium influx into neurons can solely account for cell contact-dependent neurite outgrowth stimulated by transfected L1 I Cell Biol $1992 ; 119: 883-892$. 


\section{Chapter 5B}

\section{MASA syndrome is due to mutations in the neural cell adhesion gene LICAM}

Lieve Vits, Guy Van Camp, Paul Coucke, Erik Fransen, Kristel De Boulle, Edwin

Reyniers, Bernhard Korn, Annemarie Poustka, Golder Wilson, Connie Schrander-

Stumpel, Robin M. Winter, Charles Schwartz, Patrick J. Willems

Nature Genetics 1994;7:408-413. 


\section{B.1 ABSTRACT}

MASA syndrome is a recessive $X$-linked disorder characterized by Mental retardation, Aphasia, Shuffling gait, Adducted thumbs and, in some cases hydrocephalus. Since it has been shown that X-linked hydrocephalus (HSAS) can be caused by mutations in LICAM, a neuronal cell adhesion molecule, we performed an LICAM mutation analysis in 8 unrelated patients with MASA syndrome. Three different L1CAM mutations were identified: a deletion removing part of the open reading frame and 2 point mutations resulting in amino acid substitutions. L1CAM, therefore, harbours mutations leading to either MASA syndrome or HSAS, and might be frequently implicated in X-linked mental retardation with or without hydrocephalus.

\section{B.2 INTRODUCTION}

MASA syndrome (acronym for Mental retardation, Aphasia, Shuffling gait and Adducted thumbs) is an X-linked recessive disorder with a large intrafamilial and interfamilial variability. Thirteen families with more than 50 patients have been described $(2,5,11,12,15,17,20,25,27,31,33,38,39)$. Some of these were not originally described as MASA families (12,15,33,39), but seems to fullfil the ill-defined criteria. Although the only consistent feature of MASA syndrome is mental retardation, its clinical spectrum is very wide, and may also include microcephaly, macrocephaly, agenesis of the corpus callosum, spastic paraparesis and hydrocephaly. Hydrocephaly is also present in X-linked hydrocephalus (HSAS) $(3,10,34)$, another X-linked entity with a clinical spectrum that overlaps that of MASA syndrome. The presence of hydrocephaly in several MASA families $(5,11,27,31)$ and the absence of hydrocephaly in several HSAS patients $(29,34)$ has led us to suggest that MASA and HSAS are allelic $(11,27,35,36)$. This was supported by linkage studies localizing both disorders in $\mathrm{Xq} 28$. The MASA gene has been mapped by linkage analysis proximal to $\mathrm{F} 8 \mathrm{C}$ in $\mathrm{Xq} 28$ with a total lod score exceeding $20(5,18,20,25,27,38)$ and the HSAS gene has been mapped in Xq28 between DXS52 and F8C as well $(19,35,36)$. Although the HSAS gene has been mapped in a relatively small region of $2 \mathrm{Mb}$, the candidate region of the MASA gene is still fairly extended as only one recombinational event between the MASA gene and $\mathrm{Xq} 28$ markers (F8C) has been reported (27). Further analysis of this crossover localized the MASA gene proximal to G6PD (L.V., C.S.S. P.J.W., unpublished observation). This region contains a very high density of disease genes including several other genes involved in neurological disorders such as spastic paraplegia, adrenoleukodystrophy and Emery-Dreifuss muscular dystrophy. The abundance of disease genes in the $\mathrm{Xq} 28$ region is reflected by a high concentration of $\mathrm{CpG}$ islands in this region (21) and by the isolation of numerous cDNA clones isolated from fetal brain mapping in this region (16).

Recently, mutations in the gene for neural cell adhesion molecule L1CAM, also located in Xq28, have been described in three HSAS families $(8,14,26,32)$. To 
investigate whether or not mutations in L1CAM are also responsible for MASA syndrome, we have studied eight MASA families. We report here a deletion and 2 missense mutations in LICAM in three MASA families, indicating that LICAM is the MASA syndrome gene.

\section{B.3 METHODOLOGY}

\section{B.3.1 MASA families}

LICAM mutation analysis was carried out in 8 MASA families. In each family, at least two male patients were present (Table 1). Linkage with Xq28 was confirmed with maximum lod. Scores of 1.20 for MASA 1 (27), 3.01 for MASA 3 (20), 2.86 for MASA 4 (5), 1.71 for MASA 5 (38) and 1.20 for MASA 7 (25). Linkage analysis was not performed in MASA families 2, 6 and 8 .

\section{B.3.2 Southern blot analysis}

DNA was prepared using standard procedures starting from peripheral blood, EpsteinBarr virus transformed cell lines or abortion material in the case of terminated pregnancies. DNA was digested with various restriction enzymes according to the manufacturers' recommendations. After electrophoretic separation, the restriction fragments were trans-

Table 1

MASA familes included in this study.

\begin{tabular}{|c|c|c|c|c|c|c|c|}
\hline Pedigree & Country of origgin & $\begin{array}{l}\text { Mental } \\
\text { retardation }\end{array}$ & Hydroeepthalus & Macrocephualy & $\begin{array}{l}\text { Clasped } \\
\text { thumbs }\end{array}$ & $\begin{array}{l}\text { Spastic } \\
\text { paraparesis }\end{array}$ & Referenoes \\
\hline MASA 1 & The Netherlands & th & + & + & H & 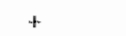 & 6 \\
\hline MASAL 2 & United States & 4 & $?$ & - & H & + & M. Jonet, pers comm. \\
\hline MASA 3 & Mexico - United States & a & - & . & $:$ & . & 12 \\
\hline MASA 4 & United Statites & + & + & - & i- & H. & 13 \\
\hline MASAS & Unifed Ko"ngdom & 4 & $?$ & $f$ & - 且 & H. & 5 \\
\hline MASA 6 & Germany & + & - & $*$ & H. & 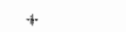 & K. Zerrew, pers oomm. \\
\hline MASA 7 & Germany & $a_{3}^{2}$ & $?$ & - & H & + & 8 \\
\hline MASA & United States & + & - & + & aster & + & C. Schwartz, pers contm. \\
\hline
\end{tabular}

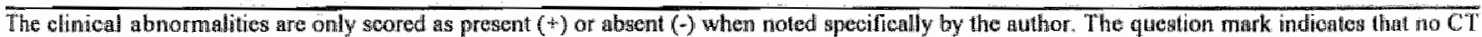
scan or MRI of the brain has been made.

ferred to Hybond- $\mathrm{N}+$ membranes (Amersham). All hybridizations were carried out overnight in a solution of $9 \%$ dextran-sulphate, $0.1 \%$ SDS, $3 \times \mathrm{XSC}$ and $10 \mathrm{X}$ Denhardt's at $65^{\circ} \mathrm{C}$. A plasmid clone with a human cDNA containing the entire open reading frame (ORF) of LICAM, a $530 \mathrm{bp}$ PstI fragment containing the $3^{\prime}$ end of this 
Table 2

LICAM primerist

\begin{tabular}{|c|c|c|}
\hline Primer & Sequasuces & Position \\
\hline 5: & 5-CCA GCA CGG CAC TTOAGT TO-3 & $2491-2472$ \\
\hline 16: & 5.CAOGAA GACATC TTO AGA CCA TGO-3 & intron 18 \\
\hline Fil: & \$* ATO GTC GTG GCO CTO GGO TAC O -3 & $\sqrt{1}-23$ \\
\hline T2: & 5. GGOCTG GTG TCT CAC CCT CAG & intron 24 (Fig. 1) \\
\hline Pis: & 5- ATG AGACCT TCG OCG AGT ACA G -3 & $3509 \cdot 3530$ \\
\hline 1:5: & 5- TCC TAC ACOCAOTGO GAC CT -3 & $3221-3240$ \\
\hline 1790: & S- GTO GCOTCT CCTCCT CTG -3 & $24-41$ \\
\hline 11: & 5. CCO OATCTACTGGAI OAACAO 3 & $501-521$ \\
\hline RI: & S. CCA CTC CIOCAC COC CTC AC -3: & intron 26, (Fig. L) \\
\hline R2: & S. GGC TGC TOC CAA AGG CCT TCTC $-3^{\circ}$ & $3574-3553$ \\
\hline RA: & 5. GCC OAT GAA CCA GCC CTC AOT G -3" & $3374-3353$ \\
\hline$R 7$ & 5-CAC CAC ATC CAO TTC OOT AC -3 & $1800-1781$ \\
\hline R8: & S' TCC ACA GGG ATC CCOTTG AT -3" & $1122 \cdot 1103$ \\
\hline $\mathbb{R l O :}$ & 5- AGT GGOCAO TGG GAG GA-3 & 3' untr, (Fug. I) \\
\hline 12 & 5'-OTO TTG GCC TCT CCC TGG AAT GA $-3^{\prime}$ & introm 27 (Fig. 1) \\
\hline 98: & 5- AAG GAO TCA GGG AGA GAG TOC AG - 3 & inturon 6 \\
\hline (121: & 5. GAA OAG CCCAOA TOG CAG GAA AG -3' & intron 13 \\
\hline 022: & 5. ATOTOA GCC CCO GCC TTC TGG AOT G -3 & intron 14 \\
\hline 944: & 5- TCA GGC TGO GGC GOO AGA AGA AG - 3 & intron $25(\mathrm{Fig} .1)$ \\
\hline G45: & 5' TA TAOOOA GAC CTT OET GTT GO-3 & intron 27 (Fig. 1) \\
\hline Q47: & 5'- TGC TTI GHA CTO GTT TAG AGO OC -3 & 3 untr. (Fig 1 ) \\
\hline 122 & 5. GTG AAG GAT AAG GAG GAC ACC - 3 & $3457-3477$ \\
\hline
\end{tabular}

- Nucleotide position in the cDNA sequence (13), with position 1 being the first nucleotide of the start codom.

L1CAM cDNA clone, and clone 17 , containing approximately the last $1000 \mathrm{bp}$ of the L1CAM ORF and approximately 700 bp of 3' untranslated sequence (13), were used as probes in the Southern blot analysis. An EcoRI blot of family 4 was also hybridized to a cosmid clone 10B7, which is located in the $3^{\prime}$ region of LICAM (B.K., unpublished observation), and to CDNA clones XAP16 and XAP17 on the 5 side of LICAM (B.K., unpublished observation).

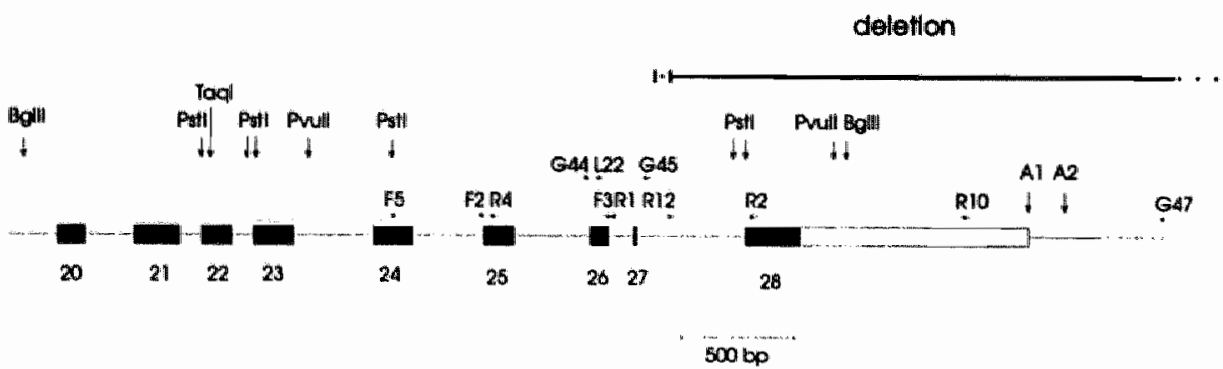

Figure 1 Gotomic struoture of the $3^{8}$ region of L ICAM (A. Riosenthal, wapublished results). Introns are represented by linew, exons by boxes. Dixons 20 to 28 are numbered. The position of the deletion and the primers used in this study are indicated. The 5 and of the dieletion so loented in intron 27 . 


\section{B.3.3 Genomic PCR}

Thirty-five PCR cycles were carried out in a $50 \mu 1$ total reaction mixture containing $300 \mathrm{ng}$ genomic DNA, $0.25 \mathrm{mM}$ dNTPs, 50 pmol of both primers and 0.2 units of Taq polymerase in $50 \mathrm{mM}$ Tris- $\mathrm{HCl}(\mathrm{pH} 9.0), 50 \mathrm{mM} \mathrm{KCl}, 7 \mathrm{mM} \mathrm{MgCl}, 0.02 \%(w / v)$

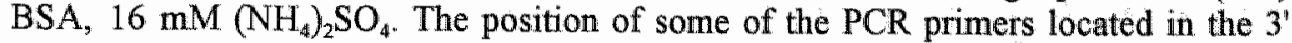
region of L1CAM, is shown in Figure 1. The sequence and nucleotide position of the primers are listed in Table 2. Exon 14 was amplified using primers G21 and G22, and the PCR product was digested with BseNI in the buffer provided by the manufacturer. Primers F11 and G8 were used to amplify exon 6. Hae III digestion of the exon 6 PCR product was performed according to the manufacturer's recommendations. Amplification products were electrophoresed in polyacrylamide or agarose gels, stained with ethidium bromide and visualized under UV illumination.

\section{B.3.4 SSCP analysis and sequencing}

$100 \mathrm{ng}$ of genomic DNA was amplified with primers G21-G22 for exon 14 and primers F1-G8 for exon 6. The PCR reactions were performed using published procedures (9). Electrophoresis was performed at $4^{\circ} \mathrm{C}$ using hydrolink MDE gels (J.T. Baker) according to the manufacturer's recommendations. Amplified PCR fragments were subcloned into PUC18 vector using the Sure clone-kit (Pharmacia), and sequenced as described (32).

\section{B.4 RESULTS}

\section{B.4.1 Screening for L1CAM mutations}

In an initial mutation search we analysed our MASA syndrome families (Table I) for previously reported L1CAM mutations. We looked for the point mutation at a potential branch point signal in intron 18 of LICAM (26); the 1.3 kilobase $(\mathrm{kb})$ duplication in the $3^{\prime}$ region of LICAM (32); the missense mutation in exon 7 resulting in a C264Y substitution (8) and the $5^{\prime}$ splice site mutation in intron 4 resulting in a premature stop codon (8). None of these mutations were present in the eight MASA families (although our PCR analysis of the $1.3 \mathrm{~kb}$ duplication in family 3 failed repeatedly).

To search for gross rearrangements, Southern blot analysis of L1CAM was performed in 7 families (not enough DNA was available from family 2). Southern blots of TaqI, BglII, PstI, HindIII and BamHI digests were hybridized to a LICAM cDNA probe containing the entire open reading frame (ORF) (13). An altered banding pattern was observed in family 3 , using all 5 restriction enzymes (data not shown).

\section{B.4.2 L1CAM Deletion in family 3}

The abnormal Southern blot and PCR results obtained for family 3 , suggested the presence of a deletion in the $3^{\prime}$ region of LICAM. Southern analysis of a TaqI digest 
using either a 530 bp PstI LICAM cDNA fragment or clone 17 , both located in the 3' region of the LICAM gene (13), showed that the normal $5.0 \mathrm{~kb}$ band was replaced by a novel band of $3.0 \mathrm{~kb}$ in all patients (Fig.2). Both bands were present in the female carriers, and the novel band cosegregated with the MASA mutation (Fig.2). An abnormal banding pattern was also seen with most restriction enzymes used (data not shown). In 129 independent $\mathrm{X}$-chromosomes analysed on Southern blots, all samples showed a normal banding pattern, indicating that this novel band is associated with the disease in this family. The mutation was also not present in the other 7 MASA families under investigation, nor in 44 families with HSAS.

To delineate the 5 breakpoint of this deletion, we performed genomic PCR with primer sets F3-R12, F3-R10 and G44-G45. PCR products of the expected sizes $(287,1600$ and $275 \mathrm{bp})$ were obtained for control samples but only the latter combination resulted in amplification using DNA from affected cases of family 3 . These data indicate that the $5^{\prime}$ breakpoint lies within a section of intron 27 of approximately 100 bp between primers R12 and G45. To characterize the extent of the deletion, amplification between L22 and the most distal 3' primer available, G47, was attempted. A $2,465 \mathrm{bp}$ product was obtained using DNA samples from control samples but not using DNA from the patient, indicating that primer G47 is deleted. Together these results indicate that the deletion spans at least $2 \mathrm{~kb}$ and extends at least $1,580 \mathrm{bp}$ beyond the coding region and 400 bp further than two polyadenylation signals. To further characterize the $3^{n}$ end of the deletion we hybridized a cosmid clone $10 \mathrm{~B} 7$, located in the $3^{\prime}$ region of LICAM, to EcoRI digested DNA of one of the MASA patients in this family. This showed a normal pattern except that a $6.5 \mathrm{~kb}$ band was deleted in the patient's DNA. As this genomic clone is only partially deleted and does not contain expressed sequences (B.K., unpublished observation), the deletion does not extend into the gene adjacent to LICAM. To investigate other possible rearrangements, we hybridized two previously isolated cDNA clones, XAP16 and XAP17 (B.K., unpublished observation), on the 5' side of L1CAM, to the same panels. No differences between patient and control DNA could be observed (data not shown), arguing against a gross rearrangement in the L1CAM region with involvement of other genes in the MASA phenotype. 
both the normal and the mutant fragment. Sequence analysis of the subcloned PCR product revealed a $G$ to A point mutation at position 1792 of the LICAM CDNA sequence (13) (Fig. 3b). The result is that aspartic acid 598, in the 6th immunoglobulin domain, is substituted by asparagine. The D598N mutation abolishes a site for the restriction enzyme BseNI, allowing us to screen for this mutation in family 5 (Fig.3a) and the general population. We digested the G21- G22 PCR product of 50 female controls with BseNI, but the D598N mutation was not present in the ccontrol population, nor among the remaining seven MASA families or 52 HSAS families.

\section{B.4.4 H191Q Missense mutation in family 4}

SSCP analysis of family 4 (Fig.4a) showed a band shift in exon 6 in the affected patients, II:3 and III:1, and in the obligate heterozygote, II:2. Sequencing the F11-G8 PCR product of patient II: 3 revealed a missense mutation of $C$ to $G$ at position 630 of the cDNA (13) in the second immunoglobulin domain (Fig.4b), replacing histidine at position 210 for glutamine. This $\mathrm{H} 210 \mathrm{Q}$ mutation creates a new Hae III restriction site in the F11-G8 PCR product (Fig.4a). The H210Q mutation was not present in 100 control $X$ chromosomes, nor in the other seven MASA families or 65 HSAS families, indicating that the $\mathrm{H} 210 \mathrm{Q}$ mutation is a private mutation.
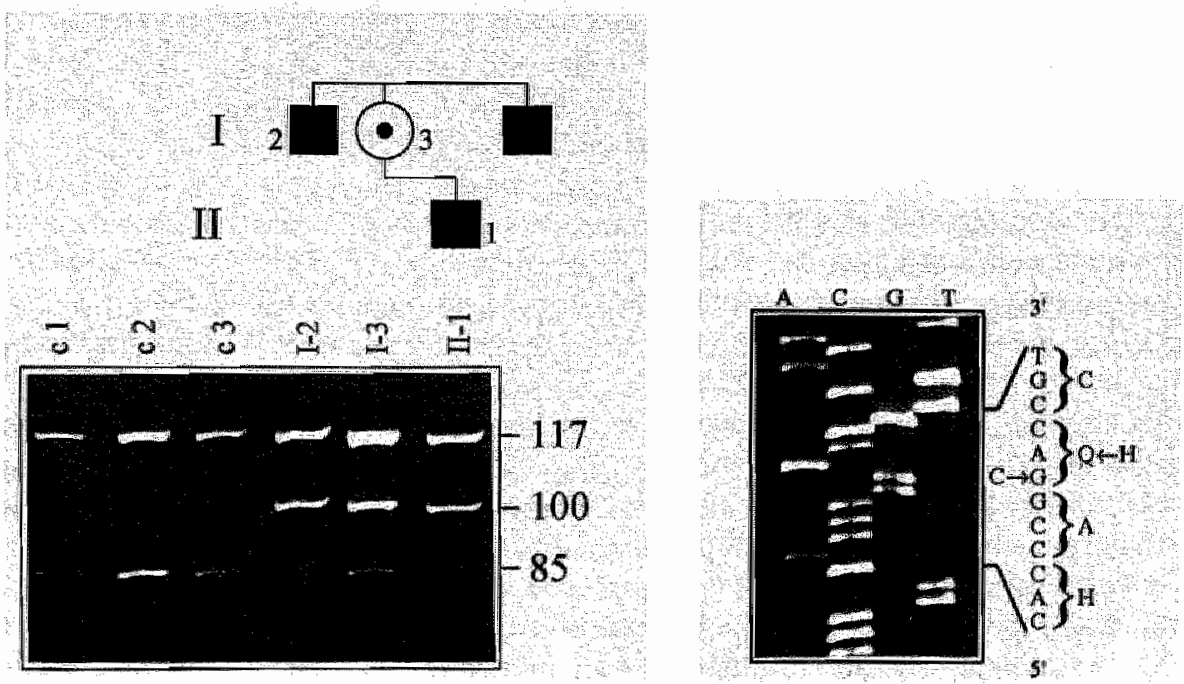

Figure 3a Pedigree and PCR analysis of exon 14 of MASA family 5. The three affected males (W) and the obligalle carriet (o) arre indicated. DNA of patient I-1 was, not available. The PCR shows, after digestion with BseNI, whree band:s of 117.85 and 15 bp in controls due to the presence of 2 BseNI sites. In the patients $1-2$ and II 1 two bands of 117 ard 100 bp are present due to absence of the second BseNI site. The obligate heterozygote I-3 has both undigested and digested bands. b: Audionadiograph of a sequenoing gel of part of the PCR profuct of exon 14. The arrow indicates the $O$ to $A$ point mulation. in L1CAM of patient 1-2, leading to a $D$ to $N$ substitution in the protein. 
the CDNA (13) in the second immunoglobulin domain (Fig.4b), replacing histidine at position 210 for glutamine. This H210Q mutation creates a new Hae III restriction site in the F11-G8 PCR product (Fig.4a). The H210Q mutation was not present in 100 control $X$ chromosomes, nor in the other seven MASA families or 65 HSAS families, indicating that the $H 210 Q$ mutation is a private mutation.

\section{B.5 DISCUSSION}

MASA syndrome and $X$-linked hydrocephalus (HSAS) have an overlapping clinical spectrum and similar gene localization in $\mathrm{Xq} 28$, suggesting that they might be allelic disorders. Several mutations $(8,14,26,32)$, have recently been identified in the LICAM gene in HSAS families. LICAM belongs to the immunoglobulin superfamily of cell adhesion molecules that contain domains similar to the $\mathrm{C}_{2}$ domains of immunoglobulins. The function of L1CAM is not yet understood completely but it is involved in neuronal cell migration, fascicula tion, outgrowth and regeneration $(18,22,30,37)$. It is a cellular adhesion molecule that is part of a network of cellular reactions that lead to morphogenesis of the nervous system. LICAM is expressed both in the brain and in the peripheral nervous system, and functions as a membrane-bound protein with an extra- and an intracellular cytoplasmic domain linked by a transmembrane domain.

To investigate whether LICAM is also implicated in MASA syndrome, we performed a mutation analysis in the LICAM gene of 8 MASA families.

Family 3 is a typical MASA family with 14 patients with mental retardation (14/14), aphasia (13/13), shuffling gait (8/13) and adduction of thumbs (14/14). The LICAM deletion found in this family is most probably the cause of the disease as it cosegregates with the disease, it is not found in the control population, and it disrupts the 
LICAM ORF. The mutation deletes the major part of the cytoplasmic domain of LICAM. Although the precise function of the cytoplasmic domain is unclear, it is probably essential in transmitting extracellular signals to the intracellular second messengers $(1,28,37)$. The importance of the cytoplasmic domain is further revealed by its high degree of interspecies conservation, and the identification of 2 different mutations in this domain: the deletion in the MASA family reported here and the duplication in the HSAS family described previously (32).

As no other gross rearrangements in LICAM have been observed in 52 MASA or HSAS families, we used SSCP analysis to screen for LICAM mutations. MASA family 5 consists of three male patients with mental retardation, delayed speech development and adducted thumbs, and shuffling gait. The D598N mutation found in this family replaces an aspartic acid that is conserved in homologous adhesion molecules in species such as mouse (23), rat (24), chicken (6) and drosophila (4), and therefore probably has an important function. This aspartic acid is located in the loop between the $B$-strands $F$ and $G$, seven aminoacids downstream of the cysteine involved in the characteristic disulfide bridging in immunoglobulin domains. The D598N mutation was not found in the control population, and we conclude that it is most probably the disease-causing mutation.

MASA family 4 is a two-generation pedigree with 5 males presenting with MASA syndrome and agenesis of the corpus callosum. The H210Q mutation in the second immunoglobulin domain is not present in controls, and no other mutations were found by SSCP analysis of all 28 exons of LICAM. The substitution of histidine, which has a basic side chain, by glutamine, which has an amide chain, will change the charge of the protein, and it is located next to the second disulfide bridge forming cysteine in the second immunoglobulin domain.

Since several LICAM mutations have now been found in both HSAS and MASA families, it is clear that HSAS and MASA are indeed allelic variants of the same disease gene. It is difficult to predict which mutations will give rise to hydrocephalus, as the different mutations found in MASA or HSAS up to now are "private" mutations, scattered throughout the gene, and of diverse nature -duplication, deletion, splice site mutation, branch point signal mutation, and missense mutation. The deletion of the major part of the cytoplasmic domain of LICAM in family 3 is located in the same region as the duplication previously identified in an HSAS family (32). We therefore investigated if the deletion and duplication could be the reciprocal result of unequal crossover in LICAM, such as is the case for Charcot-Marie-Tooth neuropathy $1 \mathrm{~A}$, caused by a duplication of chromosome $17 \mathrm{q}$, and hereditary neuropathy with liability to pressure palsies, which is caused by a reciprocal deletion (7). However, primer R12 at the 5'-end, is deleted in MASA family 3, but not duplicated in the HSAS family, and the 3 '-ends of the deletion and the duplication are separated by more than $700 \mathrm{bp}$. Therefore, these mutations cannot be the result of unequal crossover.

Detailed genotype-phenotype correlation studies will have to await the identification of more LICAM mutations in both HSAS and MASA. It is to be expected, however, that secondary factors, other than the L1CAM mutations, might contribute to the phenotype as a large intrafamilial variability is observed. It is also possible that 
mutations in L1CAM are responsible for nonspecific X-linked mental retardation. As some patients belonging to HSAS or MASA famillies, show no hydrocephalus, spastic paraparesis or adducted thumbs, but only mental retardation, L1CAM mutations might represent a frequent cause of inherited mental retardation.

\section{Acknowledgements}

We are indebted to C. Garret, M. Jones, L. Thompson and K. Zerres, S. Kenwrick, A. Rosenthal, K. Denecker, R. Bernaerts and N. Aerts for their help and contribution to this work. The mutations reported in this manuscript have independently been found by S. Kenwrick's group in Cambridge (UK).

Part of this study was supported by a grant from the Nationaal Fonds voor Wetenschappelijk Onderzoek (NFWO) to P.J.W., a grant from the Association Française contre les Myopathies to P.J.W. and a grant of the University of Antwerp to G.V.C. and P.J.W. G.V.C. holds a postdoctoral research position with the NFWO. 


\section{REFERENCES}

1. Atashi IR, Klinz SG, Ingrahan CA, Matten WT, Schachner M, Maness PF. Neural cell adhesion molecultes modulate tyrosine phosphorylation of tubulin in nerve growth cone membranes. Neuron 1992;8:831-842.

2. Bianchine JW, Lewis RC. The MASA syndrome: a new heritable mental retardation syndrome. Clin Genet 1974;5:298-306.

3. Bickers DS, Adams RD. Hereditary stenosis of the aqueduct of Sylvius as a cause of congenital hydrocephalus. Brain 1949;72:246-262.

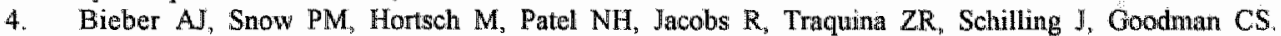
Drosophila neuroglian: a member of the immunoglobulin superfamily with extensive homology to the vertebrate neural adhesion molecule LI. Cell 1989;59:447-460.

5. Boyd E, Schwartz CE, Schroer RJ, May MM, Shapiro SD, Arena JF, Lubs HA, Stevenson RE. Agenesis of the corpus callosum associated with MASA syndrome. Clin Dysmorphol 1993;2:332-341.

6. Burgoon MP, Grumet M, Mauro V, Edelman GM, Cunningham BA. Structure of the chicken neuronglia cell adhesion molecule, $\mathrm{Ng}$-CAM : origin of the polypeptides and relation to the Ig superfamily. I Cell Biol 1991;112:1017-1029.

7. Chance PF, Alderson MK, Leppig KA, Lensch MW, Matsunami N, Smith B, Swanson PD, Odelberg SJ, Disteche CM, Bird TD. DNA deletion associated with hereditary neuropathy with liability to pressure palsies. Cell 1993;72:143-151.

8. Coucke P, Vits L, Van Camp G, Serville F, Lyonnet S, Kenwrick S, Rosenthal A, Wehnert M, Munnich A, Willems PJ. Identification of a 5 'splice site mutation in intron 4 of the LICAM gene in an X-linked hydrocephalus farnily. Hum Mol Genet 1994;3:671-673.

9. Dean M, Gerrard B. Helpful hints for the detection of single-stranded conformation polymorphism. BioTech 1991;10:331-332.

10. Edwards JH, Norman RM, Roberts JM. Sex-linked hydrocephalus; report of a family with 15 affected members. Arch Dis Childh 1961;36:481-485.

11. Fryns JP, Spaepen A, Cassiman JJ, Van den Berghe H. X-linked complicated spastic paraplegia, MASA syndrome and X-linked hydrocephaly due to congenital stenosis of the aqueduct of Sylvius: a variable expression of the same mutation at Xq28. J Med Genet 1991;28:429-431.

12. Gareis FJ, Mason JD. X-linked mental retardation associated with bilateral clasp thumb anomaly. Am J Med Genet 1984;17:333-338.

13. Hlavin ML, Lemmon V. Molecular structure and finctional testing of human LI. Genomics $1991 ; 11: 416-423$.

14. Jouet $M_{\mathrm{r}}$ Rosenthal $A$, MacFarlane J, Kenwrick $S$, Donnai $D$. A missense mutation confirms the L1 defect in X-linked hydrocephalus. Nature Genet 1993;4:331.

15. Kenwrick $\mathrm{S}$, Ionasescu $V$, Ionasescu $\mathrm{G}$, Searby $\mathrm{Ch}$, King $\mathrm{A}_{\mathrm{w}}$ Dubowitz M, Davies KE. Linkage studias of X-linked recessive spastic paraplegia using DNA studies. Hun Genet 1986;73:264-266.

16. Korn B, Sedlacek Z, Manca A, Kioschis P, Konecki D, Lehrach H, Poustka A. A strategy for the selection of transcribed sequences in the Xq28 region. Hum Mol Genet 1992;1:235-242.

17. Legius E, Kaepernick LA, Higgins JV Glover TW. Fine mapping of X-linked clasped thumb and mental retardation (MASA syndrome) in Xq28. Clin Genet 1994;45:165-168.

18. Lemmon $V$, Farr $K L$, Lagenaur $C$. LI-mediated axon outgrowth accurs via a homophilic binding mechanism. Neuron 1989;2:1597-1603.

19. Lyonnet S, Pelet A, Royer G, Delrieu O, Serville F, Le Marec B, Gruensteudel A, Pfeiffer RA, Briturd ML, Dubay C, Hors-Cayla MM, Le Merrer M, Munnich A. The gene for X-linked hydrocephalus maps: to Xq28, distal to DXS52. Genomics 1992;14:508-510.

20. Macias VR, Day DW, King TE, Wilson GN. Clasped-thumb mental retardation (MASA) syndrome confirmation of linkage to Xq28. Am J Med Genet 1992;43:408-414.

21. Maesirini E, Tamanini F, Kioschis $\mathbb{P}$, Gimbo M. Palmieri $G$, Poustka $A_{s}$ Toniolo D. An archipelago of $\mathrm{CpG}$ islands in $\mathrm{Xq} 28$ identification and fine mapping of 20 new $\mathrm{CpG}$ islands of the human $\mathrm{X}$ chromosome. Hum Mol Genet 1992,1:275-280. 
22. Miura $M$, Asou $\mathbb{H}$, Kobayash $M$, Uyemura $K$. Functional expression of a full-length cDNA coding for rat neural cell adhesion molecule Ll mediates homophilic intercellular adhesion and migration of cerebellar newrons. J Biol Chem 1992;267:10752-10758.

23. Moos M,Tacke R, Schcrer H, Teplow D, Fruh K, Schachner M. Neural adhesion molecule LI as a member of the immunoglobulin superfamily with binding domains similar to fibronectin. Nature $198 \% ; 334: 701-703$

24. Prince IT, Alberti L, Healy PA, Nauman SI, Stallcup WB. Molecular cloning of NILE glycoprotein and evidence for its continued expression in mature rat CNS. J Neurosc Res 1991;30;567-581.

25. Rietsched $M$, Friedl $W$, Uhlhas $S$, Neugebauer M, Heimann D, Zerres K. MASA syndrome: clinical variability and lirkage analysis. Am J Med Genet 1991;41:10-14.

26. Rosenthal $\mathrm{A}$ Jouet $\mathrm{M}$, Kenwrick $\mathrm{S}$. Aberrant splicing of neural cell adhesion molecule L1 mRNA in a family with X-linked hydrocephalus. Nature Genet 1992;2:107-112.

27. Schrander-Stumpel $C_{3}$ Legius $E_{3}$ Fryns JP, Cassiman JJ. MASA syndrome: new clinical features and linkage analysis using DNA probes. J Med Genet 1990;27:688-692.

28. Schuch $\mathbb{U}$, Lohse MJ, Schachner M. Neural cell adhesion molecules influence second messenger systemis. Neuron 1989;3;13-20.

29. Serville $F$, Lyonnet S, Pelet A, Reynaud M, Louail C, Munnich A, LeMerrer M. X-linked hydrocepham Lus: clinical heterogeneity at a single gene locus. Eur J Pediatr 1992;151:515-518.

30. Sonderegger $P$, Rathjen $F G$. Regulation of axonal growth in the vertebrate nervous system by interactions between glycoproteins belonging to two subgroups of the immunoglobulin superfamily. J Cell Biol $1992 ; 119: 1387-1394$.

31. Straussberg R, Blatt I, Brand N, Kessler D, Bat-Miriam Katzneison M, Goodman RM. X-linked mental retardation with bilateral clasped thumbs: report of another affected family. Clin Genet 1991;40:337341.

32. Van Camp G, Vits L, Coucke P, Lyonnet $S$, Schrander-Stumpel C, Darby J, Holden I, Munnich A, Willems $\mathbb{P}$. Duplication in the LICAM gene associated with $X$-linked hydrocephalus. Nature Genet $1993 ; 4: 421-425$.

33. Vles JSH. Fryns JP, Folmer K, Boon P, Buttiens M, Grubben C, Janevski B. Corpus callosum agenesis, spastic quadriparesis and irregular lining of the lateral ventricles on CT-scan. A distinct X-linked mental retardation syndrome? Genetic Counseling 1990;3:97-102.

34. Willems PJ, Browwer OF, Dijkstra I, Wilmink J. X-linked hydrocephalus. Am I Med Genet $1987 ; 27: 921-928$

35. Willems PJ, Dijkstra I, Van der Auwerda BJ, Vits L, Coucke P, Raeymakers $P$, van Broeckhowen C, Consalez GG, Freeman SB, Warren ST, Brouwer OF, Brunner $\mathrm{HG}$, Renier WO, van Elasen $A F$, Dumon JE. Assignment of X-linked hydrocephalus to Xq28 by linkage analysis. Genomics 1990;8:367370 .

36. Willems PJ, Vits L, Raymackers P, Beuten J, Coucke P, Holden JJA, van Broeckhoven C, Warren ST, Sagi $M$, Robinson $D$, Dennis $\mathbb{N}_{\text {s }}$ Friedman KS, Magnay $D$, Lyonnet $S$, White $B N$, Wittwer $B H$, Aylsworth AS, Reicke S. Further localization of X-linked hydrocephalus in the chromosomal region Xq28. Am Hum Genet 1992;51:307-315.

37. Williams EJ, Doherty $P$, Turner $G_{5}$ Reid A, Hemperly JJ, Walsh FS. Calcium influx into neurons can solely account for cell contact-dependent neurite outgrowth stimulated by transfected L1. J Cell Biol 1992;119:883-892.

38. Winter RM, Davies KE, Bell MV, Huson SM, Patterson MN. MASA syndrome: further clinical delineation and chromosomal localisation. Hum Genet 1989;82:367-370.

39. Yeatman GW. Mental retardation-clasped thumb syndrome. An I Med Genet 1984;17:339-344. 


\section{Chapter 5C}

$\mathrm{X}$-linked hydrocephalus and MASA syndrome present in one family are due to a single missense mutation in exon 28 of the L1CAM gene

Erik Fransen, Connie Schrander-Stumpel, Lieve Vits, Paul Coucke, Guy Van Camp, Patrick J. Willems 


\section{C.1 INTRODUCTION}

X-linked hydrocephalus (HSAS) is a recessive X-linked form of Hydrocephalus, sometimes associated with Stenosis of the Aqueduct of Sylvius. The symptoms of HSAS are highly wariable and include mental retardation, hydrocephalus, spasticity of the lower limbs and clasped thumbs $(2,16)$. MASA is an acronym for Mental retardation, Aphasia, Shuffling gait and Adducted thumbs (1). This X-linked recessive disorder has a variable and very wide clinical spectrum often including hydrocephalus, macrocephaly and agenesis of the corpus callosum, symptoms also present in HSAS. We previously suggested that HSAS and MASA could be allelic for three reasons: i) both conditions show an overlapping clinical spectrum, ii) there exist severall reports on families that contain HSAS patients as well as MASA patients $(3,12,13)$ iii) both diseases are linked to $\mathrm{Xq} 28(8,12,17,18)$. Following demonstration that $\mathrm{X}$-linked hydrocephalus is due to mutations at the locus for the neural cell adhesion molecule L1CAM (11), we and others showed that MASA syndrome is also due to mutations in this gene $(4,6,7,14,15)$.

Here we report a missense mutation in exon 28 of the LICAM gene in this family. This mutation is responsible for both HSAS and MASA, confirming that both diseases are variable expressions of the same gene defect.

\section{C.2 PATIENTS}

The family reported here was one of the first in which the co-occurrence of HSAS and MASA patients was noticed. It contains two affected males (IV:2 and III:2) with the typical symptoms of MASA syndrome (13). A third male in the family was born hydrocephalic; he died at the age of 15 years in an institute for the mentally handicapped. At that time, he had extreme macrocephaly, severe spasticity and mental retardation (13).

\section{C.3 MOLECULAR STUDIES AND RESULTS}

Southern blotting of patient IV:2 was performed using restriction enzymes EcoRI, BamHI, TaqI, BgIII, HindIII and Pstl, and hybridization with a cDNA probe containing the complete L1CAM open reading frame. However, no abnormalities could be detected (data not shown).

Genomic PCR was carried out

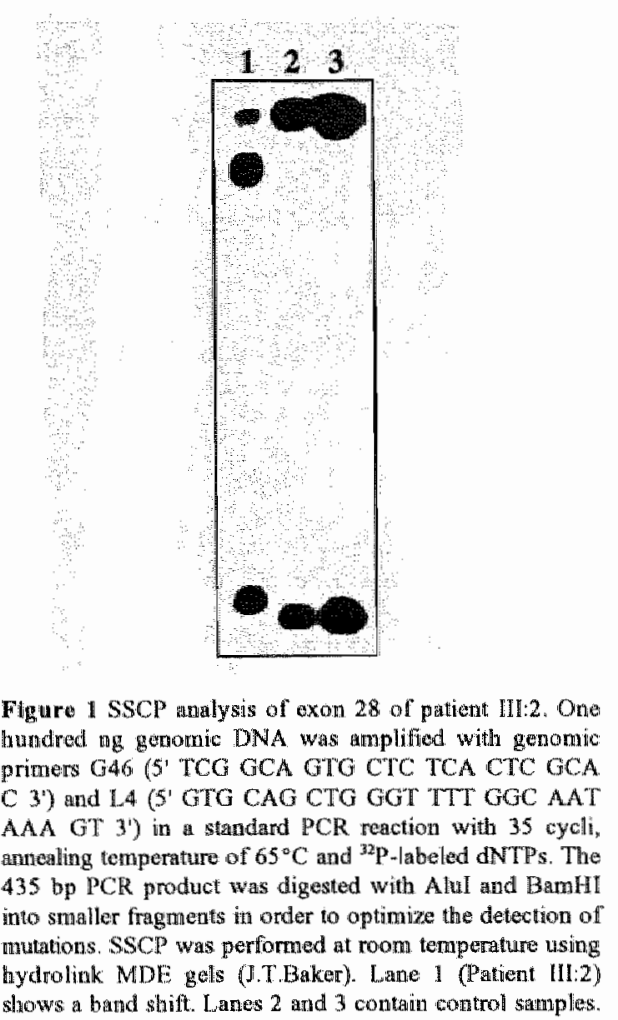


exon 28 and part of the $3^{\prime}$ untranslated spacer of LICAM. As previous SSCP (Single Stranded Conformation Polymorphism) anallysis of this long PCR product of 436 bp did not reveal any mutations (15), an Alul/BamHI digestion was carried out to cut the $P C R$ product into five fragments of $227,85,72,46$, and 4 $\mathrm{bp}$, respectively. SSCP analysis of the male patient IV: 2 showed a band shift (Fig. 1), which was never observed in controls. Sequencing of the subcloned PCR product (not shown) revealed a C to $\mathrm{T}$ mutation in exon 28 at position 3581 of the LICAM cDNA sequence (position $\mathbf{1}=$ the AUG starting codon) (5). This missense mutation causes a Ser to Leu substitution in the cytoplasmic domain of the L1CAM molecule at amino acid position 1194 .

As no known restriction sites were created or lost by the S1194L mutation, a modified primer R2M was designed flanking the mutation, creating an artificial Bcll site in patients but not in normals. Genomic PCR using normal primer G46 and modified primer R2M in controls typically yields a fragment of $99 \mathrm{bp}$ without BclI sites. In patients III:2 and IV:2 however, this PCR product is cut by BclI into two novel

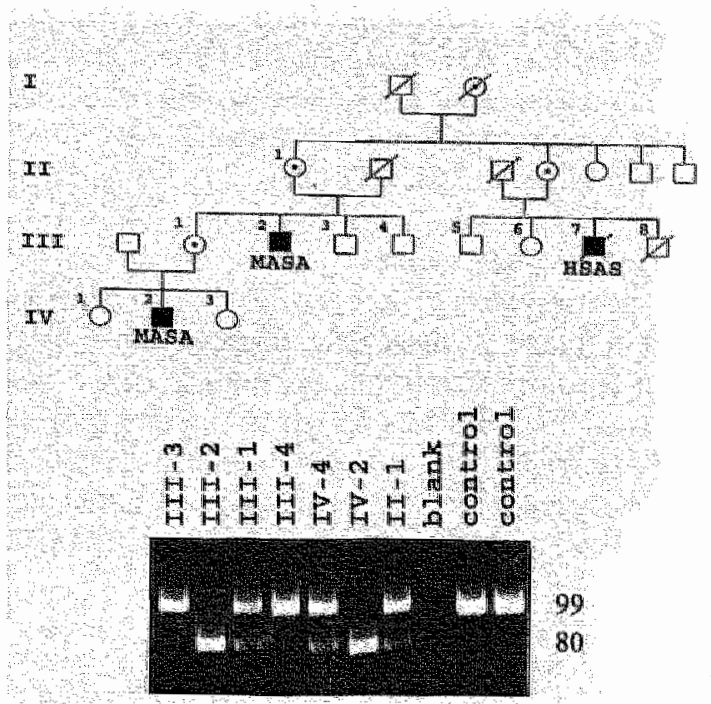

Figure 2 Podigree and modified PCR analysis of the MASAJISAS family. Familly members II:2 and IV:2 ane typical MASA patients, whereas III 7 died from severe hydrocephalus. The PCR was performed with primer $\mathrm{O} 46$ and a modified primer R2M (5 CTT GAT GTC CCC GTT GAT C 3'), which is located in exon 28 . The PCR product was digested with Bell. The digested fragments were separated an a $6 \%$ polyaerylamide gel using ethidumbromide staining. In healthy controls an unetut band of 99 bp is present, whereas affected patients 1112 and $1 V_{2}$ have a band of $80 \mathrm{bp}$ and a band of 19 bp hot visible on this gel), due to the presence of a nowel Bell site. The earriers Il: 1 , III: 1 and IV:3 show both fragnents. fragments of 80 and $19 \mathrm{bp}$, respectively.

Female heterozygotes II: 1, III: 1, IV: 1 and IV: 3 show both the digested and undigested fragments (Fig.2). Using this screening method, we also investigated 65 additional HSAS or MASA families. As the S1194L mutation was not found in any of these families, it is a private mutation, which is also the case for all other LICAM mutat-ions found up to now $(4,6,7,11,14,15)$. To exclude that the S1194L mutation was a common polymorphism, we screened 50 independent female controls, but the mutation was never found (data not shown).

\section{C.4 COMMENTS}

The cytoplasmic domain is the most conserved domain of LICAM, which indicates its functional importance. The mutated Ser residue is conserved in mouse (11CAM), rat 
(NILE), Drosophila (Neuroglian) and in chick NgCAM. Substitution of this very conserved hydrophilic Serine by a hydrophobic Leucine probably affects the function of the LICAM cytoplasmic domain and causes the HSAS/MASA phenotype.

This mutation in a family with both X-linked hydrocephalus as well as MASA syndrome confirms our revious suggestion that both syndroms are allellic and due to mutations in LICAM (15).

\section{Acknowledgements}

The assistance of R. Clerckx, R. Bernaerts and N. Aerts in preparing the manuscript and the figures is gratefully acknowledged. We are very much indebted to Sue Kenwrick and André Rosenthal for release of the genomic sequence of the LICAM gene. We thank J.J. Cassiman for providing DNA samples from this family. Part of this study was supported by a grant from the Nationaal Fonds voor Wetenschappelijk Onderzoek (NFWO) to P.J.W., by a concerted action of the University of Antwerp to G.V.C. and P.J.W. G.V.C. holds a postdoctoral research position with the NFWO. 


\section{References}

1. Bianchine JW, Lewis RC. The MASA syndrome: a new heritable mental retardation syndrome Chin Genet $1974 ; 5: 298-305$.

2. Bickers DS, Adams RD. Hereditary stenosis of the aqueduct of Sytwius as a cause of congenital hydrocephalus. Brain 1949:72:246-262

3. Boyd E, Schwartz CE, Schroer RJ, May MM, Shapino SD, Arena IF, Lutws HA, Stevenson RE. Agentesis of the corpus callosum associated with MASA syndirome. Clin Dysmorphol 1993;2:332-341.

4. Coucke $P$, Vits L, Van Camp $G$, Serville F, Lyonnet $S$, Kenwrick $S$, Rosenthal A, Wehnert M, Munnich $A$, Willems PJ. Identification of a 5 'splice site mulation in intron 4 of the LICAM gene in an X-linked hydrocephalus familly. Hum Mol Genet 1994:3:671-673.

5. Hlawin ML Lemmon V. Molecular structure and functional testing of human LI. Genomics $1991 ; 11: 416-423$.

6. Jouet $\mathrm{M}$, Rosenthal $\mathrm{A}$, MacFarlane $\mathrm{J}$, Kenwrick $\mathrm{S}$, Donnai $\mathrm{D}$. A missense mutation confirms the $\mathrm{L}$ I defect in X-linked hydrocephalus (HSAS). Nature Genet 1993;4:331.

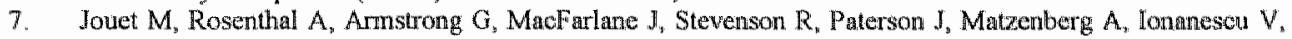
Temple K, Kenwrick S. X-linket spastic paraplegia (SPGI), MASA syndrone and X-linked hydrocephalus result from mutations in the L1 gene. Nature Genet 1994; 7:402-406.

8. Kenwrick $\mathrm{S}$, Ionasescu $V$, Ionasescu $G$, Searby $\mathrm{Ch}$, King A, Dubowitz M, Davies KE Linkage siudies of Xlinked recessive spastic paraplegia using DNA probes. Hun Genet 1986;73:264-6.

9. Macies VR, Day DW, King TE, Wilson G. Clasped-thurnb mental retardation (MASA) syndrome: confinmation of linkage to Xq28. Am J Med Genet 1992;43:408-414.

10. Rathjen $\mathrm{PG}$, Schachner M. Immunocytological and biochemical characterisation of a new neuronal celi surface: component (L.1 antigen) which is involved in cell adhesion. EMBO I 1984;3:1-10.

11. Rosenthal A, Jouei M, Kenwrick $S$. Aberrant splicing of neural cell adhesion molecule L1 mRNA in a fanuily with X-linked hydrocephalus. Nature Genet 1992;2:107-112

12. Sehrander-Stumpel $C$, Meyer H, Merckx D, Jones $M$, Israel $J$, Sonmer A, Stevens $C$, Tinschert $S$, Wison $G$, Willems P. Legius E, Fryns JP. The spectrum of "complicated spastic paraplegia, MASA syndiome and Xlinked hydrocephalus"'. Contribution of DNA linkage analysis in genetic counseling of individual families. Genetic Counseling 1994;5:1-10.

13. Schrander-Stumpel CTRM, Legius E, Fryns JP, Cassiman JJ MASA syndrome : new elinical features and linkage analysis using DNA probes. J Med Genet 1990;27:688-692.

14. Van Camp G, Vits $\mathbb{L}$, Coucke P, Lyonnet $S$, Schrander-Stumpel $C_{3}$ Darby J, Holden J, Munnich A, Willems $P$. A duplication in the LICam gene asociated with $X$-linked hydrocephalus. Nature Genet $1993,4: 421-425$.

15. Vits $\mathbb{L}$, Van Camp $G$, Coucke ${ }^{2}$, Wilson $G$, Schrander-Stumpel C, Schwartz C, Willems P. MASA syndrome is due to mutations in the LICAM gene. Nature Genet 1994;7:408-414.

16. Willems PJ, Brouwer OF, Dijkstra I, Wilmink J. X-linked hydrocephalus. Am J Med Genet 1987;27:92 l-928.

17. Willems PJ, Dijkstra I, Van der Auwerda BJ, Vits L, Coucke P, Raeymakers P, van Broeckhoven C, Consalez: GG, Freeman SB, Warren ST, Brouwer OF, Brunner HG, Renter WO, van Elasen AF. Dumon. JE. Assignment of X-linked hydrocephalus to Xq28 by linkage analysis. Genomics 1990;8:867 870.

18. Willerns JP, Vits L, Raymaekers P, Benten J, Coucke P, Holden JIA, van Broeckhoven C, Warren ST, Sagi M, Robinson D, Dennis N, Friedman KS, Magnay D, Lyonnet S, White BN, Wittwer BH, Aylsworth AS, Reicke S. Further localization of X-linked hydrocephalus in the chromosomal region Xci28. Am J Hutum Genet 1992;51;307-315. 


\section{Chapter 6}

$\mathrm{X}$-linked mental retardation and neurological symptoms: a nosological approach

Connie Schrander-Stumpel, Chris Höweler, Jean Pierre Fryns

$\overline{\text { Genetic Counseling 1995,6:21-32 }}$ 


\subsection{ABSTRACT}

Various clinical classifications of XLMR have been reported. In a recent review on Xlinked mental retardation (XLMR) genes, 127 conditions featuring XLMR as a primary or major manifestation were listed (Neri et al., 1994). In our clinical departments, we have a special interest in families of male patients with mental retardation and neurological symptoms. Since the combination of XLMR and neurological manifestations could be found in almost all categories of the previously reported classifications, we outlined a nosological approach meant for those cases where other specific symptoms are lacking.

\subsection{INTRODUCTION}

Mental retardation (MR) is common in Europe and the USA, with an estimated 2-3\% incidence in all newborns $(12,34)$. Studies of the mentally retarded population have consistently indicated that the number of males exceeds the number of females by maximally $25 \%$ (21). This excess of males among mentally retarded individuals has been recognized since the beginning of this century. Several families with a sex-linked pattern of mental retardation have been reported, the Martin-Bell family in 1943 and the Allan-Herndon-Dudley family in 1944 being well-known examples (44). In the early Seventies, the psychologist Lehrke hypothesized that X-linked genes could account for the (earlier recognized) male excess in the mentally retarded population (26). After the discovery and confirmation of the fragile $X$ syndrome $(27,45)$ the existence of X-linked mental retardation (XLMR) was further acknowledged, and research on XLMR genes developed rapidly. The Martin-Bell family appeared to be a fragile X family; the Allan-Herndon-Dudley syndrome could be linked to a locus at Xq13-q21 (44). Fragile X syndrome, after Down syndrome the second most frequent genetic cause of mental retardation, accounts for $40 \%-50 \%$ of the XLMR patients (50); about $10-15 \%$ are clinically recognizable (or yet "unknown") syndromes and the remainder is formed by the the families with so-called nonspecific X-linked mental retardation.

\subsection{CLASSIFICATION OF XLMR}

Any classification of XLMR has a relative importance in practical use. To the clinician, a classification by symptom will be of use. A pediatrician will look into features present at a young age in children with developmental delay, whereas a physician in an institute for the mentally disabled will focus on the adult phenotype. Age at diagnosis, e.g. clinical evolution in time, is important but often not reported. To the (molecular) geneticist a classification by gene location will be useful $(32,42)$.

In order to recognize previously reported conditions featuring XLMR, Glass (21) made a classification by clinical manifestation (Table 1). Not included in his classification were conditions associated with frank regression (e.g. adreno- 
leucodystrophy), delineated metabolic defects, well-described myopathic disease such as Duchenne muscular dystrophy and nonspecific mental retardation.

Table 1

Classinfoation of XLMUR by Glass (21).

\author{
1. with macrocephaly \\ 3. with macto-orchidism \\ 5. with skin disease \\ 7. with dysmorphic femtures \\ 9. with visual dysfunction
}
2. with microcephaly
4. with hypogonadism
6. with neurological features
8. with skeletal/stature anomalies
10. with deafness

This classification is of practical importance for the clinician: several conditions can be found in more than one section, enhancing the chances for making a diagnosis.

Many patients with XLMR manifest neurological symptoms; clinical recognition often depends on accompanying features such as dysmorphism, congenital malformations and eye or ear anomalies. In the clinical classification made by Glass (21), neurological symptoms were not a main entry and conditions featuring meurological symptoms were represented in every subgroup.

The number of known forms of X-linked mental retardation has rapidly increased in recent years. In their 1992 update on XLMR genes, Neri et al. could list 77 conditions (31). In the 1994 update (32), $127 \mathrm{X}$-linked conditions featuring mental retardation were reported. In the latest update, inclusion criteria were less restrictive, and metabolic disorders are now included. 80 of these X-linked conditions had a MIM (McKusick's catalogue of Mendelian Inheritance in Man) number (28); for 53 the gene had been regionally mapped and for 15 conditions the gene had been cloned. Mostly for mnemonic purposes Neri et al. subdivided the XLMR conditions into 5 major classes (Table 2).

Table 2

Subdivision of XLMR conditions by Neri at al(32)

1. Syncromes, te clinically recogmizable conditions

2. Dominant disorders, lethal in males

$\begin{array}{r}57 \\ 6 \\ 12 \\ 30 \\ 22 \\ \hline 127\end{array}$


Examples of syndromal forms of XLMR are FG syndrome and Coffin-Lowry syndrome. More recently recognized syndromal forms of XLMR with a presumed localisation and a lod score of above +2 have been given an MRXS number (30). Rett syndrome and Goltz syndrome are examples of X-dominant conditions with presumed lethality in males. Hunter syndrome and Lesh-Nyhan syndrome are examples of metabolic disorders. The group listed as "neuromuscular" disorders (a somewhat confusing term from a neurologists point of view, since this group lists a broader spectrum of diseases than the purely neuromuscular conditions) lists those forms of $\mathrm{XLMR}$, in which neurological features other than mental retardation (including impairment of vision and/or hearing) are involved. Examples in this group are Duchenne muscular dystrophy, X-linked spinocerebellar ataxia and X-linked hydrocephalus with stenosis of the aquaductus Sylvii (HSAS). In the nonspecific XLMR group 22 families, showing linkage to 18 loci at the X-chromosome, were listed. Where a locus assignment with a lod score above +2 was made, an MRX number (non-specific mental retardation symbol) had been assigned (30).

Looking at this recent update on XLMR genes (Table 2), we found neurological symptoms to be present not only in the section on "neuromuscular" disorders, but also in the first 3 classes of the subdivision: the syndromal group, the dominant disorders (e.g. Rett syndrome or Aicardi syndrome) and the metabolic disorders (e.g. Menkes syndrome). In these groups however, "neurology" did not provide a major contribution to clinical diagnosis.

In oúr departments, we take a special interest in male patients who combine mental retardation and neurological symptoms. Since the combination of XI_MR and neurological manifestations (in addition to many other symptoms) could be found in almost all categories of the previously mentioned classifications, we outlined a nosological approach based on more detailed neurological symptoms. We excluded clinical reports and/or families where additional manifestations could lead to a clinical diagnosis using the presently available classifications. The neurological symptoms listed in the following approach were selected on the basis that they are commonly encountered in clinical genetic practice. Our sources were the "basic instruments" of the clinical geneticist: (recent) literature, the classifications reported by Glass (21) and Neri et al. (32), the London Neurology Database (LNDB)(4), McKusick's catalogue (28) and Buyse's encyclopedia of birth defects (14) with updates in the journal "Dysmorphology and Clinical Genetics".

\subsection{NOSOLOGICAL APPROACH OF XLMR AND NEUROLOGICAL SYMPTOMS}

\subsubsection{XLMR with hypotonia}

Hypotonia is an important clinical symptom in the neonatal period and in early infancy. Boys with fragile $X$ syndrome who do not yet show specific dysmorphic signs in early childhood, are hypotonic. Hypotonia is a main feature in the X-linked Coffin-Lowry syndrome (MIM *303600) and in FG syndrome (MIM *305450). 
Hypotonia may change into hypertonia after 2-5 years in many supratentorial cerebral malformation syndromes (38). In cerebellar hypoplasia, the hypotonia is a constant and persistent finding (38).

\subsubsection{XLMR with epilepsy}

Epilepsy is included in the clinical spectrum of many conditions featuring XLMR. In the subdivision made by Neri et al.(32), epilepsy can be found in the syndromal group (e.g. FG syndrome), in the X-dominant disorders (for instance Aicardi syndrome, MIM *304050), in the metabolic diseases (such as Menkes syndrome), the "neuromuscular" group and in the non-specific XLMR families. Time of onset, type of convulsions, and additional clinical features are all important discriminating factors in making a clinical diagnosis. XLMR and epilepsy without additional anomalies is present in X-linked infantile spasms (MIM 308350).

\subsubsection{XLMR with spasticity, and/or ataxia (and/or chorea-athetose).}

Although neurologically peculiar, the combination of spasticity, ataxia and choreaathetose has been reported in several genetic conditions. When performing a computer search (LNDB) on XLMR and spasticity/brisk reflexes, 33 conditions were selected (4). The combination of XLMR and ataxia was listed on 24 records (4) with overlap between these 2 searches for 13 entities. Our findings are given in Table 3 . In this table, clinical symptoms are placed between brackets, when they are not the main symptoms. The disorders were listed according to McKusick numbers.

Two X-chromosomal loci are known to be associated with complicated spastic paraplegia: Xq21, SPG2 (9), and Xq28, SPG1 (MIM *312900)(23). SPG1, "MASA" syndrome (7) (acronym for Mental retardation, Aphasia or slow speech development, Shuffling gait or spastic paraplegia, and Adducted thumbs) and X-linked hydrocephalus (HSAS) have been shown to be allelic conditions caused by mutations in LICAM $(18,57,58)$. Possibly, the complicated $X$-linked corpus callosum agenesis $(X$-linked CCA, MIM *304100;52,53) belongs to this clinical spectrum as well (41). Secondly, Pelizaeus-Merzbacher disease and SPG2 appeared to be allelic disorders at the PLP (proteolipid protein) locus at Xq21 (39). It is not clear whether the family with spastic paraplegia reported by Davis (MIM 309640) fits into the spectrum of HSAS/MASA syndrome.

Cerebellar ataxia is found in several XLMR families, sometimes in combination with deafness or dementia (see Table 3). In X-linked cerebellar ataxia (MIM *302500) nystagmus develops during the early months of life, followed by a truncal ataxia and evidence of yramidal tract involvement. In Pettigrew syndrome (MRXS5, MIM *304340), patients manifest hypotonia, spasticity, ataxia and seizures; DandyWalker anomaly, hydrocephaly, and basal ganglia disease are part of the phenotype. Spastic athetotic paraplegia was the characteristic clinical manifestation in a Dutch XLMR family (MIM 312890)(3). In Lesch-Nyhan and Pelizaeus-Merzbacher 
syndrome, both progressive metabolic diseases, athetose is part of the clinical spectrum.

Trable 3

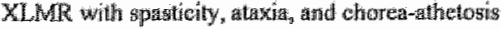

\begin{tabular}{|c|c|c|c|c|c|}
\hline Disorder & Spastici & Athitile & horea & MMM & Locus \\
\hline Adrenoleucodyontropthy & $+*$ & 4 & & $\$ 300100$ & $X \lg ^{28 *}$ \\
\hline Alaxiat deafness & & + & & 301790 & \\
\hline Misxia plus dementia & $(+9)$ & 4 & & 301840 & \\
\hline Cenebellain ataxia (Aprak) & $(4)$ & 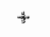 & & 302500 & \\
\hline Cerebellatue ataxia with extrapyramidal involwement & & t & & 302600 & \\
\hline Dandy-Walker, bastal ganglia discase and seizures (Pettigrew) & 4 & + & + & 304340 & \\
\hline MSASMAMA symdrome/SJCI & + & $(+\infty)$ & & $* 307000 / * 303350 / * 312900$ & $X q 28$ \\
\hline Hydrocephalus with cerebellar agenesis & $(+)$ & + & & 307010 & \\
\hline Lesereh-Nylhan & + & + & & 308000 & $\mathrm{Xg} 26.1 * *$ \\
\hline Dystono movements, ataxia and seizures (Partington, MRXS1) & )+ & H & & 309510 & \\
\hline Nypotonia and muscular atrophy (Allan-Herndon-Dudlley') & 4 & $(+)$ & $(+)$ & 309600 & $\mathrm{Xq}_{21}$ \\
\hline Spratic paraplegial (Davis) & + & & & 309640 & \\
\hline 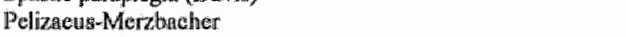 & $\$$ & i. & & $\$ 12080$ & $\operatorname{Xa} 21-22 *$ \\
\hline Pyruvate dehydrogenase deficienoy & + & 4it & + & $* 312170$ & $\mathrm{Xq} 22 *$ \\
\hline Choreonthetosis (Sehinke) & $(t)$ & & + & 312840 & \\
\hline Spastic athetotic paraplegia (13atr-Gabriel) & + & $(\stackrel{*}{*})$ & + & 312890 & \\
\hline$\$$ pastic paresis + deaf ness & + & & & 312910 & \\
\hline Goldidatt (SPG2) & + & (3) & & $* 312920$ & \\
\hline Arente el kal. (2) & + & (*) & & & \\
\hline Bentini ef all. (6) & & + & & & \\
\hline Vles et al. $(52,53)$ & + & $(+)$ & & & \\
\hline
\end{tabular}

* geres cloned $(y=$ not the maljor feature

\subsubsection{XLMR with choreoathetosis and dystonia}

Extrapyramidal signs have been reported in a number of conditions with XLMR (Table 4). In the rare X-linked dystonia syndrome (MIM 305050), sensoneurinal deafness and possible mental impairment were found as additional features; linkage analysis placed the locus to $\mathrm{Xq} 12-\mathrm{q} 21$ (25).

Tuble 4

XCMR with chorcoathetose and dyotonia.

Disionder

Spustio athetotie paraplegita

Leseh.-Wiyhan syndrome

Pellizacus Merzlacher syndrome

Dystonie movements, atuxia and seizurtes (Partington, MRXS1)

X:linked basal ganglia disorder with mental retardation

(Waismanm laxown syndrotne)

X. llinked dystonia syndrome
MIM lootas

$* 312080$

*309510

$\mathrm{Xq} 21-22 *$

*311510

$305050 \quad \times q 12-21$

**gente oloned 


\subsubsection{XLMR with neuromuscular disease}

Although many $X$-linked neuromuscular disorders do not manifest mental retardation, the following conditions could be listed (Table 5).

Table 5

XLMR with neuromuscular disease.

\begin{tabular}{|c|c|c|}
\hline Disorder & MTW & lowus \\
\hline $\begin{array}{l}\text { Muscular dystroplay Duchentue type } \\
\text { X-linked motor-sensory newiropathy type II with deafness (15) } \\
\text { Wieacker-Wolf syndrome }(54,55)\end{array}$ & +310200 & $\begin{array}{l}\mathrm{Xp} 21^{* *} \\
\mathrm{Xq}_{\mathrm{q}} 13 \% \\
\mathrm{Xq} 13-21\end{array}$ \\
\hline
\end{tabular}

About $20 \%$ of boys affected with Duchenne type muscular dystrophy have IQ's of less than 70 , and $3 \%$ have IQ's of less than 50 (17). In the family with X-linked motorsensory neuropathy reported by Chowchock (15), affected males had sensorineural deafness with childhood onset; $3 / 7$ affected patients were mentally slow. In WieackerWolf syndrome, affected patients manifest congenital contractures of the feet in addition to slowly progressive distal muscular atrophy and oculomotor apraxia (54).

\subsubsection{XLMR with microcephaly}

Microcephaly, defined as an occipitofrontal circumference (OFC) 2 or more standard deviations below the mean for age and sex (33), can be subdivided into at least 3 categories: a pure form, microcephaly in combination with other anomalies, and a progressive microcephaly. In pure microcephaly, no additional features are present and brain imaging is generally normal. An X-linked form of pure microcephaly has been reported (see Table 6). Many forms of syndromal X-linked microcephaly are known; an example is the Borjeson-Forssman-Lehman syndrome (MIM *301900). In Renpenning syndrome of nonspecific XLMR (MIM *309500), head circumferences tended to be small. Progressive microcephaly may be found in Pelizaeus-Merzbacher syndrome and in some patients with Rett syndrome. 
Tithlo 6

XINMR with microcephaty.

\begin{tabular}{|c|c|c|}
\hline Dingorder & WIM & locus \\
\hline$X-1$ iniked CCA & $* 304100$ & \multirow{9}{*}{$x p 21.1-q 12$} \\
\hline Pelizatus-Merdhacher syndrome & $\$ 312080$ & \\
\hline Pyruwate defrydrogertase deficiency & $* 312170$ & \\
\hline Renpenning syndrome & $\$ 309500$ & \\
\hline \$ay-Meyer syndrome (with trigonocephaly and shot stature) & 31.4320 & \\
\hline $\begin{array}{l}\text { Sehimke syndrome (with ophthalmoplegiand and spastic } \\
\text { paraptic gis) }\end{array}$ & 312840 & \\
\hline X.linked microesphaly & 311400 & \\
\hline MRX2, with spatistic para pareds ( 46 ) & & \\
\hline$X$-linked CCA $(52,53)$ & & \\
\hline
\end{tabular}

\subsubsection{XLMR with macrocephaly}

Macrocephaly has been defined as a proportionately enlarged brain, recognized by an increased $O F C$, or by an increased brain weight at autopsy (13) (the next subheading deals with XLMR and hydrocephalus). Syndromes like fragile $X$ syndrome, FG syndrome (MIM *305450), Lujan-Fryns syndrome (MIM *309520), Simpson-GolabiBehmel syndrome (MIM *312870), and Prieto syndrome (MIM *309612)(MRXS2) may present with macrocephaly. Metabolic diseases (e.g. Hunter syndrome) may manifest macrocephaly as well. In the group of "neuromuscular disorders" according to Neri et al. (32) macrocephaly (without hydrocephalus) is part of the clinical spectrum of X-linked hydrocephalus/MASA syndrome. Some of the "nonspecific" XLMR families manifested macrocephaly $(24,35,49)$. The main neurological conditions featuring XLMR and macrocephaly are given in Table 7 .

Table 7

XLMR with manrocephaly.

\begin{tabular}{|c|c|c|}
\hline Disorder & MM & locuss \\
\hline $\begin{array}{l}\text { Waisman-Laxowa syndrone } \\
\text { HSASMASA symdrome } \\
\text { Apraxia, ataxia, olubtetet (48) } \\
\text { XLMR with motherocephaly (49) }\end{array}$ & $\begin{array}{l}* 311510 \\
307000 * 303350\end{array}$ & $\begin{array}{l}\mathrm{Xq} 28^{* *} \\
\text { pericentromeric }\end{array}$ \\
\hline
\end{tabular}

* gent oloned

\subsubsection{XLMR with hydrocephalus}

$\mathrm{X}$-linked hydrocephalus (HSAS)(MIM*307000) is the most common genetic form of XLMR and hydrocephalus; clinical presentation varies from lethal in utero or early infancy to survival with mental retardation, spastic paraplegia and adducted thumbs (MASA syndrome, MIM *303350)(7,16,19,40,56) 
Table 8

XLMR with thydrocephatus.

Disorder $\quad$ MM laetus

HSASMMASA syndrome

Dandy-Waker and basal ganglia disease (Pettigrew, MRXS5)

Pyruwate dehydrogenase def.

Ataxia and seizures, clubfeet (48)

Renter et al (37)
$\$ 307000 / 303350 \times 28 * *$

304340

$\$ 12170$

* gene claned

Hydrocephalus or large ventricles may be found in some other XLMR conditions (see Table 8). In the fragile $X$ syndrome, hydrocephalus or large ventricles have been reported in case reports only $(47,51)$. Hydrocephalus can be found in FG syndrome; it is a component of the syndrome consisting of hydrocephaly, obesity and hypogenitalism (43) and Pettigrew syndrome (MIM *304340). In the family reported by Renier et al. (37), 2 brothers and their maternal uncle were reported; in addition to mental retardation they showed cerebellar hypoplasia and communicating hydrocephalus.

\subsubsection{XLMR with corpus callosum agenesis}

Complete or partial agenesis of the corpus callosum (CCA) is a common cerebral malformation which often has only subtle clinical expression (38). Data on CCA are biased because (in general) brain imaging is usually performed for restricted indications only. In the population with XLMR (Table 9), CCA has been reported in many syndromes (e.g. Lenz microphthalmia, (MIM *309800), FG syndrome (MIM *305450), Lujan-Fryns syndrome (MIM*309520), or in combination with other cerebral malformations as lissencephaly (5) and $X$-linked hydrocephalus (HSAS)/MASA syndrome, where CCA is a common finding. It is not clear whether the condition of XLMR, CCA, acquired micrencephaly and seizures (36), represents a different entity than the one reported as (complicated) X-linked CCA $(20,29)$. The males with complicated X-linked CCA (MIM *304100) $(22,29)$ and those reported by Vles et al..(52,53) may all fit into the spectrum of HSAS/MASA syndrome/SPG1 (4.1). 
Thalle

XIMIE with CCA.

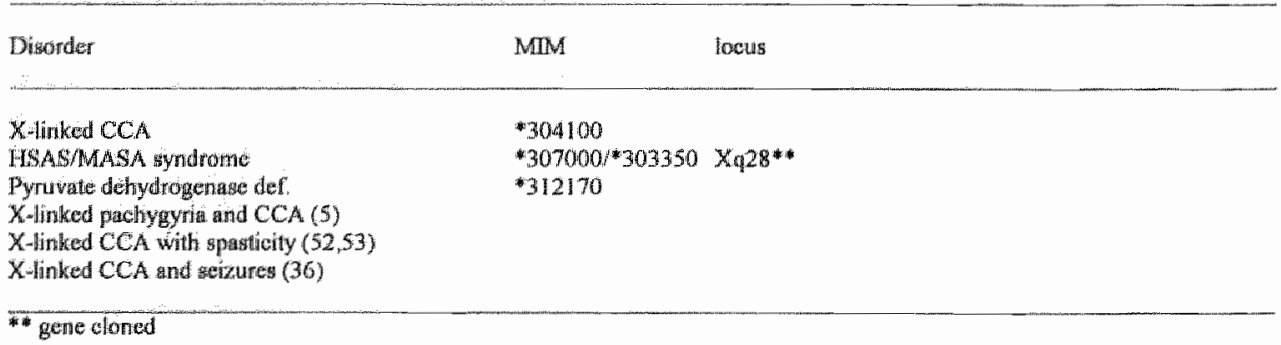

\subsubsection{XLMR with lissencephaly/pachygyria}

A small number of families has been reported in this category (Table 10). The family reported by Arena et al. (2) presented with XLMR and spastic paraplegia; brain imaging revealed pachygyria and iron deposits in the basal ganglia. Berry-Kravis and Israel (4) described a 2-generation family with X-linked pachygyria and CCA. The possibility of a lissencephaly locus at $\mathrm{Xq} 22$ has been raised, based on the finding of a girl with lissencephaly/CCA and a balanced $X ; 2$ translocation (5). The family described by Zollino et al. (60) combined XLMR with a characteristic face, hypogenitalism, congenital hypotonia, and pachygyria.

Tiable: 10

XLMR with lissencephaly/pachygyria.

Disorder

Arena et al (2)

Berry-Kitavis and lastral ( 5 )

Zollino at a $(60)$

\subsubsection{XLMR with cerebellar/vermis a/hypoplasia}

Patients in this category are likely to present with ataxia (see Table 3 ). The family reported by Arena et al. (2) can be listed in this section again. On clinical grounds, it can be wondered whether X-linked olivopontocerebellar atrophy (OPCA) of infant onset differs from X-linked ataxia (see Table 3$)(4,59)$. The family reported by Bertini et al. (6), combined congenital X-linked ataxia and progressive myoclonic encephalopathy with macular degeneration and recurrent infections. 
XINIR with cerebellar/wemils ahypoplasia.

Disorder

Spastic paraplegia, ataxia; iron deposits in the basil ganglia (2)

$X$-linked cerebellar ataxia (1)

Ataxia, hypotonia, recurremt infections (6)

X-tiniked OPCA of infarnt onset (59)

Renier et al. (37)

\subsection{XLMR with abnormal behaviour}

During the past few decades, it has been increasingly appreciated that a behavioural phenotype can be important in recognizing clinical conditions. This has been well documented for the fragile $\mathrm{X}$ syndrome (8). Agressive behaviour with automutilation is well known in the Lesh-Nyhan syndrome. In the family with XLMR, recently reported by Brunner et al. (10), behaviour was highly abnormal with outbursts of violence and sexual offences. In this family, a mutation was found in the structural gene for monoamine oxidase $A$ (11). Much work has yet to be done in documenting the psychological and behavioural characteristics in genetic disorders.

\subsection{CONCLUDING REMARKS}

As of 1994, over 125 X-linked conditions have been reported in which mental retardation is a main feature. Clinical recognition of new patients is facilitated by the reported classifications, such as the one by Glass in 1991 (21) and the recent update on X-linked genes by Neri et al. (32). The genetic databases (LDDB, LNDB, and POSSUM), and McKusick's catalogue are helpful tools as well. However, in families presenting patients with XLMR and neurological symptoms, who were lacking additional clinical manifestations which could easily lead to a diagnosis (e.g. dysmorphic signs, eye and ear abnormalities, cytogenetic abnormalities, certain metabolic diseases presenting clearly in early life) we found it difficult to make clinical diagnoses. Therefore we tried to develop a nosological approach for patients with XLMR and detailed neurological manifestations. A strict classification by symptom was not possible, because the clinical presentation often showed combinations of features. Furthermore, the presently reported approach mainly reflects a selection of the most frequently encountered neurological symptoms in a clinical genetic practice. Since the number of X-linked conditions is still increasing, this paper can represent only a contemporary update on XLMR and neurology. In addition, molecular biologists continue to discover more gene locations and to clone more genes. In this process, different clinical conditions may sometimes be lumped together, as has been the case in X-linked hydrocephalus and MASA syndrome. In 
other instances, conditions will appear to be genetically heterogeneous, with more than one gene being able to cause the condition. Given the rapid evolution in clinical genetics and molecular biology, it can be expected that a more precise list based on etiology and pathogenesis will be possible in the not too distant future. 


\section{REFERENCES}

1. Apak $S$, Yuksel $M_{x}$ Ozmen M, Saka N, Darendeliler $F_{3}$ Neuhäuser $G$. Heterogeneity of X-linked recessive (spino)cerebellar ataxia with or without spastic diplegia. Am J Med Genet 1989;34:155. 158.

2. Arena $\mathrm{JF}_{\text {, Schwartz }} \mathrm{C}$, Stevenson $\mathrm{R}$, Lawrence L, Carpenter $\mathrm{A}$, Duara $\mathrm{R}$, Ledbetter D. Huang $\mathrm{T}$, Lehner T, Ot J, Lubs HA. Spastic paraplegia with iron deposits in the basal ganglia: a new X-linked mental retardation syndrome. Am J Med Genet 1992;43:479-490.

3. Baar HS, Gabriel AM. Sex-linked spastic paraplegia. Am J Med Genet 1966;71:13-18.

4. Baraitser M, Winter RM. The London Neurology Database. Oxford University Press, 1993.

5. Berry-Kravis $E$, Israel J. X-linked pachygyria and agenesis of the corpus callosum in two generations: evidence for an X chromosome lissencephaly locus. Ann Nieurol $1994 ; 36: 229-233$.

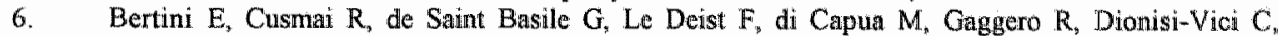
Santillo $\mathrm{C}$, Caniglia $\mathrm{M}$. Congenital $\mathrm{X}$-linked ataxia, progressive myoclonic encephalopathy, macular degeneration and recurrent infection. Am $\mathbb{M e d}$ Genet 1992:43:443-451.

7. Bianchine JW, Lewis Ir RC (1974): The MASA syndrome: A new heritable mental retardation syndrome. Clin Genet 5:298-306.

8. Borghgraef MMC. Psychological profiles and behavioural characteristics in chromosomal syndromes. Thesis. Maastricht, the Netherlands 1991.

9. Bonneau D, Rozet J-M, Bulteau C, Berhier M, Metthey $R$, Munnich A, Le Merrer M (1993): X. linked spastic paraplegia (SPG2): clinical heterogeneity at a single gene locus. J Med Genet $1993 ; 30 \div 381-384$

10. Brunner HG, Nelen MR, van Zandvoort P, Abeling NGGM, van Gennip AH, Wolters EC, Kuiper MA, Ropers HH, van Oost BA. X-linked bordenline mental retardation with prominent behavioural disturbance: phenotype, genetic localization, and evidence for disturbed monoamine metabolism. Am J Hum Genet 1993a; $52: 1032-1039$.

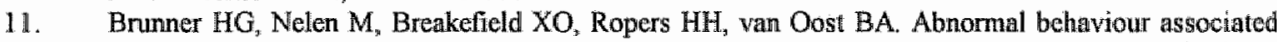
with a point mutation in the structural gene for monoamine oxidase A. Science 1993b;262,578-580.

12. Bundey $\mathrm{S}$, Carter $\mathrm{CO}$. Recurrence risk in severe undiagnosed mental deficiency. J Ment Defic Res $1974 ; 18: 115-128$.

13. Bundey S. Genetics and Neurology, 2nd ed. Churchill Livingstone London, 1992.

14. Buyse ML. Birth Defects Encyclopedia, 1st ed. Blackwell Scientific Publications, Inc, 1990.

15. Cowchock FS, Duckett SW, Stretz $\mathbb{L} J$. X-linked motor-sensory neuropathy type II with deafiness and metnal retardation: a new disorder. An J Med Genet 1985;20:307-315.

16. Edwards JH. The syndrome of sex-linked hydrocephalus. Arch Dis Childh 1961;36:486-493.

17. Emery AEH. Duchenne nuscular dystrophy, revised edition. Oxford University Press, 1988.

18. Fransen $E$, Sclurander-Stumpel $C$, Vits L, Coucke $P$, Van Canip $G$, Willems PJ (1994) X-linked hydrocephalus and MASA syndrome present in one fartily are due to a single missense mutation in exon 28 of the LICAM gene. Hum Molec Genet 1994:3:2255-2256.

19. Fried K (1972): X-linked mental retardation and/or hydrocephalus. Clin Genet 3.258-263.

20. Fryns JP. X-linked mental retardation with agenesis of the corpus callosum. Am J Med Gienet $1993 ; 45: 533$

21. Glass IA. X-linked mental retardation. I Med Genet 1991;28:361-371.

22. Kaplan P. X-linked recessiwe inheritance of agenesis of the corpus callosum. I Med Genet $1983,20: 122-124$.

23. Kenwrick $S_{\text {s }}$ Ionasescu $V$, Ionasescu $G$, Searby $C h$, King $A$, Dubowitz $M$, Davies KE. Linkage studies of X-linked recessive spastic paraplegia using DNA probes. Hum Genet 1986;73:264-6.

24. Kerr B, Turner $G$, Mulley J, Turner $G$. Non-specific X-linked mental retardation. J Med Genet $1991 ; 28: 378-382$

25. Kupke KG, Graeber MB, Muller U. Dystonia-parkinsonism syndrone (XPD) locus: flanking markers in Xq12-q21.1. Am I Hum Genet 1992;50:808-815

26. Lehrke RG. A theory of X-linkage of major intellectual traits. Am J Ment Defic $1972 ; 76: 611-619$.

27. Lubs HA. A marker X chromosome. Am I Hum Genet 1969;21;231-244. 
28. MeKusick V. Mendetian inheritance in man. Catalogs of autosomal doninamt, autosomal recessive, and $X$-liniked recessive phenotypes. 1992, 10 th edition.

29. Menkes $\mathrm{JH}_{0}$ Philippart $\mathrm{M}_{*}$ Clark $\mathrm{DB}$. Hereditary partial agenesis of corpus callosum. Arch Nerrol $1964 ; 11: 198-208$

30. Mulley JC, Kerr R, Stevenson $R$, LUBS H. Nomenclature guidelimes for X-linked mental retardation. Ann J Med Genet 1992;43:383-391.

31. Neni $G_{n}$ Chiurazai P, Arena $\mathbb{F}$, Lubs HA, GLASS IA. XLMR genes: update 1992. Am J Med Genet $1992,43: 373-382$

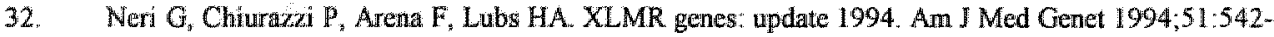
549 .

33. Opitz IM, Holt MC. Microcephaly: general considerations and aids to nosology. J Craniofac Genet $1990 \div 10: 175-204$

34. Priest $\mathrm{JH}_{3}$, Thuline $\mathrm{HC}_{\mathrm{s}}$ La Veck $\mathrm{GD}$, Jarvins $\mathrm{DG}$. An approach to genetic factors in mental retardation. Studies of families containing at least two siblings admitted to a state institution for the retarded. Am J Ment Defic 1961;66:42-50.

35. Proops $\mathbb{R}$, Mayer $M$, Jacobs $P A$ A study of mental retardation in children in the island of Hawaii. Clin Genet 1983;23:81-96.

36. Proud VK, Levine C, Carpenter NJ. New X-linked syndrome with seizures, aquired micrencephaly, and agenesis of the corpus callosum. Am J Med Genet 1992;43:458-466.

37. Renier WO. X-linked mental retardation. A clinical study of $6 \mathrm{X}$-linked syndromes with mentail retardation. Leuven, thesis, 1983.

38. Sarnat $\mathrm{HB}$. Cerebral dysgenesis. Embryology and clinicall expression, 1st ed Oxford University Press 1992, 215.

39. Saugier-Veber $\mathbb{P}$, Munnich $A$, Bonneau $D$, Rozett JM, Le Merrer M, Gil R, Boespflug-Tanguy $O$ (1994). X-linked spastic paraplegia and Pelizaeus-Merzbacher disease are allelic disorders at the proteolipid protein locus. Nature Genet 6:257-262.

40. Schrander-Stumpel C, Fryns JP, Cassiman JJ, Legius E, Spaepen A, Howeler CJ. MASA syndrome (a form of complicated spastic paraplegia) and X-linked hydrocephallus: variable expression of the same mutation? Call for damilies. J Med Genet 1992;29:215.

41. Schrander-Stumpel CTRM, Höweler $C_{\text {n }}$ Jones $M$, Sommer A, Stevens C, Tinschert S, Israel J, Fryns JP. Spectrum of X-linked hydrocephalus (HSAS), MASA syndrome and complicated spastic paraplegia. Clinical review with 6 additional families. Am J Med Genet 1995;56:1-8.

42. Schwartz CE. Invited editorial: X-linked mental retardation: in pursuit of a gene map. Am J Hum Genet 1993;52:1025-1031.

43. Sengers RCA, Hamel BCJ, Otten BJ, van Gils JF, de Pagter AGF. Congenitale hydrocephalus, oligofrenie, dwerggroei, centripetale adipositas en hypogenitalisme; cen X-gebonden recessief owerervende ziekte. Tijdschr Kindergeneesk 1985;53:31-34.

44. Stevenson RE, Schwartz CE, Arena JF, Lubs HA. X-linked mental retardation: the early era from 1943 to 1969. Am J Med Genet 1994;51;538-541

45. Sutherland GR. Fragile sites on human chromosomes. MII. Detection of Fra $(X)(\mathrm{q} 27)$ in males with $X$ linked mental retardation and their female relatives. Hum Genet $1977 ; 53 ; 23-27$.

46. Sutherland GR, Gedeon AK, Haan EA, Woodroffe P, Mulley JC. Linkage studies with the gene for an X-linked syndrome of mental retardation, microcephaly and spastic diplegia (MRX2). Am J Med Genet 1988;30:493-508.

47. Tajara E, Varella-Garcia M Letter to the editor. Xq27 fragile site and hydrocephaly. Ain J Hum Genet 1986;37:1232-1233.

48. Tranebjaerg L, Lou $\mathrm{H}$, Andersen $\mathrm{K}$. New X-linked syndrone with apraxia, ataxia, and mental deficiency: clinical, cytogenetic and neuropsychological studies in two danish families. Am $\mathrm{J}$ Med Genet $1992 ; 43: 498-504$

49. Turner $\mathrm{G}_{4}$ Gedeon $\mathrm{A}$, Mulley J. X-linked mental retardation with heterozygous expression and macrocephaly: pericentromeric gene localization. Am J Med Genet 1994;5];575-580.

50. Veenema $\mathrm{H}_{\text {}}$ Clinicall, cytogenetic and molecular aspects of the fragile $\mathrm{X}$ syndrome. Thesis, Leiden, the Netherlands, 1989 . 
51. Veenema H, Geraedts JPM, Beverstock GC, Pearson PL. The fragile X syndrome in a large family I Cytogenetic and elinical investigations. J Med Genet $1987 ; 24: 23-31$.

52. Vles JSH, Fryns $I P$, Folmer $K$, Boon $P$, Buttiens $M$, Gnubben $C$, Janevski B. Corpus calosum agenesis, spastic quadriparesis and irregular lining of the lateral ventricles on CT-scan. A distinct Xlinked mental retardation syndrone? Genetic Counseling 1992;3:97-102.

53. Vles JSH, de Die-Smulders $\mathrm{C}$, van der Hoeven M, Fryns JP. Corpus callosum agenesis in two male infants of a heterozygotic triplet pregnancy. Genetic Counseling $1993,4: 239-240$.

54. Wieacker P, Wolff G, Wienker TF, Sauer M. A new X-linked syndrone with muscle atroply, congenital contractures, and oculomotor apraxia. An J Med Genet 1985;20:597-606.

55. Wieacker $P$, Wolff $G$, Wienker TF. Close linkage of the Wieacker-Wolff syndrome to the DNA segments DXY SI in proximal Xq. Am J Med Genet 1987;28:245-254.

56. Willems PJ, Brouwer OF, Dijkstra I, Wilmink J (1987): X-linked hydrocephalus. An J Med Genet 27:921-928.

57. Willems PJ, Dijkstra I, Van der Auwerda BJ, Vits L, Coucke P, Raeymakers P, van Broeckhoven C, Consalez GG, Freeman SB, Warren ST, Brouwer OF, Brunner HG, Renier WO, van Elasen AF, Dumon JE. Assignment of X-linked hydrocephalus to $\mathrm{Xq} 28$ by linkage analysis. Genomics $1990 ; 8: 867-870$

58. Winter RM, Davies $\mathrm{K}$, Bell MV, Huson SM, Paterson MN. MASA syndrome: further climical delineation and chromosomal location. Human Genet 1989;82:367-370.

59. Young ID, Moore $\mathbb{J R}$, Tripp $J \mathrm{H}$. Sex-linked recessive congentital ataxia. I Neurol Neurosurg Psychiatry 1987;50:1230-1232.

60. Zollino $M$, Mastroiacovo $P$, Zampino $G$, Mariotti $P$, Neri $G$. New XLMR syndrome with characteristic face, hypogenitalism, congenital hypotonia and pachygyria. Am J Med Genet 1992;43;-452-457. 


\section{Chapter 7}

\section{GENERAL DISCUSSION}

\subsection{INTRODUCTION}

In a department of clinical genetics, mentally retarded patients form a large and challenging group. Genetic counseling of the relatives depends on a reliable diagnosis, which is not always available, especially in adult patients. Looking at the X-linked mental retardation (XLMR) group, over 100 recognizable conditions have been reported (20). Among these are the complicated spastic paraplegia (SPG1)(MIM *312900), MASA syndrome (acronym for Mental retardation, Aphasia, Shuffling gait, and Adducted thumbs)(MIM *303350) and X-linked hydrocephalus with stenosis of the aqueduct of Sylvius (HSAS)(MIM *307000), all located at Xq28 $(14,31,33)$. We observed the concurrence of these three conditions in several families and designated this condition as the HSAS/MASA spectrum (25).

In the present study, our aim was to answer clinical and molecular questions regarding the HSAS/MASA spectrum.

\subsection{CLINICAL ASPECTS OF THE STUDY.}

In the clinical section we wondered how variable the clinical spectrum is; what could be the minimal diagnostic clinical criteria and would it be possible to make a reliable diagnosis on clinical grounds alone?

A literature review was done and 9 families with HSAS/MASA spectrum could be studied. HSAS varied clinically from being lethal in utero or early infancy to survival with mental retardation, spastic paraplegia and adducted thumbs. In most reported HSAS families, patients died during pregnancy (partly due to induced labour after prenatal diagnosis), during or shortly after birth or after some weeks/months (18). We did a literature review of families with HSAS presenting with surviving male patients and of families with MASA syndrome (including the one family reported as SPG1 (14)). Major overlap of the clinical features was documented (24). On the other hand HSAS and MASA syndrome showed great clinical variation as well $(5,13,23,26,30)$. About $10 \%$ of the male patients did not show spastic paraplegia or adducted thumbs (see chapter 3 ). This $10 \%$ group consisted of children as well as adult patients. Spastic paraplegia can be absent before puberty (chapter $2 \mathrm{~B} ; 33$ ), enhancing the problem of an early diagnosis when there is no male relative presenting with the full-blown clinical picture. Families with HSAS/MASA syndrome sometimes 
present an adult male relative with mental retardation only, illustrating the end of the clinical spectrum. Here a clinical diagnosis of HSAS/MASA spectrum would be difficult as well in the absence of an affected male relative showing more characteristic symptoms.

In the differential diagnosis, a second locus for complicated spastic paraplegia on the $X$ chomosome at Xq21 should be kept in mind (SPG2)(MIM *312920). Clinical overlap with the HSAS/MASA spectrum is evident $(1,6)$. Recently, in the family reported by Bonneau et al. (1) a mutation was reported in the proteolipid protein (PLP) gene, mapped at the long arm of the X chromosome (Xq21-q22) (22). In male patients with SPG2, hydrocephalus has not been documented up to now; this might be an important discriminating feature between the two forms of X-linked complicated spastic paraplegia.

In conclusion: the clinical spectrum of HSAS/MASA syndrome is variable with diagnostic problems in about $10 \%$ of the surviving patients. X-linked mental retardation can be regarded as the minimal clinical criterium. Since clinical overlap with the second locus for complicated spastic paraplegia exists, there may be pittfalls in making the diagnosis of HSAS/MASA spectrum on clinical grounds only (see molecular section), especially when hydrocephalus is absent in the affected males. Therefore, it is difficult to make a reliable diagnosis on clinical grounds alone.

\subsection{MOLECULAR ASPECTS OF THE STUDY}

The molecular biological aims of this study consisted of two parts: DNA linkage analysis and the search for mutations in LICAM. We wondered whether all studied families showed linkage to the distal Xq markers and in how many families LICAM mutations could be found.

Literature data give no evidence for genetic heterogeneity in the HSAS/MASA spectrum. In the 7 presently reported families where it was possible to perform DNA studies (see chapters $2 \mathrm{~A}$ and 4 ), we could demonstrate linkage to the distall $\mathrm{Xq}$ markers. In small families however, difficulties arose with the interpretation of the data. In one family (family $E$ in chapter 4 ) the haplotype in both affected brothers was recognized in the asymptomatic maternal grandfather. Here we could assume germline mosaicism in the grandfather, a de novo mutation in the mother, or genetic heterogeneity. A de novo LICAM mutation has been reported in only few patients $(11,12)$. A selection bias could be operating since only at least two-generation families with HSAS/MASA spectrum have been studied. Therefore, we assume that the chance of finding a de novo LICAM mutation is small. Moreover, in one family (family B in chapter 4) we had to assume 3 crossovers within a genetic distance of 4 centimorgans and we seriously considered the possibility of genetic heterogeneity. Clinical diagnosis here was fully compatible with HSAS/MASA spectrum, but brain imaging was not available in the 2 affected brothers. In this family, further studies in collaboration with collegues in Paris (Dr.A.Munnich, Dr.S.Lyonnet and Dr.P.SaugierVeber) will be performed in order to investigate the second locus on the $\mathrm{X}$ chromosome involved in complicated spastic paraplegia (Xq21). 
Up to december 1994 L1CAM mutations have been found in two of the 7 families in this thesis: a point mutation in our "original" family (reported in chapters $2 \mathrm{~A}$ and $5 \mathrm{C}$ ), and a deletion in the family reported by Macias et al.(17) (this is family A in chapter 4 and family 3 in chapter $5 B$ ).

In conclusion, in the large families no evidence of genetic heterogeneity of the HSAS/MASA spectrum has been documented. Also in the families studied in this thesis linkage could be demonstrated to $\mathrm{Xq} 28$. However, in small families interpretation of the haplotypes can be difficult and genetic heterogeneity cannot be excluded. In 2 of the 7 families studied in this thesis a mutation in LICAM was found.

\subsection{L1CAM AND THE RELATION WITH THE HSAS/MASA SPECTRUM}

L1CAM was the only neuronal gene known to be located in $\mathrm{Xq} 28$ (3). Since HSAS/MASA spectrum families showed linkage to Xq28, it has been the candidate gene for some years. Now we know that the gene responsible for both MASA syndrome and HSAS does encode for the neural cell adhesion molecule LI. LICAM belongs to the immunoglobulin superfamily of cell adhesion molecules that contain domains similar to the $\mathrm{C} 2$ immunoglobulin domains. Although its function is not completely understood, L1CAM is involved in neuronal cell migration, fasciculation, outgrowth and regeneration $(7,15,16,19,27,32)$. It is part of a network of cellular reactions that lead to morphogenesis of the nervous system. LICAM is expressed both in the brain and in the peripheral nervous system (primarily on the axons of postmitotic neurones), and functions as a membrane-bound protein with an extra- and an intracellular cytoplasmatic domain linked by a transmembrane domain. The high degree of conservation between the cytoplasmic portion of human L1CAM and its homologues in mouse, rat and chick suggests an important role for this region $(8,9)$.

Although it is not yet clear how mutations in L1CAM lead to specific patterns of defective development of the central nervous system, hope has been raised to learn more about pathogenesis of this clinical spectrum. In retrospect, the statement made by Edwards in his clinical paper on HSAS in 1961, is remarkable: "It is tempting to associate these peculiarities (abnormal thumbs, spasticity, hydrocephalus (CSS)) with a primary and highly specific disturbance of cortical control, and to associate this with a primary deficiency of the corticospinal tracts" (5).

At this stage, the following hypothesis can be made: different mutations in LICAM may give rise to different abnormal or even absent protein products, thus giving rise to various types of central nervous system maldevelopment, with clinical variability as a result. This, however, does not explain the variability seen in the different patients in one family who were all affected with the same L1CAM mutation $(4,29)$. Thus, environmental factors or modifying factors (genes) in the individuals themselves are needed to understand this intrafamiliall variability. 


\subsection{GENETIC COUNSELING}

When the presentation of a male patient with mental retardation, spastic paraplegia, slow speech development and adducted thumbs with or without hydrocephalus (and a positive family history) has raised the clinical suspicion of the HSAS/MASA spectrum, neurological studies including brain imaging are indicated. Since mental retardation can be the sole manifestation of the spectrum, it is important to perform brain imaging (hydrocephalus, corpus callosum agenesis?) in patients with nonspecific XLMR as well. To make a reliable diagnosis on clinical grounds only, is difficult. The difficulty in recognizing female carriers on clinical grounds only, underlines the need for molecular studies in these families as well. Possibly, the HSAS/MASA spectrum in the absence of hydrocephalus, is heterogeneous, with (at least) 2 loci at the $X$ chromosome: $\mathrm{Xq} 28$ and $\mathrm{Xq} 21$. The finding of hydrocephalus in an affected family member will lead to the Xq28 locus. With demonstrated linkage to the Xq28 markers, a search for an LICAM mutation is worthwhile. When linkage is demonstrated to the $\mathrm{Xq} 21$ region, the PLP locus is a serious candidate for further studies.

Prenatal diagnosis by chorionic villus sampling is possible when linkage analysis is informative or, even more reliable, when a mutation in the gene encoding LICAM has been found. Recently, two pedigrees with apparently sporadic hydrocephalic boys were reported, in which LICAM mutations were documented and prenatal diagnosis could be offered (12).

\subsection{FUTURE PERSPECTIVES}

By the end of 1994, over 20 different mutations in L1CAM have been found in HSAS/MASA families $(2,4,10,11,12,21,28,29)$. Almost every family has its "private" mutation. This number will probably increase in the coming years. Detailed genotypephenotype correlation studies will have to await the identification of (more L1CAM mutations and) the study of the abnormal protein products and their effects on neuronal development. In this respect, autopsy studies and animal models will be of great importance. It is to be expected, however, that secondary factors, other than the LICAM mutations, might contribute to the phenotype as a large intrafamilial variability is observed.

Some patients belonging to HSAS or MASA families, show no hydrocephalus, spastic paraparesis or adducted thumbs, but only mental retardation. Therefore, it is possible that mutations in LICAM are responsible for some of the families c.q isolated male patients with nonspecific $X$-linked mental retardation. Since the gene for LICAM is located at the distal part of the X chromosome, further studies in the XLMR population are indicated when linkage to the distal $\mathrm{Xq} 28$ markers is demonstrated. Almost every family with a LICAM mutation has a different mutation and the gene contains 28 exons; therefore it is not yet possible to perform a mutation "screening" in families with XLMR in general. L1CAM mutations might represent an important cause of part of the XLMR population. 


\section{REFERENCES}

1. Bonneau D, Rozet J-M, Bulteau C, Berhier M, Metthey R, Munnich A, Le Merrer M (1993): X-linked spastic paraplegia (SPG2): clinical heterogeneity at a single gene locus. J Med Genet 1993;30:381 -384.

2. Coucke P, Vits L, Van Camp $G_{v}$ Serville F, Lyonnet $S$, Kenwrick S, Rosenthal A, Welnert M, Muninich $A_{n}$ Willens PJ. Identification of a 5 'splice site mutation in intron 4 of the LICAM gene in an X-linked hydrocephalus family. Hum Mol Genet 1994;3:671-673.

3. Djabali $M$, Mattei MG, Nguyen $C$, Roux D, Demengeot J, Denzot F, Moos $M$, Schachner M, Goridis $C$, Jordan BR. The gene encoding L1, a neural adhesion molecule of the immunoglobulin fumily, is located on the X chromosome in mouse and man. Genomics 1990;7:587-593.

4. Fransen E, Schrander-Stumpel CTRM, Vits L, Coucke P, Van Camp G, Willens $P . X$-linked hydrocephalus and MASA syndrome present in one family are due to a single missense mutation in exon 28 of the LICAM gene. Hum Mol Genet 1994;3:2255-2256.

5. Edwards JH. The syndrome of sex-linked hydrocephalus. Arch Dis Childh 1961;36:486-493.

6. Goldblatt J, Ballo R, Sachs B, Moosa A. X-linked spastic paraplegia evidence for homogeneity with a variable phenotype. Clin Genet 1989;35:116-120.

7. Grumet M. Cell adhesion molecules and their subgroups in the nervous systen. Curr Op Neunobiol $1991 ; 1: 370-376$

8. Harper JR, Prince JT, Healy PA, Stuart JK, Nauman SJ, Stallup WB. Isolation and sequence of partial cDNA clones of human $\mathrm{LI}$ - homology of human and rodent $\mathrm{L} 1$ in the cytoplasmic region. I Neurochem $1991 ; 56797-804$.

9. Hlavin ML, Lemmon V. Molecular structure and functional testing of human L1. Genomics $1991 ; 11: 416-423$.

10. Jouet M, Rosenthal A, MacFarlane J, Kenwrick S, Donnai D. A missense mutation confirms the LI defect in X-linked hydrocephalus (HSAS). Nature Genet 1993;4;331

11. Jouet $M$, Rosenthal A, Armstrong G, MacFarlane J, Stevenson R, Paterson J, Matzenberg, A, lonanescu $\mathrm{V}$, Temple $\mathrm{K}$, Kenwrick S. X-linked spastic paraplegia (SPGL), MASA syndrome and X-linked hydrocephalus result from mutations in the 1.1 gene. Nature Genet 1994;7:402-406.

12. Jouet $\mathrm{M}, \mathrm{K}$ enwrick $\mathrm{S}$. Gene analysis of $\mathrm{Ll}$ meural cell adhesion molecule in prenatal diagnosis of hydrocephalus. Lancet 1995;345:161-162.

13. Kaepernick LA, Legius E, Higgins J, Kapur S. Clinical aspects of MASA syndrome in a large lamily including expressing fenales. Clin Genet 1994;45:181-185.

14. Kenwrick $S$, Ionasescu $V$, Ionasescu $G$, Searby $C h$, King A, Dubowitz M, Davies KE. Linkage studies of X-linked recessive spastic paraplegia using DNA probes. Hum Genet 1986;73:264-6.

15. Lander $\mathrm{AD}$. Understanding the mollecules of neural cell contacts: emerging patterns of structure and function. TINS 1989; 12:189-195.

16. Lemmon V, Farr KL, Lagenaur C. LI-Inediated axon outgrowth occurs via a homophilic binding mechanisn. Neuron 1989;2:1597-1603.

17. Macias VR, Day DW, King TE, Wilson G. Clasped-thumb mental retardation (MASA) syndrone: confirmation of linkage to Xq28. Am J Med Genet 1992:43:408-414.

18. McKusick V. Mendelian inheritance in man. Catalogs of autosomal dominant, autosomal recessive, and $X$-linked recessive phenotypes. 1992, 10th edition.

19. Miura $M$, Asou $H$, Kobayashi $M$, Uyemura $K$. Functional expression of a full-Jength cDNA coding for rat neural cell adhesion molecule $L 1$ mediates homophillic intercellular adhesion and migration of cerebellar neurons. J Biol Chem 1992;267:10752-10758

20. Neri G, Chiurazi P, Arena JF, Lubs HA. XLMR Genes: Update 1994. An J Med Gened 1994,51:542 549.

21. Rosenthal $A$, Jouet $M$, Kenwrick $S$. Aberrant splicing of neural cell adhesion molecule $L I$ mRNA in a family with X-linked hydrocephalus. Nature Genet 1992;2:107-112

22. Saugier-Veber P, Munnich A, Bonneau D, Rozet JM, Le Merrer M, Gill R, BoespflugaTanguy O (1994) $X$-linked spastic paraplegia and Pelizacus-Merzbacher disease are allelic disorders at the proteolipid protein locus. Nature Genet 6:257-262.

23. Sehrander-Stumpel CTRM, Legius E, Fryns JP, Cassiman JJ MASA syndrome: new clinical features and linkage analysis using DNA probes. J Med Genet 1990,27:688-692. 
24. Sehrandkr Stumpel C, Fryns JP, Cassiman J, Legius E, Spaepen A, Höweler CJ. MASA syndrome (a form of complicated spastic paraplegia and $X$-linked hydrocephalus: variable expression of the same mutation? Call for farmilies. J Med Cenet 1992;29:215.

25 Schrander-Stumpel CTRM, Howeler C, Jones M, Sommer A, Stevens C, Tinschert S, Israel J, Fryns JP. Spectrum of X-linked hydrocephalus (HSAS), MASA syndrome and complicated spastic paraplegia. Clinical rowew with 6 additional lamilies. Am J Med Genet 1995;56:1-8.

26. Serville $F_{i}$ Lyonnet. S. Pelet A, Reynaud M, Louail C, Muninich A, LeMerrer M. X-linked hydrocephalus: clinical heterogeneity at a single gene locus. Eur J Pediatr 1992;151:515-518.

27. Sonderegger $\mathrm{P}$, Rathjen $\mathrm{FG}$. Regulation of axonal growth in the vertebrate nervous system by interactions between glycoproteins belonging to two subgroups of the immunoglobulin superfamily. $I$ Cell Biol 1992;119:138:7-1394

28. Van Camp $G_{i}$ Vits $L_{*}$ Coucke $P_{\text {, L }}$ Lyonnet $S$, Schrander-Stumpel $C$, Darby J, Holden J, Munnich $A$, Willems P. A duplication in the L1Cam gene asociated with X-linked hydrocephalus. Nature Genet $1993 ; 4: 421.425$.

29. Vits L, Van Camp G, Coucke P, Wilson $G$, Schrander-Stumpel C, Schwartz $C_{w}$ Willems P. MASA syndrome is due to mutations in the LICAM gene. Nature Genet 1994;7:408-414.

30. Willems PJ, Brouwer OF, Dijkstra $\mathbb{I}$, Wilmink J. X-Linked hydrocephalus. Am I Med Genet $1987: 27: 921-928$.

31. Willems PJ, Dijkstra I, Van der Auwerda BJ, Vits $L$, Coucke P, Raeymakers $P$, van Broeckhoven $C$, Consalez GG, Freman SB, Warren ST, Brouwer OF, Brunner HG, Renier WO, wan Elasen AF, Dumon JE. Assignment of X-linked hydrocephalus to Xq28 by linkage analysis Genomics $1990 ; 8: 867-870$.

32. Williams EJ, Doherty $P_{\text {, Turner }} G_{0}$ Reid $A$, Hemperly JJ, Walsh $F S$. Calcium influx into neurons can solely account for cell contact-dependent neurite outgrowth stimulated by transfected $\mathrm{L} 1$. J Cell Biol $1992 ; 119: 883-892$.

33. Winter RM, Davies $\mathrm{K}$, Bell MV. Huson SM, Paterson MN. MASA syndrome: further clinical delineation and chromosomal location. Human Genet 1989;82:367-370. 


\section{Chapter 8}

\section{SUMMARY}

In Chapter 1, an introduction on mental retardation and on X-linked mental retardation (XLMR) in general, and on XLMR with spastic paraplegia in particular is presented.

Up to recently, spastic paraplegia has been considered as a non-genetic condition. In the past few years however, autosomal and X-linked genetic forms of spastic paraplegia have been reported. Two X-linked forms of spastic paraplegia have been delineated: a "pure" form, SPG2, with a gene location at Xq21 (MIM *312920) and a "complicated" form, SPG1, located at Xq28 (MIM *312900).

SPG1 and MASA syndrome (acronym for Mental retardation, Aphasia, Shuffling gait and Adducted thumbs), also located at Xq28 (MTM *303350), appeared to be the same condition. The gene for X-linked hydrocephalus with stenosis of the aqueduct of Sylvius (HSAS) (MIM *307000) was mapped to Xq28 as well. Based on the finding of families presenting with either MASA syndrome or HSAS, it was hypothesized that HSAS and MASA syndrome resulted from mutations in the same gene at Xq28. To test this hypothesis families with MASA syndrome and/or HSAS were studied from the clinical as well as the molecular point of view.

In Chapter 2A, a two-generation family in which two males presented with MASA syndrome is described. A third male in this family died at the age of 15 years from congenital hydrocephalus. For the first time, hydrocephalus was also documented in the patients with MASA syndrome. Linkage analysis confirmed the chromosomal localization at Xq28. A crossover between the genes for coagulation factor VIII locus (F8C) and MASA syndrome helped to map the gene for the latter. The possible relationship between MASA syndrome and X-linked hydrocephalus was discussed.

Chapter 2B deals with the clinical and neurological findings in 2 brothers with MASA syndrome and the changes in phenotypic and neurological findings during the prepubertal period.

Chapter 3 presents a clinical study in 6 families with HSAS/MASA syndrome and a literature review featuring a number of clinical aspects in order to further dellineate the clinical spectrum. Clinical inter- and intrafamiliar variability appeared to be great. Problems in genetic counseling and prenatal diagnosis, the possible overlap with $\mathrm{X}$ - 
linked corpus callosum agenesis and FG syndrome, and the different forms of $\mathrm{X}$ linked complicated spastic paraplegia were discussed. Since adducted thumbs and spastic paraplegia were found in $90 \%$ of the patients, the condition may be present in males with nonspecific mental retardation. Finally, the abandonment of the designation "MASA symdrome" and the adoption of the term "HSAS/MASA spectrum" was proposed.

In Chapter 4, data on DNA linkage analysis in 6 individual families are given. These data illustrated the importance of DNA linkage analysis in each particular family. However, they also showed the problem of studying small families: in 2 families it was difficult to interpret the data and unambiguous counselling could not be provided. Genetic heterogeneity could not always be excluded.

Chapter 5 deals with further molecular studies on families with HSAS/MASA spectrum.

In Chapter 5A, the second LICAM mutation in a family with HSAS was reported: a 1.3 kilobase $(\mathrm{kb})$ genomic duplication was identified. It cosegregated with HSAS and changed the intracellular domain of the L1CAM protein significantly. This finding confirmed that LICAM is the HSAS gene.

In Chapter 5B, LICAM mutations in patients with MASA syndrome are reported. Three different mutations were identified: a deletion and 2 (different) point mutations. L1CAM, therefore, harbours mutations leading to either MASA syndrome or HSAS.

The family reported in Chapter $\mathbf{5 C}$ is the original family in which the cooccurrence of MASA syndrome and HSAS was reported (see chapter $2 \mathrm{~A}$ ). In this family a missense mutation in exon 28 of the LICAM gene was found. The demonstration of a mutation in this family with both HSAS and MASA syndrome confirmed our previous suggestion that both clinical conditions are due to mutations in the same gene.

Chapter 6 deals with a nosological approach of the patients presenting with XLMR in combination with neurological features. A subdivision was made into several neurological symptoms commonly encountered in clinical genetic practice.

In Chapter 7 the questions, raised in chapter $\mathbb{1}$, are answered and discussed. Practical guidelines for genetic counseling are provided and some future perspectives are given. 


\section{Chapter 9}

\section{SAMENVATTING}

In hoofdstuk 1 wordt een inleiding gegeven over verstandelijke handicap (mentale retardatie) en over geslachtsgebonden mentale retardatie (XLMR) in het algemeen en over de combinatie van XLMR en spasticiteit van de benen (spastische paraplegie) in het bijzonder.

Tot voor kort werd spasticiteit van de benen meestal niet als een genetische aandoening beschouwd. In de afgelopen jaren zijn echter verschillende autosomale en $\mathrm{X}$-gebonden vormen van spastische paraplegia beschreven. Ondermeer werden twee $\mathrm{X}$-gebonden vormen van spastische paraplegia nader afgebakend: een "pure" vorm, SPG2, met een gen locatie ter hoogte van Xq21 (MIM *312920) en een "complexe" vorm, SPG1, gelegen ter hoogte van Xq28 (MIM *312900). SPGl en MASA syndroom (acronym voor Mentale handicap, Aphasia, Schuivelende gang en Adductie stand van de duimen en eveneens genetisch gelocaliseerd ter hoogte van Xq28) (MIM *303350) bleken dezelfde aandoening te zijn. Het gen voor geslachtsgebonden hydrocephalus met stenose van de aquaduct van Sylvius (HSAS) (MIM *307000) bleek ook op Xq28 geplaatst te kunnen worden. Op grond van het feit dat er families bestaan met zowel MASA syndroom als HSAS patiënten, werd de hypothese opgesteld dat HSAS en MASA syndroom variabele uitingen zijn van mutaties in hetzelfde gen op Xq28. Deze hypothese werd getoetst aan de hand van families met MASA syndroom en/of HSAS, die klinisch en moleculair werden onderzocht.

In hoofdstuk $2 \mathrm{~A}$ wordt een 2-generatie familie beschreven waarin bij 2 mannen de diagnose MASA syndroom gesteld werd. Een derde mannelijke patient in deze familie stierf op de leeftijd van 15 jaar aan de gevolgen van een aangeboren waterhoofd. Deze familie was de eerste waar bij de patienten met het MASA syndroom een hydrocephalie vastgesteld werd. DNA koppelingsanalyse bevestigde de chromosomale lokalisatie op Xq28. Een recombinatie tussen het stollingsfactor VIII locus (F8C) en MASA syndroom kon worden gebruikt voor een meer precieze localisatie. De mogelijke relatie tussen MASA syndroom en X-gebonden hydrocephalus werd in dit hoofdstuk besproken.

Hoofdstuk 2B gaat over de klinische (en met name neurologische) bevindingen bij 2 broers met het MASA syndroom en de veranderingen in de kliniek gedurende de prepubertale periode. 
Hoofdstuk 3 is een klinische studie van 6 families met HSAS/MASA syndroom. Er wordt een literatuuroverzicht gegeven over een aantal klinische aspecten met als doel tot een verdere afbakening van het klinische spectrum te komen. De klinische interfamiliaire - en intrafamiliaire variabiliteit bleek groot te zijn. Problemen bij de genetic counseling en prenatale diagnostiek, de mogelijke overlap met X-gebonden corpus callosum agenesie en $F G$ syndroom, en de verschillende vormen van $X$ gebonden komplexe spastische paraplegie kwamen aan de orde. Omdat duimen in adductie stand en spastische paraplegie maar bij $90 \%$ van de patienten vastgesteld werden, kan de aandoening bestaan bij mannen met een aspecifieke vorm van Xgebonden mentale retardatie. Tenslotte werd voorgesteld om de benaming MASA syndroom niet meer te gebruiken en de term HSAS/MASA spectrum, daarbij SPGI inbegrepen, te gebruiken.

Hoofdstuk 4 bevat gegevens over DNA koppelings-analyse in 6 families. Deze gegevens illustreerden het belang van DNA onderzoek in de afzonderlijke familie. Ze toonden echter ook de problemen als men kleine families onderzoekt: in 2 families was het moeilijk de gegevens te interpreteren en konden geen zekere uitspraken worden gedaan. Genetische heterogeniteit kon niet altijd worden uitgesloten.

Hoofdstuk 5 is gewijd aan verdere moleculaire studies in het HSAS/MASA spectrum.

Hoofdstuk 5A beschrijft de tweede LICAM mutatie in een familie met HSAS in de literatuur. Een 1.3 kilobase $(\mathrm{kb})$ duplicatie erfde over met HSAS en veranderde het intracellulaire domein van het LICAM eiwit significant. Deze bevinding bevestigde dat LICAM het gen voor HSAS is.

Hoofdstuk 5B bevat de beschrijving van L1CAM mutaties in patienten met MASA syndroom. Drie verschillende mutaties werden geïdentificeerd: een deletie en 2 (verschillende) punt mutaties. Mutaties in L1CAM kunnen dus zowel tot MASA syndroom als HSAS leiden.

De familie beschreven in hoofdstuk $5 \mathrm{C}$ was een van de eerste waarin zowel MASA syndroom als HSAS voorkwam (zie hoofdstuk 2A). In deze familie werd een punt mutatie in exon 28 van het L1CAM gen gevonden. Deze mutatie in een familie met zowel HSAS als MASA syndroom bevestigde onze oorspronkelijke suggestie dat beide klinische aandoeningen veroorzaakt worden door mutaties in hetzelfde gen.

Hoofdstuk 6 beschrijft een klinische indeling gericht op de patiënten die zich met XLMR in combinatie met neurologische kenmerken presenteren. Er werd een onderverdeling gemaakt in verschillende neurologische symptomen, zoals deze zich deze voordoen in een klinisch genetische praktijk.

In hoofdstuk 7 worden de vragen, gesteld in hoofdstuk 1, beantwoord en besproken. Er worden praktische richtlijnen voor de erfelijkheidsvoorlichting gegeven en enkele nog open staande vragen c.q. toekomstige ontwikkelingen worden aangegeven. 


\section{LIST OF ABBREVATIONS}

CCA

CNS

FG syndrome

HSAS

L1CAM

MASA

MIM

MR

MRX

$\mathrm{OFC}$

ORF

PCR

PLP

PMD

RFLP

SPG1

SPG2

SSCP

XLMR
Corpus Callosum Agenesis

Central Nervous System

Clinical recognizable syndrome with XLMR, hypotonia and anus abnormalities. The characters " $F G$ " are the initials of the index patient in the family reported by Opitz and Kaveggia in 1974

Hydrocephalus with Stenosis of the Aqueduct of Sylvius

L1 is one of the Cell Adhesion Mollecules, important for meuronal development

MASA is acronym for Mental retardation, Aphasia (slow speech development), Shuffling gait (Spastic paraplegia) and Adducted thumbs

Numbers derived from McKusick's "Mendelian Inheritance in Man" catalogue

Mental Retardation

Symbol to denominate families with nonspecific X-linked mental retardation, in which the gene has been regionally mapped; each family has a number (MRX1, MRX2 etc.)

Occipito-Frontal Circumference

Open Reading Frame

Polymerase Chain Reaction

Proteo-Lipid Protein

Pelizaeus-Merzbacher Disease

Restriction Fragment Length Polymorphism

X-linked Complicated Spastic Paraplegia Type 1

$\mathrm{X}$-Linked (Complicated) Spastic Paraplegia Type 2

Single-Stranded Conformation Polymorphism

$X$-Linked Mental Retardation 


\section{NAWOORD}

Reeds in het begin van mijn opleiding tot kinderarts kreeg ik speciale belangstelling voor kinderen met aangeboren afwijkingen en ontwikkelingsproblemen. De klinische genetica als specialisme bestond nog niet officieel, maar werd vorm gegeven door een aantal (kinder)artsen in het land. Mijn kennismaking met het vak vond plaats in de figuur van Drs. J. Bijlsma, die de consulten deed in het Onze Lieve Vrouwe Gasthuis te Amsterdam. Hij was mijn eerste stimulans in de klinische genetica; dit leidde ondermeer tot de publicatie over het Aarskog-Scott syndroom.

In 1985 begon ik in Maastricht als kinderarts. De Stichting Klinische Genetica Limburg (SKGL) was toen sedert een paar jaar van start gegaan. Prof.dr. J. Geraedts, directeur van de SKGL, gaf alle steun om de afdeling klinische genetica verder uit te te bouwen en legde contact met Prof.dr. J.P. Fryns hoofd van de afdeling klinische genetica van het Centrum voor Menselijke Erfelijkheid te Leuven, België. Daar kreeg ik de mogelijkheid om de "klinische genetica" te leren.

Speciale dank ben ik verschuldigd aan een aantal personen:

Prof.dr. J.P. Fryns is sedert mijn daadwerkelijke start in de klinische genetica in 1985 een voorbeeld en stimulans geweest in de zorg voor patienten en hun familieleden. Hij heeft de groei van de afdeling ondersteund, stimuleert de wetenschappelijke output en heeft me in contact gebracht met de internationale collega's. Dit proefschrift is het resultaat van zorgvuldige planning over een aantal jaren, waarbij de ontwikkelingen in de tijd haast synchroon liepen met de vorderingen van dit boek. JeanPierre, hartelijk dank voor alles.

Prof.dr. J. Geraedts heeft altijd een positieve en ondersteunende houding naar de afdeling klinische genetica van de SKGL getoond. Als tweede promotor heeft hij vlot en stimulerend gewerkt. Joep, bedankt voor je steun.

Dr. C. Höweler is als copromotor een grote stimulans geweest bij de tot standkoming van dit proefschrift. Beste Chris, speciaal wil ik je bedanken voor de fijne samenwerking in de patientenzorg en een aantal papers.

Dr.H. Meyer en D. Merckx, beste Henk en Diane, HSAS/MASA spectrum is een aandoening waar we in Maastricht als enig Nederlands klinisch genetisch centrum aan werken. Bedankt voor het vele werk en de discussies n.a.v de gegevens van onze families.

Dr. P. Willems, beste Patrick, dank voor de samenwerking betreffende de L1 mutatie analysen in de families en voor de stimulerende discussies. Ook Lieve Vits, Guy van Camp en Erik Franssen, hartelijk dank voor de prettige samenwerking.

Mijn oprechte dank gaat uit naar de families met HSAS/MASA spectrum, die dit proefschrift mogelijk maakten. Met name de gezinnen Geraeds-Fisher en BertrandFisher wil ik hier hartelijk danken voor hun gemotiveerde medewerking en belang- 
stelling.

Special thanks goes to the international collegues, who referred the families studied in this thesis: Dr. Jeanette Israel (Chigago, USA), Dr. Marilyn Jones (San Diego, California, USA), Dr. Annemarie Sommer (Columbus, Ohio, USA), Dr. Cathy Stevens (Chattanooga, Tennessee, USA), Dr. Sigrid Tinschert (Berlin, Germany) and Dr. Golder Wilson (Dallas, Texas, USA).

Drs. C. de Die-Smulders, beste Christine, mijn naaste medewerker van het "eerste uur", hartelijk dank voor je stimulans en bereidheid om in de afrondingsfase van dit proefschrift in te springen.

Francis van der Lubbe, fotografe, heeft met grote toewijding en kennis van zaken een groot aantal klinische foto's voor de publikaties én dia's voor de voordrachten gemaakt. Francis, bedankt voor je hulp en steun.

Dr. J.J.P. Schrander, lieve Jaap, mijn echtgenoot en collega. Jouw promotie op 9 juni 1994 was een grote stimulans om dit proefschrift af te ronden (het moest ook wel, want het stond in de ziekenhuis krant!). Veel dank ben ik je verschuldigd voor je stimulans, praktische hulp en de bewerking van het manuscript.

Lieve Dirk en Anna, nu hebben papa en mama allebei een boekje geschreven en een groot feest gegeven. Jullie zijn niet verplicht het ons na te doen! 


\section{CURRICULUM VITAE}

De schrijfster van dit proefschrift werd geboren in Amsterdam op 12 augustus 1954. In 1972 werd het eindexamen gymnasium B behaald aan het Pius $X$ lyceum te Amsterdam. Zij studeerde geneeskunde aan de Vrije Universiteit te Amsterdam. Het doctoraalexamen werd in 1977 behaald. In aprill 1979 werd het artsexamen cum laude afgelegd.

Van 1980 tot 1984 volgde de opleiding tot kinderarts, anvankelijk in het Onze Lieve Vrouwe Gasthuis (opleider Dr. L.H.B.M. van Benthem), vervolgens in het academisch ziekenhuis der Vrije Universiteit (AZVU)(opleider Prof.dr. G.A. de Jonge). Tot 1985 was zij als kinderarts werkzaam op de afdeling neonatologie van het AZVU.

Januari 1985 volgde de overstap naar Maastricht, waar zij gedurende 9 maanden als kinderarts werkzaam was op Medisch Kleuter Dagverblijf "Kleuterdal". In mei 1985 begon zij haar werkzaamheden bij de Stichting Klinische Genetica Limburg (SKGL), aanvankelijk als kinderarts, sedert mei 1989 als klinisch geneticus. De vorming tot klinisch geneticus vond voor een belangrijk deel plaats onder leiding van Prof.dr. J.P. Fryns, hoofd klinische genetica van het Centrum voor Menselijke Erfelijkheid te Leuven, België, en sinds 1988 bijzonder hoogleraar klinische genetica aan de Rijksuniversiteit Limburg vanwege de SKGL. $\mathrm{Zij}$ is hoofd van de afdeling klinische genetica van de SKGL en sedert oktober 1992 opleider voor het specialisme klinische genetica.

Op 22 juni 1977 is zij getrouwd met Jaap Schrander. Zij hebben twee kinderen, Dirk en Anna. 


\section{ARTIKELEN}

Schrander-Stumpel CTRM, van Benthem LHBM, Bijlsma JB. Het faciodigitogenitale syndroom (Aarskog syndroom). Ned Tijdschr Geneesk 1985; 129:684-688.

Schrander-Stumpel CTRM. Aangeboren toxoplasmose: een klinische illustratie. N Tijdschr Geneesk 1985;129:2241-2243.

Schrander-Stumpel CTRM, Schrander JJP, Fryns JP, Hamers A. Caudal defíciency sequence in $7 \mathrm{q}$ terminal deletion. Am J Med Genet 1988;30:757-761.

Schrander-Stumpel CTRM, Schrander JJP, Fryns JP, Hamers A. Trisomy $17 \mathrm{p}$ due to a $\mathrm{t}(8 ; 17)(\mathrm{p} 23 ; \mathrm{p} 11.2)$ pat translocation. Case report and review of the literature. Clin Genet 1990;37:148-152.

Schrander-Stumpel CTRM, Fryns JP, Hamers A. Sotos syndrome and de novo balanced autosomal translocation $(\mathrm{t}(3 ; 6)(\mathrm{p} 21 ; \mathrm{p} 21))$. Clin Genet 1990;37:226-229.

Schrander-Stumpel CTRM, de Die-Smulders CEM, Fryns JP, da Costa J, Bouckaert P. Limb reduction defects and renal dysplasia: confirmation of a new, apparently lethal, autosomal recessive MCA syndrome. Am J Med Genet 1990;37:133-135.

de Die-Smulders CEM, Schrander-Stumpel CTRM, Fryns JP. The lethal multiple pterygium syndrome: a nosologic approach. Genetic Counseling 1990;1:13-23.

Meijer H, Hekking M, van den Enden A, Jongbloed R, Schrander-Stumpel CTRM, Geraedts J. Fenylketonurie als modelsysteem voor DNA-diagnostiek van erfelijke aandoeningen. Ned Tijdschr Geneesk 1990;140:1954-1959.

Gerritsma C, Schrander-Stumpel CTRM. Erfelijkheidswoorlichting in Limburg. Huisarts en Wetenschap 1990:335.

Schrander-Stumpel CTRM, Legius E, Fryns JP, Cassiman JJ. MASA syndrome: new clinical features and linkage analysis using DNA probes. J Med Genet 1990;27:688692. 
Schrander-Stumpel CTRM, Fryns JP, Hamers A. The partial monosomy 10q syndrome:report of two patients and review of the developmental data. J Ment Defic Res $1991 ; 35: 259-267$.

Schrander-Stumpel CTRM, Fryns JP, Beemer FA, Rive FA. The association of distal arthrogryposis, mental retardation, whistling face, and Pierre-Robin sequence: evidence for nosologic heterogeneity. Am J Med Genet 1991;38:557-561.

Schrander-Stumpel C, Fryns JP, Cassiman JJ, Legius E, Spaepen A, Höweler CJ. MASA syndrome (a form of complicated spastic paraplegia) and X-linked hydrocephalus: variable expression of the same mutation? Call for families. J Med Genet $1992 ; 29: 215$.

Spaepen A, Schrander-Stumpel CTRM, Fryns JP, de Die-Smulders CEM, Borghgraef $M$, van de Berghe H. Hallermann-Streiff syndrome: clinical and psychological findings in children. Nosologic overlap with oculodigitodental dysplasia? Am J Med Genet 1991;41:517-520.

Schrander-Stumpel CTRM, Theunissen PMVM, Hulsmans RFHJ, Fryns JP. Unknown. The combination of vitiligo vulgaris with somatic and psychomotor retardation, cleft palate and facial dysmorphism: a distinct entity? Genetic Counseling 1991;2:259-261.

Schrander-Stumpel CTRM, Fryns JP, Howeler CJ, Spaepen A, Cassiman JJ. MASA syndrome (a form of complicated spastic paraplegia) and X-linked hydrocephaly: a variable expression of the same mutation at Xq28? Proceedings of the first European congress on mental retardation and medical care. Editor Jos J.Roosendaal, Kerkebosch, Zeist 1991:134-142.

de Die-Smulders $C$, van de Burght $I$, Schrander-Stumpel CTRM, Wagemans A, van Dongen T, Thiry P, Fryns JP. Smith-Lemli-Opitz syndrome: a nosologic approach. Proceedings of the first European congress on mental retardation and medical care. Editor Jos 』 Roosendaal, Kerkebosch, Zeist 1991:153-158.

de Die-Smulders CEM, Theunissen P, Schrander-Stumpel CTRM, Fryns JP. On the variable expression of the Brachmann-de Lange syndrome. Clin Genet 1992;41:42-45.

Schrander-Stumpel CTRM, Spaepen A, Fryns JP, Dumon JE. Mandibuloacral dysplasia: report of a severe female case and review of the literature. Am J Med Genet $1992 ; 43: 877-891$. 
Schrander-Stumpel CTRM, de Die-Smulders CEM, Hennekam RCM, Fryns JP, Bouckaert PXGM, Brouwer OF, da Costa J, Lommen E, Maaswinkel-Mooy P. Oculoauriculovertebral spectrum and cerebral anomalies: 3 Dutch case histories and a review of the literature. J Med Genet 1992;29:326-331.

Schrander-Stumpel CTRM. Dysmorfie, syndroomherkenning en de rol wan de computer. Hoofdstuk in: "Syndroomdiagnostiek en mentale retardatie", Eds.P.Curfs en J.P.Fryns, Leuven, 1992.

Fryns JP, Schrander-Stumpel CTRM, de Die-Smulders C., Borghgraef M, Van Den Berghe H. MASA Syndrome: delineation of the clinical spectrum at prepubertal age. Am J Med Genet 1992;43:402-407.

Engelen J, Hamers A, Schrander-Stumpel CTRM, Mulder H, Poorthuis B. Assignment of AGA gene to 4q33-35 based on decreased activity in a girl with a 46,XX,del(4)(q33) karyotype. Cytogenet Cell. Genet 1992;60:208-209.

Hanssen AMN, Schrander-Stumpel CTRM, Thiry PAE, Fryns JP. Fryns syndrome: another example of non-lethal outcome with severe mental handicap. Genetic Counseling 1992;3:187-195.

Schaap C, Schrander-Stumpel CTRM, Fryns JP. Opitz-C syndrome: on the nosology of mental retardation and trigonocephaly. Genetic Counseling 1992;3:209-217.

Hulsmans RFHJ, Schrander-Stumpel CTRM, Koopman RJJ, Hoorntje TM, Starink TM. Le syndrome Protée. L'expansion de phénotype. A propos de trois cas pédiatriques. Phlébologie 1992;45:463-469.

Schrander-Stumpel CTRM, Höweler C, Reekers A, De Smet N, Hall J and Fryns JP. Arthrogryposis, ophthalmoplegia and retinopathia: confirmation of a new type of arthrogryposis. J Med Genet 1993;30:78-80.

Schrander JJP, van de Bogart JPH, Forget PP, Schrander-Stumpel CTRM, Kuyten RH, Kester ADM. Cow's Milk Protein Intolerance in infants under one year of age: a prospective epidemiologic study. Eur I Pediatr 1993;152:640-644.

Schrander-Stumpel CTRM, de Die-Smulders C, de Krom M, Schyns-Fleuren S, Hamel B, Jaeken D, Fryns JP. Marden-Walker syndrome: case report, literature review and nosologic discussion. Clin Genet 1993;43:303-308.

Evers R, Schrander-Stumpel CTRM, Mulder H, Engelen J, Fryns JP. Terminal deletion of chromosome 4q: patient report and literature review. Genetic Counseling $1993 ; 4: 139-145$. 
van Camp G, Vits L, Coucke P, Lyonnet S, Schrander-Stumpel CTRM, Darby J, Holden $J$, Munnich A, Willems P. A duplication in the LICAM gene associated with X-llinked hydrocephalus. Nature Genet 1993;4:421-425.

Schrander-Stumpel CTRM, Groot-Wijnands A, de Die-Smulders C "Fryns JP. Type III syndactyly and oculodentodigital dysplasia: a clinical spectrum. Genetic Counseling 1993;4:271-277.

Hulsmans RFHJ, Schrander-Stumpel CTRM, Koopman RJ, Hoorntje ThM, Starink Thm. "Chimp's" feet and "Tarzan's" chest constitute distinct clinical hallmarks in many pediatric patients with proteus syndrome. Scripta Phlebologica 1994;2:7-17.

Schrander-Stumpel CTRM, Meyer H, Merckx D, Jones M, Israël J, Sommer A, Stevens C, Tinschert S, Wilson G, Willems P, Legius E, Fryns JP. The spectrum of "complicated spastic paraplegia, MASA syndrome and X-linked hydrocephalus". Contribution of DNA linkage analysis in genetic counseling of individual families. Genetic Counseling 1994;5:1-10.

Schrander-Stumpel CTRM, Govaerts LCP, Engelen JJM, van der Blij-Philipsen M, Borghgraef M, Loots WJG, Peters JJM, Rijnvos WPIM, Smeets DFCM, Fryns JP. Mosaic tetrasomy $8 \mathrm{p}$ in two patients: clinical data and review of the literature. Am J Med Genet 1994;50;377-380.

Schrander-Stumpel CTRM, Gerver WJ, Meyer H, Engelen J, Mulder H, Fryns JP. Prader-Willi-like phenotype in fragile X syndrome. Clin Genet 1994;45:175-180.

Schrander-Stumpel CTRM, Meinecke P, Wilson G, Gillessen-Kaesbach G, Tinschert S, König R, Philip N, Pfeiffer L, Maat-Kievit A, van de Burgt I, van Essen T, Latta E, Hillig $U_{*}$ Verloes A, Journel H, Schrander J, Hamers G, Fryns JP. The Kabuki (Niikawa-Kuroki) syndrome: further delineation of the phenotype in 29 nonJapanese patients. Eur J Pediatr 1994;153:438-445.

Schrander-Stumpel CTRM, Schrander JJP, Hamers AJH, Fryns JP. Het Kabuki (Niikawa-Kuroki) syndroom: niet alleen in Japan. Tijdschr Kindergeneeskd 1994:63:132-136.

Schrander-Stumpel CTRM, Havenith M, Maertzdorf W, Offermans J, van den Linden E, van der Harte J. Atelosteogenesis Type II: case report and review of the literature. Clin Dysmorphol 1994;3:318-327. 
Vits L, Van Camp G, Coucke P, Fransen E, De Boulle K, Reyniers E, Korn B, Poustka A, Wilson G, Schrander-Stumpel CTRM, Winter RM, Schwartz C, Willems PJ. MASA syndrome is due to mutations in the neural cell adhesion gene LICAM. Nature Genet 1994;7:408-414.

Gerver WJ, v.d.Neucker A, Schrander-Stumpel CTRM. A patient with pituitary hormone deficiency and May-Hegglin anomaly: a distinct entity? Genetic Counseling 1994;5:307-310.

Plomp AS, Schrander-Stumpel CTRM, Engelen J, Sijstermans J, Loneus W, Fryns JP. Interstitial deletion of the short arm of chromosome 8: report of a patient and review of the literature. Genetic Counseling 1995;6:55-60.

Fransen E, Schrander-Stumpel CTRM, Vits L, Coucke P, Van Camp G, Willems P. $\mathrm{X}$-linked hydrocephalus and MASA syndrome present in one family are due to a single missense mutation in exon 28 of the LICAM gene. Hum Mol Genet $1994 ; 3: 2255-2256$.

Schrander-Stumpel CTRM, Höweler C, Jones M, Sommer A, Stevens C, "Tinschert S, Israel J, Fryns JP. Spectrum of X-linked hydrocephalus (HSAS), MASA syndrome and complicated spastic paraplegia. Clinical review with 6 additional families. Am J Med Genet 1995;56:1-8.

Schrander-Stumpel CTRM, Höweler CJ, Fryns JP. X-linked mental retardation and neurological symptoms: a nosological approach. Genetic Counseling 1995; 6:21-32.

de Die-Smulders C, Engelen J, Schrander-Stumpel CTRM, Govaerts L, de Vries B, Vles J, Wagemans A, Schyns-Fleuren S, Gillessen-Kaesbach G, Fryns JP. Trisomy $8 p$ due to interstitial inverted duplication: clinical data on seven patients and review of the literature. Am J Med Genet 1995; in press.

Bastiaens MT, Hulsmans RFHJ, da Costa AJ, Schrander-Stumpel CTRM, Steijlen PM, Vermeulen AHM, Lambers JCCA. A new lethal syndrome: porokeratosis ichthyosiformis diffusa partim exfoliativa et erosiva and bilateral sensorineural hearing loss in a child of a parent with systematized porokeratotic eccrine ostial and dermal duct nevi and unilateral sensorineural hearing loss. J Am Ac Dermatol 1995 ; in press.

Schrander JJP, Schrander-Stumpel CTRM, Berg J, Frias JL. Opitz BBBG syndrome: new family with late onset serious complication. Clin Genet 1995; in press. 
Schrander-Stumpel CTRM, Schrander JJP. Het bijzondere kind. Tijdschr Huisartsen 1995;accepted.

Zwamborn-Hanssen AMN, Schrander-Stumpel CTRM, Smeets E, Decock P, Fryns IP. FG syndrome: the trias mental retardation, hypotonia and constipation reviewed. Genetic Counseling 1995; accepted.

Schaap C, Schrander-Stumpel CTRM, Colla-Pijkels E, Driessen J, Kusters R, Fryns JP. A genetic survey in an institutionalized population of 116 moderately to severely retarded patients: the Rekem experience. Genetic Counseling 1995; accepted..

\section{LETTERS TO THE EDITOR:}

Schrander-Stumpel CTRM, Haspeslagh M, Fryns JP. Mental retardation with pterygia, shortness and distinct facial appearance. Confirmation of a new MCA/MR syndrome. Clin Genet 1988:34:279-281.

Vles H, Spaapen L, Schrander-Stumpel CTRM, van der Meer S. Metabolic investigation of a patient with Rett syndrome. Eur J Pediatr 1989; 148:786.

Schrander-Stumpel CTRM, Fryns JP, Spaepen A. Letter to the editor: Mandibuloacral dysplasia as a form of idiopathic osteolysis. Ped Radiol 1991;21$: 605$.

Schrander-Stumpel CTRM. Announcement. Call for families with MASA syndrome with or without hydrocephalus. Clin Genet 1991;40:473.

Schrander-Stumpel CTRM, Fryns JJ, Cassiman JJ, Höweler CJ, Spaepen A, Legius E. MASA syndrome (a form of complicated spastic paraplegia) and X-linked hydrocephaly: a variable expression of the same mutation at $\mathrm{Xq} 28$ ? Call for families. J Med Genet 1992;29:215.

Schrander-Stumpel CTRM, Fryns JP. Letter to the Editor. MASA syndrome. Clin Genet 1992;42:102-103.

Schrander-Stumpel CTRM, Theunissen P. Letter to the Editor. Kabuki make-up syndrome in an "unknown" patient presenting with vitiligo vulgaris. Genetic Counseling 1993;4:71-72. 
de Die-Smulders C, C.Schrander-Stumpel CTRM, Fryns JP. Familial occurence of renal and Müllerian duct hypoplasia, craniofacial anomalies, severe growth and developmental delay: a 4p deletion? Am J Med Genet 1993;47:936.

de Die-Smulders C, Theunissen P, Schrander-Stumpel CTRM, Fryns JP. Exclusively maternal transmission of autosomal dominant Brachmann-de Lange syndrome. Am I Med Genet 1994;52:363.

Fryns JP, Schrander-Stumpel CTRM, Van den Berghe. Letter to the editor. The Kabuki (Niikawa-Kuroki) syndrome and paracentric inversion of the short arm of chromosome 4. Am J Med Genet 1994;53:204-205.

Schrander-Stumpel CTRM, Pulles-Heintzberger P, Fryns JP. Follow-up on a patient with Haspeslagh syndrome. Clin Genet 1995; in press. 